Estudios Geológicos, 65(1)

enero-junio 2009, 5-47

ISSN: 0367-0449

doi:10.3989/egeol.39755.056

\title{
La dorsal NE de Tenerife: hacia un modelo del origen y evolución de los rifts de islas oceánicas
}

\author{
The NE Rift of Tenerife: towards a model on the origin \\ and evolution of ocean island rifts
}

\author{
J.C. Carracedo', H. Guillou², E. Rodríguez Badiola³, F.J. Pérez-Torrado ${ }^{4}$, \\ A. Rodríguez González ${ }^{4}$ R. Paris ${ }^{5}$, V. Troll 6 , S. Wiesmaier ${ }^{7}$, A. Delcamp ${ }^{7}$, \\ J.L. Fernández-Turiel ${ }^{8}$
}

\section{RESUMEN}

El Rift NE de Tenerife, conocido localmente como la Dorsal de La Esperanza, es un excelente ejemplo de un rift persistente y recurrente. Su estudio ha aportado evidencias significativas del origen y dinámica de este tipo de estructuras volcánicas.

Los rifts son posiblemente las estructuras más relevantes en la geología de las islas volcánicas oceánicas: 1. Controlan, tal vez desde su inicio, la construcción de los edificios insulares; 2 . Son elementos sustanciales en la configuración (forma y topografía) de estas islas; 3. Dan origen a sus principales formas del relieve y el paisaje; 4. Al concentrar la actividad eruptiva, son asimismo estructuras cruciales en la distribución del riesgo volcánico; 5. Condicionan la distribución de recursos naturales básicos, como el agua subterránea.

En las Canarias están muy bien representados tanto los rifts típicos de los estadios juveniles de desarrollo en escudo, como los más tardíos, correspondientes a las fases de rejuvenecimiento post-erosivo. El Rift NE es un buen ejemplo de este último tipo de rifts.

El Rift NE se ha desarrollado en tres etapas diferentes separadas por periodos más largos de quiescencia o actividad reducida. La primera etapa, en el Mioceno (datada en 7,26 Ma), se formó como una extensión hacia el NE del escudo central de Tenerife, donde aflora debajo del macizo plioceno de Anaga. La segunda etapa, del Plioceno (datada en 2,71 Ma), sólo ha sido alcanzada en galerías. La tercera etapa se desarrolla en el Cuaternario, con una fase de gran actividad volcánica en el periodo comprendido entre 1,0 Ma y 0,5 Ma, en que se produjeron tres colapsos laterales (Micheque, Güímar y La Orotava). Posteriormente, la actividad eruptiva se hizo más espaciada y los centros eruptivos se dispersaron. Una última fase de renovada actividad se localiza alrededor de los 30-40 ka, con varios centros eruptivos en la parte del rift cercana a la Caldera de Las Cañadas y el complejo volcánico del Teide, y otros anidados en los diferentes valles de colapso (la alineación de Taoro, en el Valle de La Orotava, datada en 27 ka, y la alineación de volcanes de Arafo, Fasnia y Siete Fuentes, de 1705 AD).

La elaboración de una detallada cartografía geológica y geomagnética (utilizando las inversiones del campo magnético terrestre impresas en las lavas) y la datación radioisotópica de las unidades volcanoestratigráficas y magneto-estratigráficas definidas (con 14 edades K/Ar nuevas) ha permitido la reconstrucción de la historia volcánica de esta última fase de desarrollo del Rift NE y la delimitación del tiempo de ocurrencia de los sucesivos colapsos laterales.

En las fases iniciales de esta etapa los centros eruptivos se agrupan apretadamente en el eje del rift y las lavas muestran consistentemente polaridad inversa (correspondiente al cron Matuyama). Los diques muestran tanto polaridad normal como inversa. Sin embargo, en las fases finales tanto las lavas como los diques tienen siempre polaridad normal, correspondiente al cron Brunhes. Algunas secciones concretas están formadas por lavas de polaridad normal, atravesadas por diques que presentan tanto polaridad normal como inversa, correspondiendo, por consiguiente, a algún subcron de polaridad nor-

\footnotetext{
1 Estación Volcanológica de Canarias, IPNA-CSIC, La Laguna, Tenerife, Spain. Email: jcarracedo@ipna.csic.es

2 Laboratoire des Sciences du Climat et de l'Environnement, CEA-CNRS, France.

3 Dpto. Geología, Museo Nacional de Ciencias Naturales, CSIC, Madrid, Spain.

4 Dpto. Física-Geología, Universidad de Las Palmas de Gran Canaria, Spain.

5 Géolab UMR 6042 CNRS, Clermont-Ferrand, France.

6 Uppsala University, Sweden.

7 Trinity College Dublin, Ireland.

8 Instituto de Ciencias de la Tierra Jaume Almera, CSIC, Barcelona, Spain.
} 
mal dentro del cron Matuyama, de polaridad inversa. En este caso se han definido y datado los subcrones M-B Precursor (819-798 ka) y Jaramillo (1.072-988 ka), que corresponden al Matuyama Superior.

De los tres colapsos laterales que afectaron los flancos del Rift NE, los dos primeros (Micheque y Güímar) fueron esencialmente opuestos y simultáneos (hace $830 \mathrm{ka}$ ), posiblemente con el primero iniciando el proceso coincidiendo con una fase de gran actividad eruptiva e intrusiva. El colapso debió dejar el rift en un estado crítico de inestabilidad, lo que ocasionó el subsiguiente deslizamiento gravitatorio de Güímar. La fecha de ocurrencia del colapso de La Orotava no ha podido determinarse con igual precisión, quedando limitada entre 690 ka y 566 ka.

La actividad eruptiva anidada en las sucesivas cuencas de colapso presenta una clara disminución, siendo muy intensa en la cuenca de Micheque, que quedó completamente colmatada, mientras que la de Güímar sólo se rellenó parcialmente y en la de La Orotava apenas hubo relleno a partir de centros anidados. Esto puede explicar la evolución de los magmas en la cuenca de Micheque desde erupciones inicialmente basálticas hasta intermedias y félsicas (traquitas y fonolitas) en las fases finales de relleno. Este proceso no se da en las demás cuencas de colapso ni en el resto del rift, donde las erupciones son consistentemente basálticas fisurales. La ocurrencia de los colapsos laterales en el rift NE parece coincidir con las diversas glaciaciones, sugiriendo que estos colapsos pudieran finalmente producirse como respuesta a los cambios en el nivel del mar.

Los rifts en las Canarias podrían ser la manifestación en superficie de una pluma del manto, generando fracturas primordiales que darían lugar a rifts que actuarían a lo largo de la historia volcánica de las islas. Una vez establecidos, los rifts tienden a desarrollarse manteniendo el mismo sistema de alimentación y el mismo tipo de volcanismo, en forma de erupciones basálticas fisurales. Sin embargo, los colapsos laterales suponen un drástica y brusca ruptura del sistema establecido, que puede dar lugar al emplazamiento y residencia del magma en zonas superficiales y a su diferenciación, dando erupciones intermedias y felsíticas. Por consiguiente, los rifts y sus colapsos laterales actúan como impulsores de variabilidad petrológica en las Canarias, donde los volcanes centrales félsicos aparecen con frecuencia asociados (anidados) a colapsos laterales. En sentido contrario, estos volcanes félsicos pueden actuar como marcadores de colapsos laterales previos.

Palabras clave: Rifts, Dorsal NE de Tenerife, Islas Canarias, dataciones radioisotópicas, colapsos, colapsos laterales y evolución geoquímica, volcanes centrales félsicos y colapsos laterales.

\section{ABSTRACT}

The NE Rift of Tenerife is an excellent example of a persistent, recurrent rift, providing important evidence of the origin and dynamics of these major volcanic features. The rift developed in three successive, intense and relatively short eruptive stages (a few hundred ka), separated by longer periods of quiescence or reduced activity: A Miocene stage (7266 $\pm 156 \mathrm{ka}$ ), apparently extending the central Miocene shield of Tenerife towards the Anaga massif; an Upper Pliocene stage (2710 $\pm 58 \mathrm{ka})$ and the latest stage, with the main eruptive phase in the Pleistocene.

Detailed geological (GIS) mapping, geomagnetic reversal mapping and stratigraphic correlation, and radioisotopic (K/Ar) dating of volcanic formations allowed the reconstruction of the latest period of rift activity. In the early phases of this stage the majority of the eruptions grouped tightly along the axis of the rift and show reverse polarity (corresponding to the Matuyama chron). Dykes are of normal and reverse polarities. In the final phase of activity, eruptions are more disperse and lavas and dykes are consistently of normal polarity (Brunhes chron). Volcanic units of normal polarity crossed by dykes of normal and reverse polarities yield ages apparently compatible with normal subchrons (M-B Precursor and Jaramillo) in the Upper Matuyama chron. Three lateral collapses successively mass-wasted the rift: The Micheque collapse, completely concealed by subsequent nested volcanism, and the Güímar and La Orotava collapses, that are only partially filled. Time occurrence of collapses in the NE rift apparently coincides with glacial stages, suggesting that giant landslides may be finally triggered by sea level changes during glaciations. Pre-collapse and nested volcanism is predominantly basaltic, except in the Micheque collapse, where magmas evolved towards intermediate and felsic (trachytic) compositions.

Rifts in the Canary Islands are long-lasting, recurrent features, probably related to primordial, plume-related fractures acting throughout the entire growth of the islands. Basaltic volcanism forms the bulk of the islands and rift zones. However, collapses of the flanks of the rifts disrupt their established fissural feeding system, frequently favouring magma accumulation and residence at shallow emplacements, leading to differentiation of magmas, and intermediate to felsic nested eruptions. Rifts and their collapse may therefore act as an important factor in providing petrological variability to oceanic volcanoes. Conversely, the possibility exists that the presence of important felsic volcanism may indicate lateral collapses in oceanic shields and ridge-like volcanoes, even if they are concealed by post-collapse volcanism or partially mass-wasted by erosion.

Key words: Rifts, NE Rift of Tenerife, Canary Islands, K/Ar ages, sector collapses, lateral collapses and geochemical evolution, central felsic volcanoes and lateral collapses. 


\section{Introducción}

En las islas volcánicas oceánicas los rifts (conocidos en Canarias como dorsales) representan probablemente la expresión superficial de una pluma mantélica (Wyss, 1980; Carracedo, 1994). Constituyen las estructuras más relevantes y persistentes en el desarrollo de las islas volcánicas oceánicas ya que: 1. Controlan, posiblemente desde las etapas iniciales, la construcción de los edificios insulares; 2. Son determinantes en su configuración (forma y topografía); 3. Dan origen a sus principales formas de relieve; 4. Al concentrar la actividad eruptiva, son asimismo estructuras cruciales en la distribución del riesgo volcánico; y 5. Condicionan la distribución de recursos naturales básicos, como el agua subterránea.

Aunque estudiados inicialmente en las Islas Hawaii (Walker, 1986, 1987, 1992; Dieterich, 1988; Swanson et al., 1976), buena parte de los avances en el conocimiento de su génesis y estructura se han logrado a través de su estudio en las Islas Canarias (Carracedo, 1975, 1994, 1999; Carracedo et al., 1992, 1998, 2001, 2007; Walter \& Schmincke, 2002; Walter \& Troll, 2003; Walter et al., 2005). Comparados con los de las Islas Hawaii, los rifts de las Canarias son considerablemente más persistentes, ejercen un mayor control general en la construcción de las islas y son elementos más conspicuos en el relieve. La menor actividad magmática de la pluma del manto o punto caliente que ha generado las Canarias da lugar a tasas eruptivas muy inferiores, favorece la mayor acumulación puntual y menor recorrido de las lavas, dando lugar frecuentemente a zonas de rift con una elevada relación de aspecto que configuran dorsales muy sobresalientes en el relieve de estas islas. Por otra parte, a causa de la escasa subsidencia en las Canarias y la menor velocidad de desplazamiento de la placa Africana, la historia volcánica emergida de estas islas es mucho más dilatada que la de las Hawaii, donde las tasas de subsidencia son mucho más elevadas y la velocidad de movimiento de la placa Pacífica un orden de magnitud mayor. Esta circunstancia permite una mayor persistencia de los rifts en las Canarias, con frecuencia de actividad recurrente.

La práctica ausencia de agua superficial y la fuerte demanda por la elevada demografía de las Canarias ha impulsado la perforación de numerosas galerías (túneles de 2 × 2 m y varios kilómetros de longitud) para el aprovechamiento del agua subterránea, particularmente en las islas de Tenerife, La
Palma y el Hierro (donde se han perforado unos $3.000 \mathrm{~km}$ en total). Estas galerías permiten el acceso a la estructura profunda de los rifts y facilitan extraordinariamente su observación y muestreo (Coello, 1973; Carracedo, 1994; Carracedo et al., 2007; Guillou et al., 1996, 1998, 2004).

Los procesos que originan los rifts son aún objeto de debate, que se centra fundamentalmente en dos ideas. En una de ellas los rifts se forman a partir de fracturas originadas por el empuje magmático vertical producido por la pluma mantélica, que produce la ruptura inicial de la corteza oceánica, proceso que condiciona posteriormente el desarrollo de todo el edificio insular, al constituir las fracturas zonas preferentes de salida del magma a la superficie. En este modelo, la acumulación preferente de los centros eruptivos en la vertical de las fracturas iniciales permite el desarrollo de los rifts hacia niveles de inestabilidad crecientes (Carracedo, 1994, 1996).

En el modelo alternativo los rifts se forman en una fase mucho más tardía y sin carácter general, generándose en cada aparato volcánico que logre alcanzar el suficiente nivel de inestabilidad para inducir esfuerzos gravitacionales distensivos que atrapen los conductos eruptivos. Éstos han de propagarse en una dirección preferente, paralela al rift, dando lugar a un sistema autosostenido al progresar el rift y su propia inestabilidad gravitatoria. Esta idea se fundamenta en experimentos con modelos de análogos en gelatina (Fiske \& Jackson, 1972; Walter \& Troll, 2003; Walter et al., 2005, 2006). No explican, sin embargo, cómo el volcán adquiere la configuración alargada de las zonas de rift y llega a alcanzar los niveles críticos de inestabilidad necesarios para iniciar y mantener el mecanismo de concentración de diques y la persistencia observada en estas estructuras volcánicas. Consciente de esta incongruencia, Dieterich (1988) propuso mecanismos adicionales, fallas profundas generadas por deslizamiento de la base de las islas sobre los sedimentos del fondo oceánico (spreading), que explicarían tanto la continua inyección de diques, como la forma alargada de las zonas de rift resultantes.

Otra característica de los rifts es que pueden alcanzar un crecimiento excesivo y derrumbarse. Generalmente llegan a este estadio crítico coincidiendo con fases de máxima concentración eruptiva e intrusiva. En estas fases, a los esfuerzos gravitatorios impuestos por el creciente peso y el aumento de la pendiente del rift se suma la progresiva expansión de la estructura, necesaria para acomodar la continuada inyección de diques. En último extremo, 
el sistema cede catastróficamente, generando colapsos laterales masivos.

La relación entre la generación de deslizamientos laterales masivos — que ahora se aceptan como procesos normales en la evolución de islas oceánicas y en la configuración de su relieve- y el desarrollo de los rifts, parece evidente (Carracedo, 1994; Carracedo et al., 1999a,b). Sin embargo, el papel de los deslizamientos gravitacionales puede ser, asimismo, relevante como inductores de cambios en la composición de los magmas, ampliando la variabilidad petrológica del volcanismo de las islas (Presley et al., 1997; Hildenbrand et al., 2004; Carracedo et al., 2001, 2004, 2007, 2008a, 2008b). Cambios en la composición de los magmas tras la ocurrencia de deslizamientos masivos han sido apuntados en el volcán Waianae, en Oahu, Islas Hawaii (Presley et $a l ., 1997)$ y en la isla de Tahiti-Nui, en la Polinesia francesa (Hildenbrand et al., 2004). En ambos casos se trata de colapsos de flanco en volcanes en escudo, con volúmenes muy importantes $\left(>6.000 \mathrm{~km}^{3}\right.$ en el volcán Waianae), que generan aparentemente cambios hacia erupciones de magmas menos diferenciados, que estos autores asocian a la descompresión por el efecto de descarga de peso, que aumentaría significativamente el grado de fusión parcial del manto ascendente. Sin embargo, el estudio del volcanismo de relleno de colapsos en Canarias muestra una tendencia opuesta, incrementando el grado de diferenciación, tendencia claramente observada en los volcanes Bejenado, en La Palma y El Golfo, en El Hierro (Carracedo et al., 2001) y con mayor claridad aún en el sistema volcánico formado por los rifts NO y NE y el complejo TeidePico Viejo, en Tenerife (Carracedo et al., 2006; Carracedo et al., 2004, 2007).

En este trabajo se presenta el estudio del Rift Noreste de Tenerife, uno de los mejores ejemplos posibles para aportar evidencias que ayuden a la clarificación de los aspectos mencionados. Hasta la realización de este estudio el conocimiento geológico de esta importante estructura volcánica, que forma buena parte del noreste de Tenerife, era muy deficiente. De hecho, se desconocía la parte más reveladora y crucial de la historia volcánica del rift, consistente en un deslizamiento inicial totalmente recubierto por la actividad eruptiva posterior, que incluye importantes erupciones de magmas muy diferenciados - traquitas, fonolitas (Carracedo et $a l .$, 2008a, 2008b). Este rift presenta, pues, un buen paradigma de deslizamiento enmascarado, a la vez que ejemplifica, a sensu contrario, el papel que el volcanismo diferenciado puede tener como marcador de procesos de deslizamientos desmantelados o recubiertos.

\section{Marco geológico y trabajos previos}

En las Canarias están muy bien representados tanto los rifts típicos de los estadios juveniles de desarrollo en escudo, como los más tardíos, correspondientes a las fases de rejuvenecimiento posterosivo. Al primer grupo pertenecen los rifts de El Hierro o la dorsal de Cumbre Vieja, en La Palma. Al segundo, los rifts noroeste (NO) y noreste (NE) de Tenerife. De estos últimos, el NO ejemplifica un rift aún muy activo, recubierto en su práctica totalidad por volcanismo del Holoceno. En consecuencia, es un escenario muy adecuado para estudiar la distribución espacial y temporal del volcanismo y las variaciones geoquímicas y petrológicas en estas estructuras volcánicas (Ablay \& Martí, 2000, Carracedo et al., 2006; Carracedo et al., 2007, 2008c). El Rift NE, en cambio, lleva prácticamente inactivo centenares de miles de años en la mayor parte de su trazado. La erosión resultante, aumentada por varios deslizamientos laterales masivos, algunos con escaso relleno posterior, ha exhumado su estructura interna, dejando al descubierto el correspondiente enjambre de diques.

El rift o dorsal NE de Tenerife tiene un recorrido de $30 \mathrm{~km}$, conectando el edificio central de Las Cañadas, al SO, con el macizo de Anaga, al NE (figs. 1 y 2). En conjunto, la dorsal pierde altura al alejarse del edificio volcánico de Las Cañadas, sobre el que se apoya. La altura se reduce progresivamente en dirección SO-NE (Izaña, $2.386 \mathrm{~m}$; Ayosa, $2.078 \mathrm{~m}$; Joco, $1.956 \mathrm{~m}$; Gaitero, $1.748 \mathrm{~m}$ ), acabando su extremo más distal recubierto en discordancia por el escudo mio-plioceno de Anaga (fig. 1).

Las características y edad de esta prolongación hacia el NE de la parte central de la isla de Tenerife es uno de los aspectos aún controvertidos del desarrollo de la isla. La observación a través de galerías había demostrado la continuidad de formaciones volcánicas antiguas (Mioceno) en todo el subsuelo de la isla (Coello, 1973), y se consideraba a Tenerife formada por un gran escudo central del Mioceno (que sólo aflora al sur de la isla, en la zona de Adeje), al que se adosaron dos escudos más modernos: Teno al oeste y Anaga al noreste (Carracedo, 1979; Guillou et al., 2004). Sin embargo, en época más reciente Ancochea et al. (1990) describen a Tenerife como 


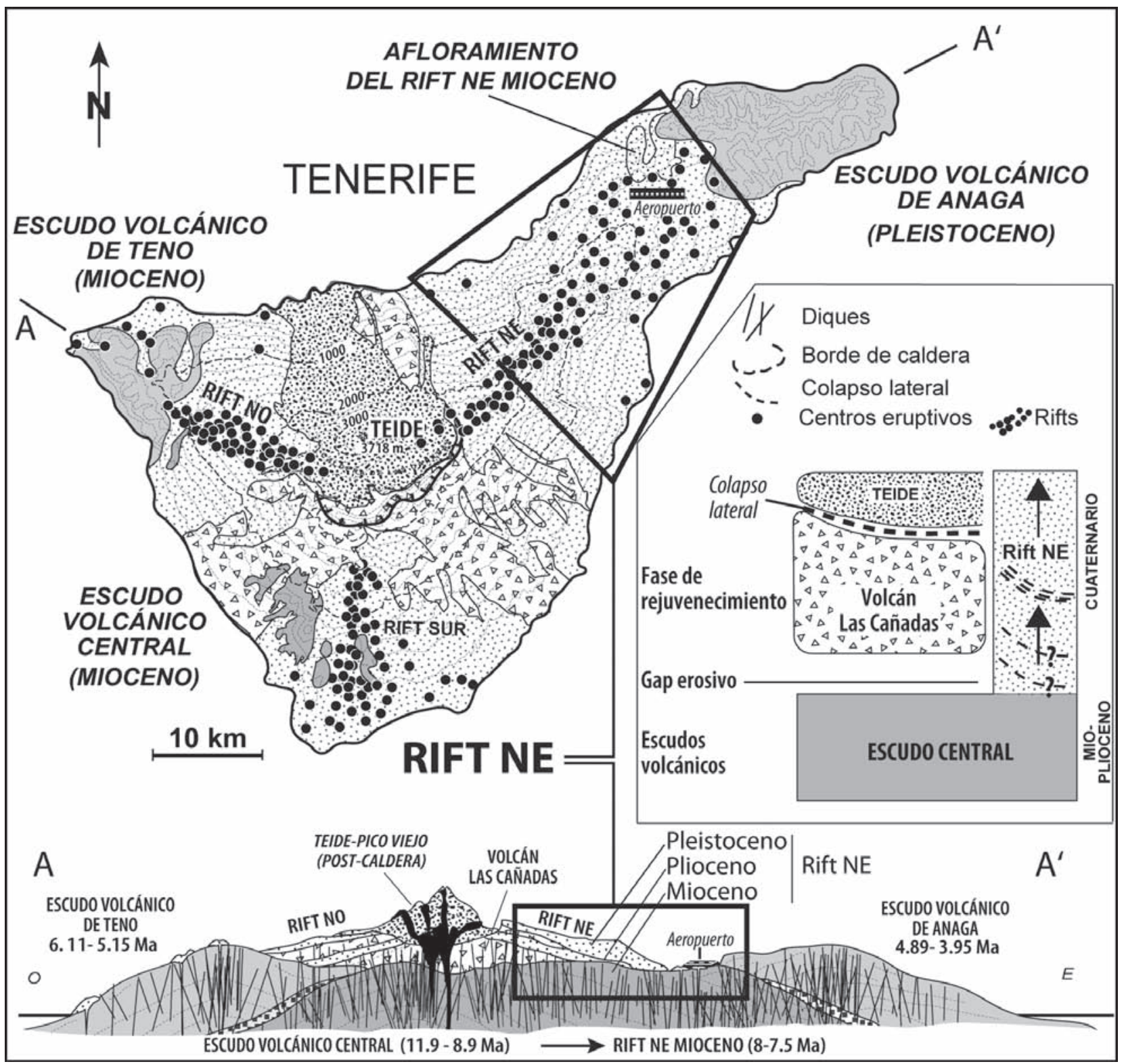

Fig. 1.-Mapa geológico simplificado de Tenerife indicando la localización del Rift NE. Obsérvese, tanto en el mapa como en el corte geológico, cómo el escudo mioceno que forma la parte central de la isla se extiende ya en esta época hacia el NE, subyaciendo el escudo adventicio más moderno de Anaga.

formada en el Mioceno por tres escudos-isla (la Serie Basáltica Antigua) totalmente independientes, unidos en la etapa de rejuvenecimiento posterosivo por el edificio central de Las Cañadas. Para estos autores sólo existiría en el Mioceno en la parte central de Tenerife una isla (el afloramiento actual de Roque del Conde en Adeje), y no un gran escudo central. Sin embargo, estos mismos autores se contradicen, ya que al calcular las tasas eruptivas de la Dorsal de La Esperanza (el Rift NE), admiten que 1/3-1/4 de este edificio volcánico esté formado por la Serie Basáltica Antigua; esto supone aceptar la presencia en el Mioceno, entre la parte donde hoy aflora el macizo del Roque del Conde y Anaga, de un edificio volcánico de al menos 400-500 m de altura, lo que concuerda con la existencia de un Escudo Central mioceno y su prolongación NE aquí propuesta.

Como se observa en las galerías, este escudo mioceno ocupa la parte central de Tenerife, aunque intensamente erosionado y posteriormente recubier- 


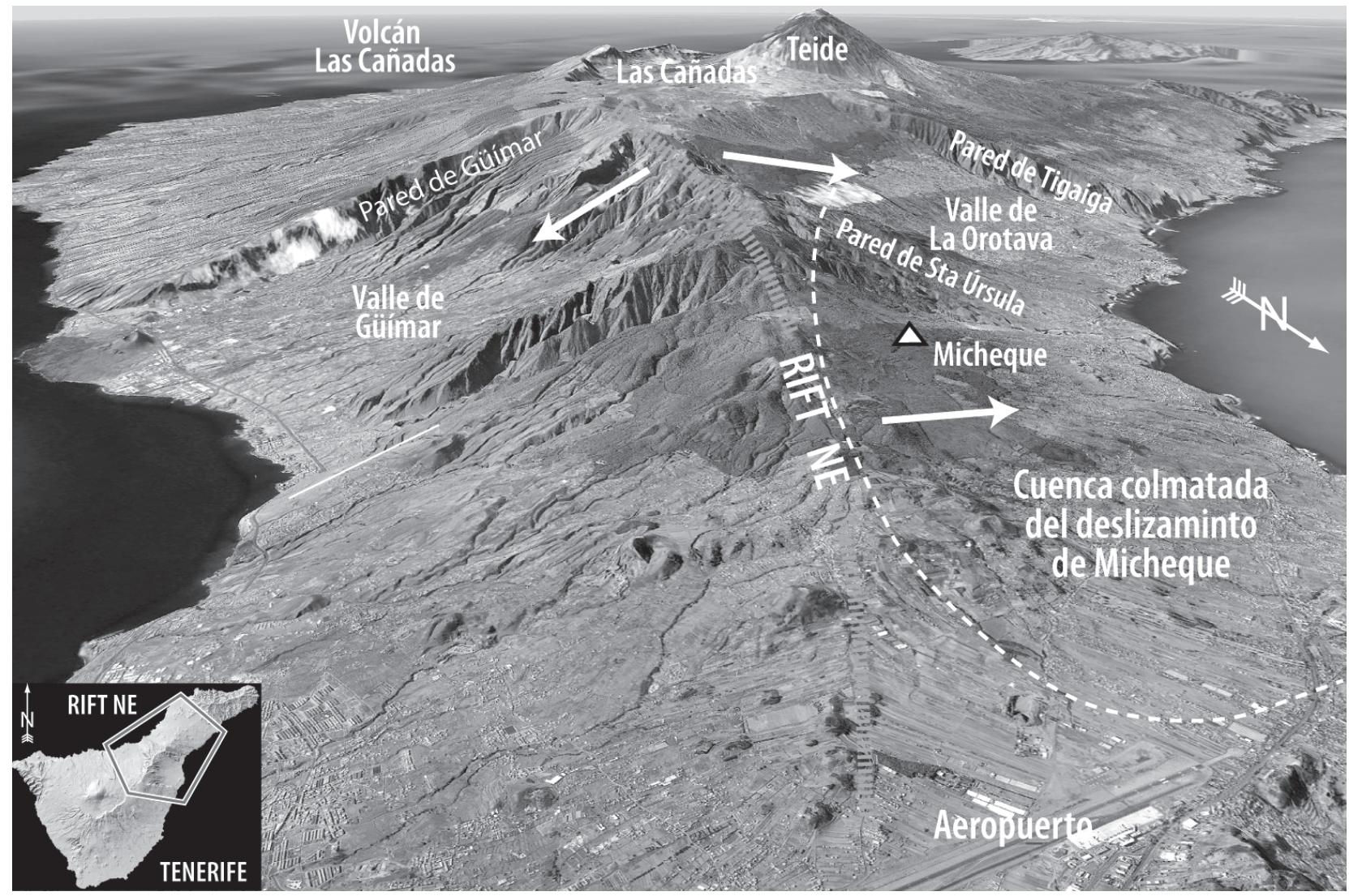

Fig. 2.- Imagen del Rift NE visto desde el macizo de Anaga. Puede apreciarse cómo el rift conecta en efecto, posiblemente desde el Mioceno, el edificio central plioceno de Las Cañadas con el macizo mio-plioceno de Anaga. Los valles de deslizamiento de La Orotava y Güímar son muy evidentes, no así el de Micheque, que al estar completamente relleno pasa desapercibido y ha sido puesto de manifiesto por evidencias geológicas, particularmente a través de galerías (Imagen GRAFCAN).

to (Carracedo, 1975, 1979; Guillou et al., 2004). En este trabajo se presentan evidencias geológicas y geocronológicas que indican que el rift NE de Tenerife es, en realidad, la prolongación del escudo central mioceno (véase corte en fig. 1), de forma similar a como el escudo central plio-pleistoceno de la isla de La Palma (el escudo del norte o Taburiente), se prolonga hacia el sur con las dorsales de Cumbre Nueva y Cumbre Vieja (Carracedo, 1999; Carracedo et al., 1999a,b, 2001).

A pesar de su indudable interés y complejidad el Rift NE de Tenerife apenas está estudiado, limitándose su conocimiento a un mapa, fundamentalmente petrológico (Fúster et al., 1968) y una versión algo más reciente del Mapa Geológico Nacional-MAGNA (IGME, 1978). Aunque hay un considerable número de dataciones radioisotópicas (K/Ar) publicadas para este rift (Abdel-Monem et al., 1972; Ancochea et al., 1990; Thirlwall et al., 2000; Guillou et al., 2004; Carracedo et al., 2007), estas dataciones se hicieron dentro del marco de un estudio general de la isla de Tenerife, y no en el de un estudio detallado del Rift NE, quedando sin datar muchas formaciones importantes. A este insuficiente conocimiento ha podido contribuir lo escarpado del terreno, con fuertes pendientes y profundos barrancos, y las dificultades de acceso, limitado a una carretera que discurre por la cresta del rift y a pistas forestales; por otra parte, el Rift NE está recubierto de densos bosques, lo que dificulta la observación de las formaciones volcánicas, particularmente las cotas medias del flanco norte, recubierto de un tupido bosque de laurisilva, en el que los afloramientos se reducen casi exclusivamente a los cortes de las pistas forestales y los cauces de los barrancos. Estos inconvenientes se ven compensados por la existencia de numerosas galerías excavadas para la captación del agua subterránea, que han permitido la observación y toma de muestras de la estructura profunda del rift, asî 


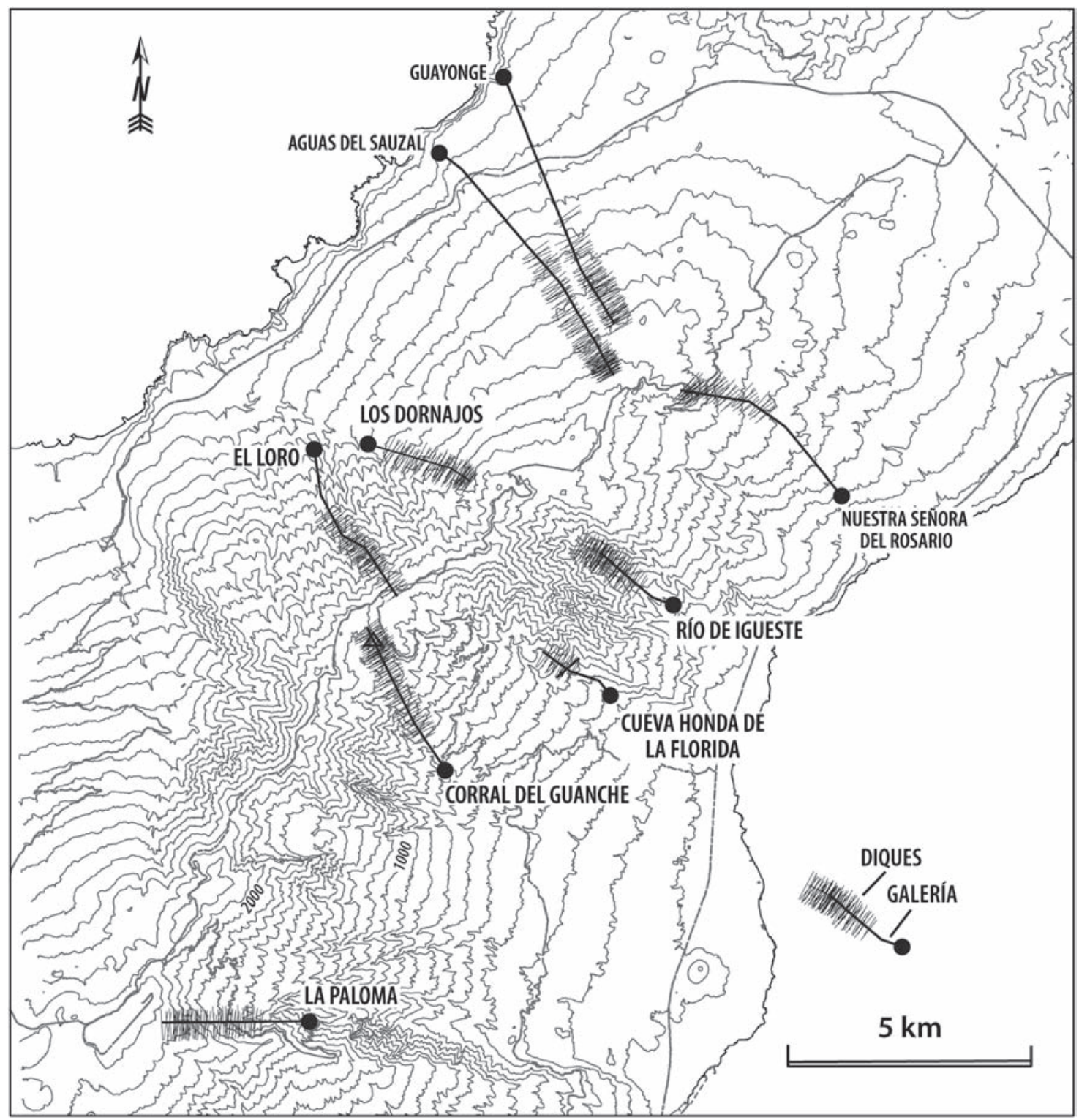

Fig. 3.-Distribución de diques en algunas galerías del Rift NE (datos cedidos por el Consejo Insular de Aguas de Tenerife). Puede observarse la aparición de la malla de diques al sobrepasar la cobertera de lavas recientes (del cron Brunhes). La densidad aumenta progresivamente al avanzar hacia el núcleo del rift.

como de las secuencias de relleno de las cuencas de colapso. Se ha especulado (aunque sin dataciones) que las formaciones con elevada alteración y densidad de diques cortadas en el fondo de algunas galerías (fig. 3) podían corresponder al Mioceno (Coello, 1973; Carracedo, 1979), idea que parece reforzarse en este trabajo, como se discute más adelante.

Aunque los dos conspicuos valles de La Orotava y Güímar han sido correctamente interpretados como originados por colapsos laterales (Navarro \&
Coello, 1989; Carracedo, 1994; Watts \& Masson, 1995), el colapso lateral inicial de este rift (Micheque), completamente rellenado y fosilizado por la actividad eruptiva posterior (Carracedo et al., 2008a, 2008b), ha pasado desapercibido, incluso en los estudios de geología marina. Sin embargo, como se analiza más adelante, esta primera etapa de crecimiento y colapso es crucial para comprender la evolución del Rift NE, del que los deslizamientos de Güímar y La Orotava son sólo episodios subsiguientes y similares. 


\section{Geocronología}

La ausencia de suficientes dataciones dificulta la correlación de las diferentes formaciones volcánicas e impide una precisa reconstrucción de la evolución geológica de este rift. Aunque los mapas publicados delimitan unidades de diferente petrología, no se relacionan esos cambios con los edificios volcánicos concretos que jalonan el desarrollo de esta compleja estructura volcánica, y evidencian cambios eruptivos y estructurales relevantes. Por ello, se ha prestado en este trabajo una atención especial a la geocronología, aplicando técnicas paleomagnéticas (inversiones geomagnéticas) y radioisotópicas (dataciones K/Ar). Tal aproximación se demostró acertada, ya que la evolución de este rift es tan rápida que las inversiones geomagnéticas, una vez identificadas y datadas, particularmente a nivel de eventos, permiten la datación y correlación de las formaciones volcánicas con una precisión que puede igualar e incluso superar los límites de error de las edades radioisotópicas.

Las limitaciones indicadas en los mapas geológicos disponibles, elaborados hace más de 30 años, aconsejó la elaboración de una cartografía completamente nueva (a escala 1/10.000 y en un sistema GIS), aprovechando la existencia de mapas topográficos e imágenes muy precisas (GRAFCAN, Google Earth, etc.), inexistentes en la época en que se elaboró la cartografía geológica publicada (1978). El trabajo de campo, que ha ocupado varios años, era, por otra parte, necesario para realizar las numerosas determinaciones de la polaridad geomagnética de lavas y diques, así como la correspondiente toma de muestras.

\section{Paleomagnetismo}

Las determinaciones paleomagnéticas se han centrado en la identificación de la polaridad geomagnética de coladas y diques. Determinaciones y análisis más específicos de la dirección e inclinación de la remanencia magnética y la anisotropía de la susceptibilidad magnética (ASM), se publicarán separadamente.

Para la comprobación de la polaridad geomagnética se han seguido dos procedimientos: 1. Directamente en el campo, con magnetómetros portátiles digitales del tipo fluxgate; 2 . Mediante la obtención con perforadoras portátiles de testigos, orientados con brújula solar y/o magnética.
En las galerías las muestras se tomaron como bloques orientados.

La remanencia magnética natural (NRM) de las muestras orientadas se midió con un magnetómetro Molspin del tipo spinner y la mayoría fueron sometidas a un proceso de desmagnetización térmica progresiva a temperaturas de hasta $600{ }^{\circ} \mathrm{C}$. La gran mayoría de las muestras, tanto de coladas como de diques, mostraron un comportamiento similar, sin experimentar cambios de polaridad durante la desmagnetización. Aunque en algunas muestras es evidente la presencia de componentes secundarios sobreimpuestos a la remanencia original (indicados por cambios bruscos de dirección en el trazado de los vectores), éstos son de baja coercividad y son fácilmente eliminados en la desmagnetización térmica, pasando los vectores primarios a mantener un trazado recto hasta el origen.

Esta comprobación de laboratorio coincide con la consistencia de las polaridades medidas directamente en el campo. Centenares de determinaciones ponen claramente de manifiesto que la polaridad determinada corresponde a la remanencia original adquirida al enfriarse la roca. Las medidas efectuadas permiten separar dos grupos bien definidos de lavas y diques de polaridad normal e inversa. Sin embargo, para poder utilizar estas polaridades como elementos de datación y correlación de secuencias volcánicas era preciso cartografiarlas y correlacionarlas con la escala temporal de inversiones geomagnéticas (GPTS).

La cartografía de polaridades geomagnéticas de coladas y diques ha permitido la definición de tres unidades principales (A, B y C en la fig. 4). La unidad inferior (A) corresponde a lavas de polaridad inversa atravesadas por diques de polaridad tanto normal como inversa; la unidad intermedia (B) está integrada por lavas de polaridad normal intruidas por diques de polaridad tanto normal como inversa; finalmente, la superior $(C)$ está formada por lavas de polaridad normal atravesadas por diques únicamente de polaridad normal. El hecho de que no se haya observado nunca un dique de polaridad inversa en la unidad $\mathrm{C}$ parece indicar claramente, incluso antes de datarla por métodos radioisotópicos, que corresponde al cron Brunhes, lo que haría que A fuera del cron Matuyama y la unidad B corresponda a uno o dos subcrones del Matuyama.

Dentro de la unidad A se diferencian claramente dos subunidades $-\mathrm{A}_{1}$ y $\mathrm{A}_{2}$-, separadas por una discordancia que en las galerías observadas se corresponde con una capa de unos 50-100 m de bre- 


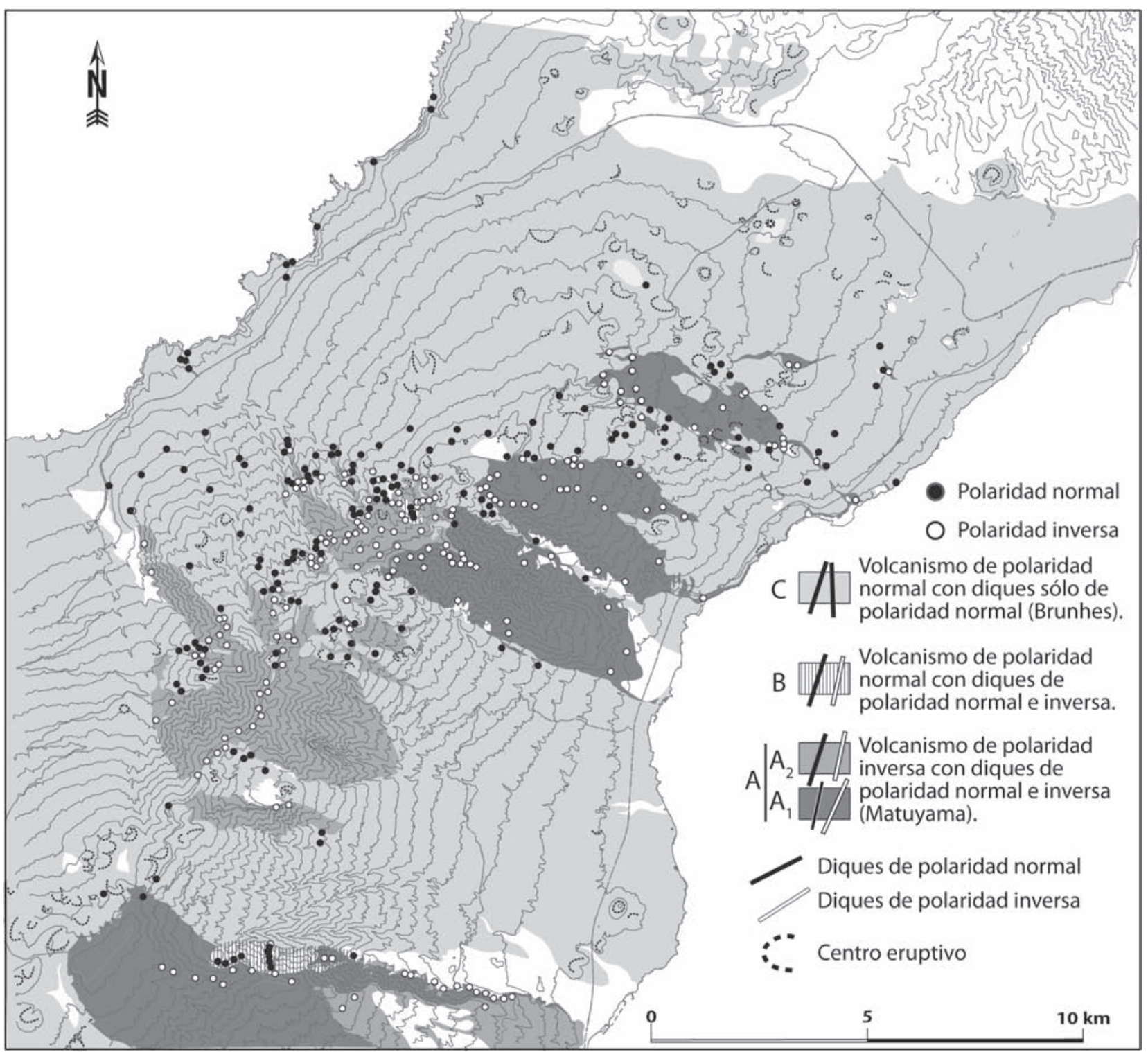

Fig. 4.-Polaridad geomagnética de muestras orientadas (415 determinaciones) de lavas y diques en el Rift NE de Tenerife. Sumadas a las determinaciones directas en el campo con magnetómetros portátiles han permitido separar tres unidades definidas en función de la polaridad de las lavas y de las intrusiones. Estas unidades han demostrado ser extremadamente útiles para correlacionar y reconstruir las sucesivas erupciones que han formado este rift, como se explica en el texto.

chas de avalancha (fig. 5). La unidad inferior $\left(\mathrm{A}_{1}\right)$, formada por piroclastos y lavas basálticas alteradas de polaridad inversa y una densa malla de diques, de polaridad inversa en su gran mayoría, no aflora en el flanco noreste del rift, ni siquiera en las galerías. Forma, en cambio, casi todo el flanco sureste del rift, salvo en las zonas colapsadas (véase fig. 4). La unidad superior $\left(\mathrm{A}_{2}\right)$ tiene una mayor proporción de diques de polaridad normal y los piroclastos y coladas, igualmente basálticas y de polaridad inver- sa, presentan en general un menor grado de alteración. Esta unidad aparece en el flanco NE del rift y en su zona central, así como en lo alto de la parte baja de la Pared de Güímar (véase fig. 4). Esta correspondencia se observa, asimismo, en las galerías situadas en el flanco norte del rift (fig. 5), con la salvedad de que en las observadas no se ha encontrado la subunidad $\mathrm{A}_{1}$, pasándose directamente de la brecha de avalancha a una formación mucho más antigua que la $\mathrm{A}_{1}$. 


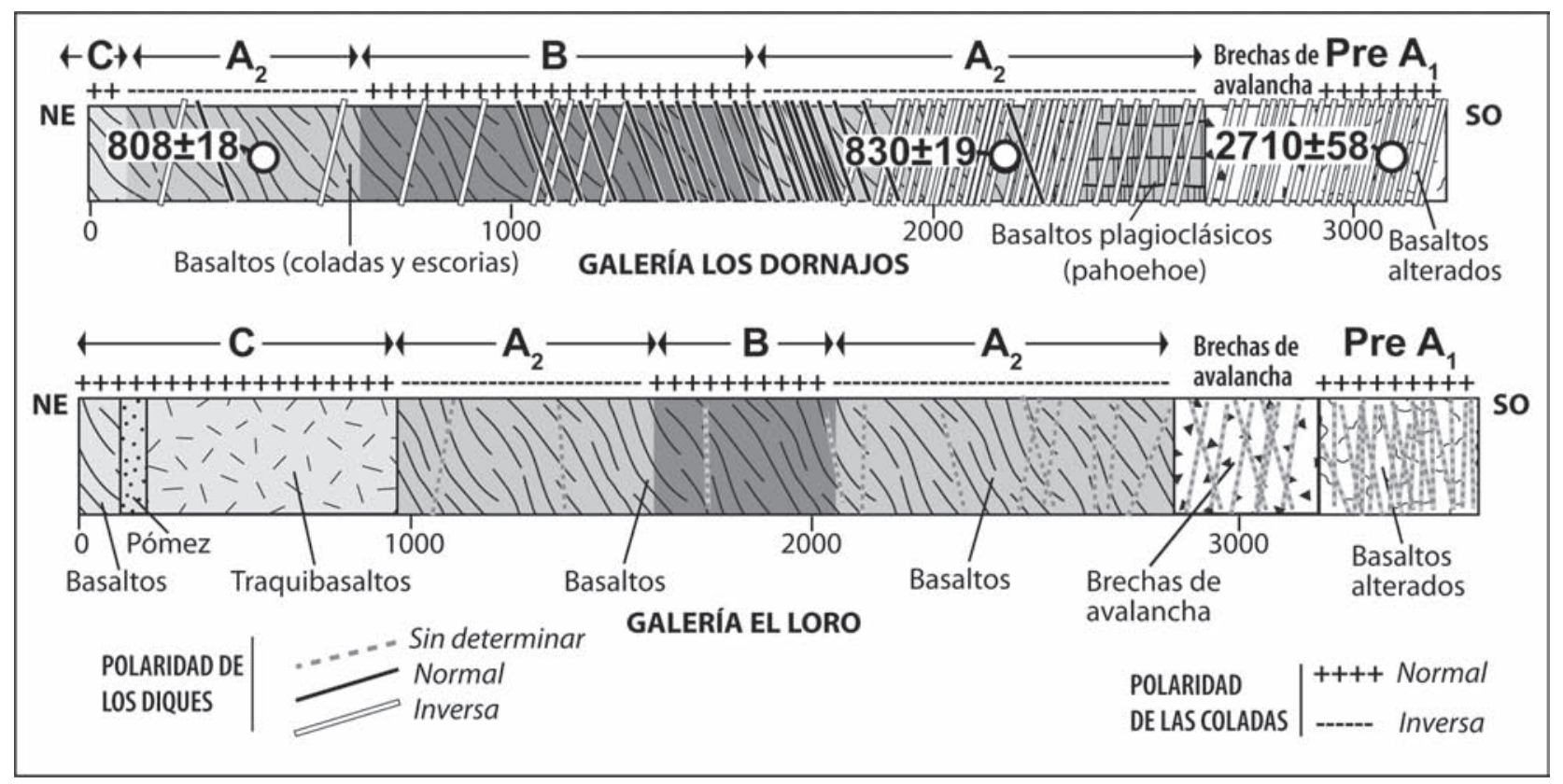

Fig. 5.-Formaciones encontradas en las galerías Los Dornajos y El Loro (véase fig. 3), ambas en el flanco norte del Rift NE. La correlación de estas formaciones, que incluyen una gruesa capa de brechas de avalancha, es evidente, así como la polaridad de las secuencias.

En la galería El Loro (abajo en la fig. 5), descrita inicialmente por Carracedo (1979), la unidad B fue correctamente interpretada como un evento del Matuyama, pero se confundió la brecha de avalancha que aparece en el tramo final de la galería con depósitos sedimentarios asociados a una discordancia erosiva, relacionando el volcanismo anterior a la brecha con una formación pre-Gilbert (Mioceno). La secuencia se repite en la galería Los Dornajos (arriba en la fig. 5), situada a una cota más elevada, donde se obtuvieron las muestras que han dado las edades K/Ar que han sido cruciales para la datación de las unidades descritas.

\section{Dataciones K/Ar y correlación de secuencias volcánicas}

Es obvio que una vez determinadas las unidades con la misma polaridad geomagnética descrita, lo más importante era su datación radioisotópica. Un análisis previo de las edades publicadas puso de manifiesto que éstas se concentraban fundamentalmente en áreas concretas (por ejemplo los escarpes de la Pared de Güímar y de Tigaiga), quedando sin datar la mayor parte del rift.

Para subsanar esta deficiencia se realizaron 14 nuevas dataciones K/Ar (tabla 1), con el método descrito en Guillou et al., 1996; la localización y polaridad geomagnética de las muestras datadas, que corresponden principalmente a las unidades previamente definidas por la polaridad geomagnética de las lavas y sus intrusiones, se indican en la figura 6.

Era evidente que el rápido desarrollo del rift exigía una gran precisión en la datación de las secuencias volcánicas. Por otra parte, la presencia de eventos de corta duración (unos miles a pocas decenas de miles de años) podía facilitar la correlación de estas secuencias con la escala establecida de inversiones geomagnéticas (GPTS), si eran adecuadamente datados y definidos.

Las edades obtenidas se indican en la tabla 1 y la figura 6 , en la que se han indicado, asimismo, todas las edades publicadas en trabajos anteriores. La edad de $7.266 \pm 156 \mathrm{ka}$ de la muestra TF-801, en el Valle de Tegueste, confirma la edad miocena de este volcanismo, anterior al del macizo de Anaga, del Plio-Pleistoceno. La muestra GLD-20, en el frente de la galería Los Dornajos $(3.070 \mathrm{~m})$, que corresponde a una formación basáltica muy alterada e intensamente intruida situada estratigráficamente bajo la brecha de avalancha, ha dado una edad de $2.710 \pm 58 \mathrm{ka}$, confirmando que el núcleo del rift ha tenido sucesivas fases de actividad eruptiva separadas por largos periodos de quiescencia. El que esta 
Tabla 1.-Edades K/Ar del Rift NE de Tenerife

\begin{tabular}{|c|c|c|c|c|c|c|c|c|c|c|}
\hline $\begin{array}{l}\text { Muestra } \\
\text { ID }\end{array}$ & Localización & Polaridad & UTM & $\begin{array}{c}\text { Peso } \\
\text { fundido (g) }\end{array}$ & $\begin{array}{c}\text { Unidad } \\
\text { Magneto- } \\
\text { estratigráfica }\end{array}$ & $\begin{array}{c}\mathrm{K}^{*} \\
(\mathrm{wt} . \%)\end{array}$ & $\begin{array}{l}{ }^{40} \mathrm{Ar}^{*} \\
(\%)\end{array}$ & $\begin{array}{c}{ }^{40} \mathrm{Ar}^{*} \\
\left(10^{-13} \mathrm{~mol} / \mathrm{g}\right)\end{array}$ & $\begin{array}{c}{ }^{40} \mathrm{Ar}^{*} \text { media } \\
\text { ponderada } \\
( \pm 1 \sigma)\end{array}$ & $\begin{array}{c}\text { Edad } \pm 2 \sigma \\
\quad k a\end{array}$ \\
\hline $\begin{array}{l}\text { JCD-500 } \\
\text { JCD-500 }\end{array}$ & Pista Orticosa, al oeste & $\mathrm{R}$ & $359.444 / 3.141 .213$ & $\begin{array}{l}1,13947 \\
2,02545\end{array}$ & $\mathrm{~A}_{2}$ & $\begin{array}{l}1,752 \pm 0,018 \\
« \ldots \ldots \ldots \ldots . \cdots\end{array}$ & $\begin{array}{l}15,482 \\
37,970\end{array}$ & $\begin{array}{l}24,297 \pm 0,144 \\
24,312 \pm 0,127\end{array}$ & $24,305 \pm 0,095$ & $800 \pm 17$ \\
\hline $\begin{array}{l}\text { GLD-04 } \\
\text { GLD-04 }\end{array}$ & Galería Los Dornajos (320 m) & $\mathrm{R}$ & $357.920 / 3.144 .100$ & $\begin{array}{l}1,12005 \\
2,50433\end{array}$ & $\mathrm{~A}_{2}$ & $\begin{array}{l}1,287 \pm 0,13 \\
« \ldots \ldots \ldots \ldots \ldots\end{array}$ & $\begin{array}{l}23,335 \\
18,642\end{array}$ & $\begin{array}{l}17,937 \pm 0,139 \\
18,069 \pm 0,094\end{array}$ & $18,028 \pm 0,078$ & $808 \pm 18$ \\
\hline $\begin{array}{l}\text { JCD-520 } \\
\text { JCD-520 }\end{array}$ & Volcán Cho Marcial & $\mathrm{R}$ & $355.425 / 3.137 .116$ & $\begin{array}{l}1,07593 \\
1,51367\end{array}$ & $\mathrm{~A}_{2}$ & $\begin{array}{l}2,241 \pm 0,024 \\
« \ldots \ldots \ldots \ldots . .\end{array}$ & $\begin{array}{l}17,391 \\
27,323\end{array}$ & $\begin{array}{l}32,130 \pm 0,186 \\
31,533 \pm 0,164\end{array}$ & $31,795 \pm 0,123$ & $818 \pm 18$ \\
\hline $\begin{array}{l}\text { JCD-576 } \\
\text { JCD-576 }\end{array}$ & Pared norte del valle de Gǘmar (1.025 m) & $\mathrm{R}$ & $361.153 / 3.140 .396$ & $\begin{array}{l}1,57350 \\
1,49589\end{array}$ & $\mathrm{~A}_{1}$ & $\begin{array}{l}2,100 \pm 0,021 \\
\text {. } \ldots \ldots \ldots \ldots . . \cdots\end{array}$ & $\begin{array}{l}28,355 \\
12,441\end{array}$ & $\begin{array}{l}33,456 \pm 0,177 \\
34,399 \pm 0,221\end{array}$ & $33,824 \pm 0,137$ & $929 \pm 20$ \\
\hline $\begin{array}{l}\text { JCD-533 } \\
\text { JCD-533 }\end{array}$ & Pared de Güímar & $\mathrm{R}$ & $355.893 / 3.131 .436$ & $\begin{array}{l}1,25272 \\
2,59277\end{array}$ & $\mathrm{~A}_{1}$ & $\begin{array}{l}1,428 \pm 0,014 \\
« \ldots \ldots \ldots \ldots \ldots\end{array}$ & $\begin{array}{l}23,888 \\
31,536\end{array}$ & $\begin{array}{l}23,993 \pm 0,141 \\
23,744 \pm 0,121\end{array}$ & $23,849 \pm 0,092$ & $963 \pm 21$ \\
\hline $\begin{array}{l}\text { KAR-38 } \\
\text { KAR-38 }\end{array}$ & Pared de Güímar & $\mathrm{R}$ & $356.800 / 3.131 .128$ & $\begin{array}{l}1,62239 \\
1,66946\end{array}$ & $\mathrm{~A}_{1}$ & $\begin{array}{l}12,075 \pm 0,021 \\
« \ldots \ldots \ldots \ldots . .\end{array}$ & $\begin{array}{l}24,622 \\
20,904\end{array}$ & $\begin{array}{l}34,991 \pm 0,189 \\
34,651 \pm 0,205\end{array}$ & $34,834 \pm 0,139$ & $968 \pm 21$ \\
\hline $\begin{array}{l}\text { KAR-25 } \\
\text { KAR-25 }\end{array}$ & Pared de Güímar & $\mathrm{R}$ & $355.835 / 3.131 .460$ & $\begin{array}{l}1,52310 \\
1,48870\end{array}$ & $\mathrm{~A}_{1}$ & $\begin{array}{l}1,785 \pm 0,018 \\
« \ldots \ldots \ldots \ldots \ldots .\end{array}$ & $\begin{array}{l}27,054 \\
12,652\end{array}$ & $\begin{array}{l}30,398 \pm 0,164 \\
30,611 \pm 0,190\end{array}$ & $30,489 \pm 1,241$ & $985 \pm 21$ \\
\hline $\begin{array}{l}\text { JCD-550 } \\
\text { JCD-550 }\end{array}$ & Pared de Güímar & $\mathrm{N}$ & $355.189 / 3.131 .365$ & $\begin{array}{l}2,22261 \\
2,02602\end{array}$ & B & $\begin{array}{l}1,254 \pm 0,013 \\
« \ldots \ldots \ldots \ldots \ldots\end{array}$ & $\begin{array}{l}21,660 \\
29,307\end{array}$ & $\begin{array}{l}22,077 \pm 0,117 \\
21,750 \pm 0,120\end{array}$ & $21,917 \pm 0,083$ & $1.008 \pm 22$ \\
\hline
\end{tabular}

El cálculo de las edades se ha basado en las constantes de Steiger \& Jäger (1977).

parte del núcleo del rift, considerablemente más antigua (Plioceno), aflore en el fondo de la galería bajo la brecha de avalancha significa que el colapso de Micheque se excavó por debajo del edificio volcánico correspondiente a la última fase de crecimiento del rift, que tiene una edad pleistocena.

Esta última fase de desarrollo del Rift NE queda bien delimitada por las edades de las muestras JCD-576 (929 $\pm 20 \mathrm{ka})$ y JCD-550 $(1.008 \pm 22 \mathrm{ka})$, respectivamente en la base de los escarpes norte y sur del Valle de Güímar, y las edades JCD-501 (806 $\pm 18 \mathrm{ka})$ y JCD-533 (963 $\pm 21 \mathrm{ka})$, respectivamente del techo de estos escarpes. El periodo de formación del escarpe norte del Valle de Güímar definido por estas edades concuerda con la uniformidad de la secuencia, cuyas lavas son consistentemente de polaridad inversa y con la ausencia de otras discordancias en este escarpe, en el que no se han detectado lavas de polaridad normal correspondientes al evento Jaramillo, presentes, en cambio, en el escarpe sur de esta cuenca de deslizamiento. Estos datos sugieren que esta fase de desarrollo del rift esté comprendida en el Matuyama post-Jaramillo. En este contexto, la edad de $1.560 \pm 110 \mathrm{ka}$ de Abdel Monem et al. (1972), parece demasiado antigua, posiblemente por exceso de Ar, al igual que las edades similares de estos mismos autores del escarpe sur de este mismo Valle de Güímar.

Por otra parte, estas edades confirman que la secuencia de unos $500 \mathrm{~m}$ de polaridad normal evolucionando a transicional (N-T-R) que forma la Pared de Güímar (con la parte superior formada por lavas de polaridad inversa) abarca parte del evento Jaramillo (988-1.072 ka, Horng et al., 2002). A su vez, las edades de $830 \pm 19$ ka (GLD-14) y 


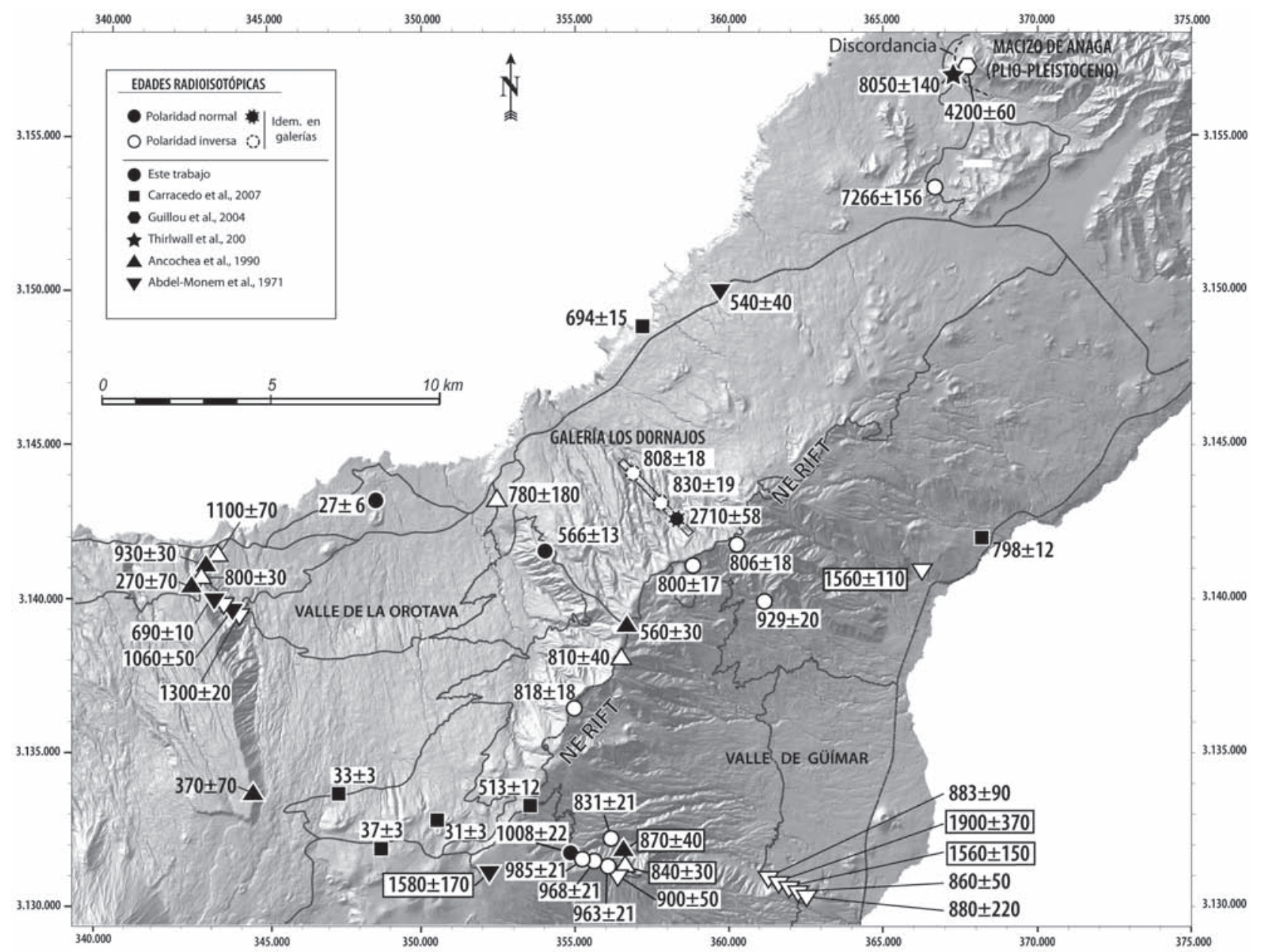

Fig. 6.-Edades K/Ar obtenidas en este trabajo y por autores y trabajos anteriores en el Rift NE de Tenerife (edades en ka). Las edades enmarcadas son inconsistentes en base a la nueva información presentada en este trabajo.

$808 \pm 18$ ka (GLD-04), de la galería Los Dornajos, que corresponden a lavas de polaridad inversa, tienen intercalada una secuencia de 400-500 m de espesor de polaridad normal, que, en consecuencia, podría corresponder al evento Matuyama-Brunhes (M-B Precursor, 798-819 ka). La importancia de los afloramientos de estos eventos radica en que constituyen jalones de muy corta duración, de gran relevancia y precisión en la correlación de formaciones volcánicas y elementos cruciales para acotar al máximo la fecha de ocurrencia de los sucesivos colapsos laterales en el Rift NE.

Las edades KAR-40 (831 $\pm 18 \mathrm{ka})$ y JCD-520 $(818 \pm 18 \mathrm{ka})$, pertenecen a lavas del relleno temprano del valle de colapso de Güímar, mientras que la JCD-324 (566 $\pm 13 \mathrm{ka})$ corresponde a las primeras lavas que caen en cascada por el escarpe este del Valle de La Orotava (ladera de Santa Úrsula).
Si analizamos ahora estas nuevas edades en el conjunto de las publicadas en trabajos anteriores y las correlacionamos con la escala temporal de inversiones geomagnéticas establecida (GPTS), podemos apreciar que la mayoría de las edades concuerdan con lo anteriormente indicado y el marco geológico general definido en este trabajo (fig. 7). Sin embargo, unas pocas dataciones han de ser necesariamente erróneas (recuadradas en la fig. 6); no sólo discrepan totalmente de los datos expuestos y de sus respectivas posiciones estratigráficas y con la GPTS, sino que limitaban la consistencia de todo el conjunto de edades, al no existir, cuando se realizaron, un marco geológico de referencia que permitiera distinguir las edades consistentes de las afectadas por pérdida o exceso de Ar. Esta limitación, claramente expuesta por los propios autores (Abdel Monem et al., 1972; Ancochea et al., 1990), puede 


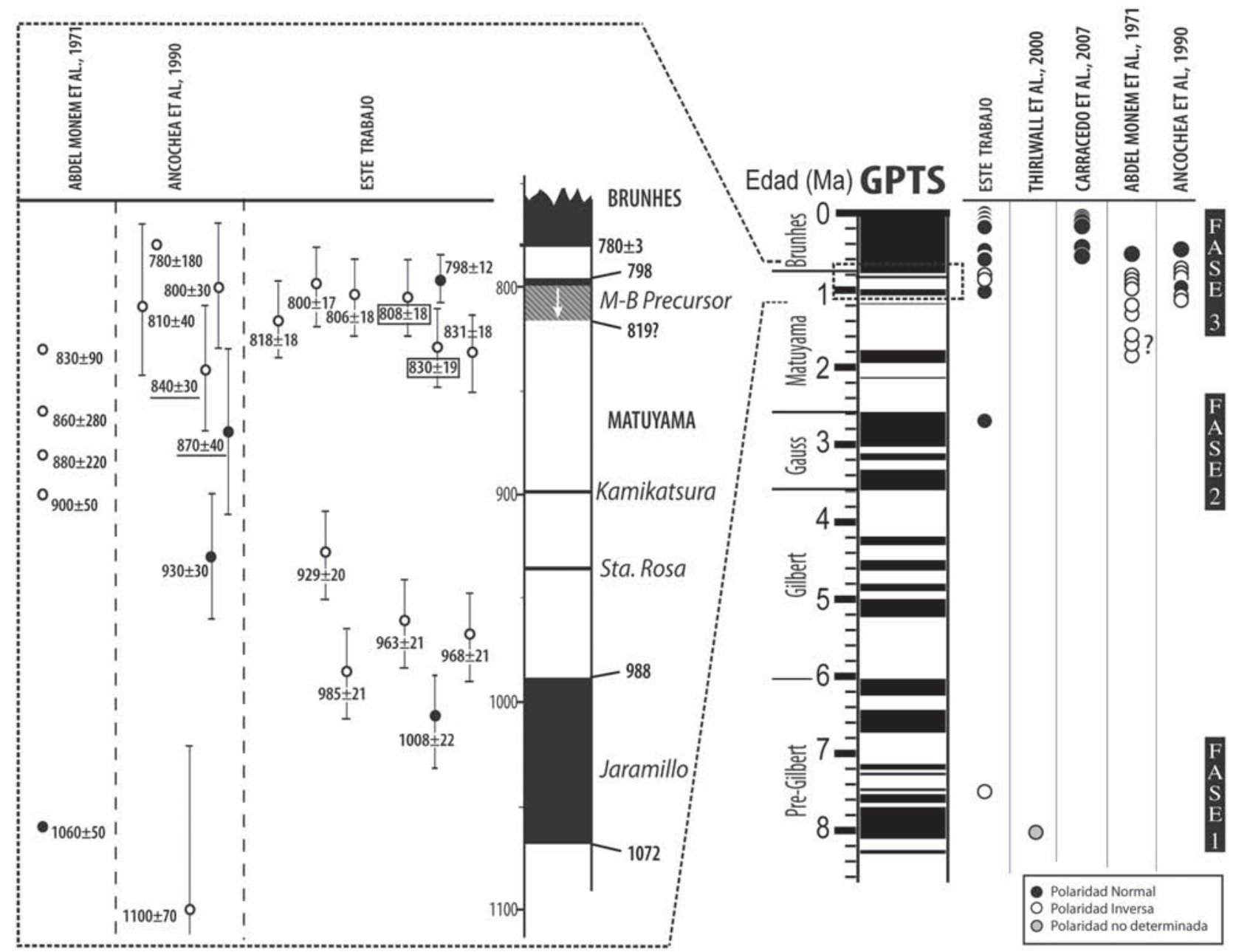

Fig. 7.-A la derecha de la figura se muestran las edades K/Ar obtenidas en este trabajo y por autores y trabajos anteriores en el Rift $\mathrm{NE}$ confrontadas con la escala temporal de inversiones geomagnéticas establecida (GPTS). Se apuntan las tres posibles etapas de actividad recurrente del rift: 1 . Miocena, 2. Pliocena y 3. Pleistocena. En el recuadro de la izquierda aparece ampliado el tramo de la GPTS que incluye la etapa más importante de desarrollo del rift. Las edades recuadradas delimitan la secuencia de polaridad normal que puede corresponder al evento M-B Precursor; las subrayadas son claramente dataciones demasiado jóvenes, posiblemente por pérdida de $\operatorname{Ar}$ (edades en ka).

ahora resolverse: la edad de $870 \pm 40$ ka de Ancochea et al. (1990) es claramente inferior a la de la secuencia a que pertenece, que corresponde al evento Jaramillo (fig. 7), lo que podría explicarse por una pérdida de Ar. Las edades de $1.560 \pm 150$ y $1.900 \pm 370$ ka de la zona costera de la Pared de Güímar (Abdel Monem et al., 1972) son claramente más antiguas que las situadas estratigráficamente por debajo $(830 \pm 90)$, y por encima $(860 \pm 50 \mathrm{y}$ $880 \pm 220 \mathrm{ka}$ ), todas de polaridad inversa. Los autores indicaron claramente esta inconsistencia y expresaron su preferencia por las edades más jóvenes, explicando las más antiguas como una consecuencia del exceso de Ar, interpretación coherente con los datos del presente trabajo. Una explicación similar serviría para la edad de $1.580 \pm 170 \mathrm{ka}$, de polaridad normal, que está claramente en una posición estratigráfica más alta que la muestra JCD-550 $(1.008 \pm 22 \mathrm{ka})$ de este trabajo. Dos edades más de la parte alta de la Pared de Güímar, KAR-25 y KAR-38, han dado edades de $985 \pm 21 \mathrm{ka} \mathrm{y}$ $968 \pm 21 \mathrm{ka}$. Junto con la edad de la muestra JCD$533(963 \pm 21 \mathrm{ka})$ del techo de la secuencia, demuestran que toda la Pared de Güímar en esa zona supera los $900 \mathrm{ka}$.

Una edad de gran interés es la de la muestra KAR-40 (831 $\pm 18 \mathrm{ka})$, correspondiente a la primera colada accesible del relleno del Valle de Güímar, 
situada en la pared norte del cauce del Bco. de Badajoz. Esta colada, de polaridad inversa, da una edad mínima (831 ka) para este colapso lateral similar a la obtenida para la primera lava de relleno del valle de colapso de Micheque (830 ka).

En conjunto parece evidente que la Pared de Güímar comprende una secuencia de unos $500 \mathrm{~m}$ de coladas basálticas que se acumularon en un periodo extremadamente corto, de unos $50 \mathrm{ka}$. En la cumbre del escarpe se localiza un conjunto de centros eruptivos basálticos cuyas lavas, de polaridad inversa, caen en cascada por el escarpe, aflorando ahora en su base, donde pueden confundirse en una observación superficial con depósitos de ladera. En la parte inferior del flanco oriental del rift, al norte del Valle de Güímar y cerca de la costa, se localiza un grupo de centros eruptivos basálticos, alterados y muy desmantelados por la erosión. Sus coladas, de polaridad normal, han dado una edad de $798 \pm 12 \mathrm{ka}$ (Carracedo et al., 2007), en principio compatible con el evento M-B Precursor. Es posible, pues, que mientras se rellenaba la cuenca de deslizamiento de Micheque, donde abunda el volcanismo durante este evento, se estuvieran produciendo también algunas erupciones en el flanco opuesto del rift.

Un aspecto interesante es comparar la edad de los escarpes de los valles de deslizamiento de Güímar y La Orotava (véase fig. 6). Mientras que las formaciones del escarpe oeste (Tigaiga) del Valle de La Orotava tiene edades similares a las de la Pared de Güímar, es evidente el diferente periodo de formación de éstas con las de la pared este (ladera de Santa Úrsula) del Valle de La Orotava, explicable por el hecho de que lo que aflora en la pared este de esta cuenca es la secuencia de relleno del colapso de Micheque, que hemos acotado en una edad máxima de $830 \pm 19$ ka (GLD-14). La base de esta secuencia de relleno sólo aflora en las galerías y en la pared norte del Valle de La Orotava, donde ha sido datada en $780 \pm 180 \mathrm{ka}$ (Ancochea et al. 1990). Una formación brechoide, con cantos de variada composición (basaltos a traquitas), aflora en la base de la pared norte, pudiendo corresponder a la brecha de deslizamiento de la base del relleno de Micheque. El afloramiento de esta aparente formación de avalancha, que se corta a una altura similar en las galerías de El Loro y Los Dornajos, sería posible porque el colapso de La Orotava excava más profundamente que el anterior de Micheque, dejando colgada la secuencia de relleno de la cuenca de colapso de Micheque. Los potentes depósitos de ladera, que recubren la base del escarpe, impiden una observación más detallada de la base del escarpe y de otros posibles afloramientos de la brecha de avalancha.

Los afloramientos de la formación de relleno de Micheque en los cantiles de la costa del norte, entre Santa Úrsula y Tacoronte, han dado edades muy inferiores, $694 \pm 15 \mathrm{ka}$ (Carracedo et al., 2007) y $540 \pm 40 \mathrm{ka}$ (Abdel Monem et al., 1972), ambas de polaridad normal.

Por último, las erupciones basálticas más dispersas y de menor frecuencia de la etapa final de actividad del Rift NE, que rellenan parcialmente las cuencas de deslizamiento de Güímar y La Orotava, y terminan de colmatar la de Micheque, presentan edades que van de los $513 \pm 12 \mathrm{ka}$, de la cresta del rift a la altura de La Cumbrecita (Carracedo et al., 2007), a las erupciones históricas de los volcanes de Fasnia y Arafo, ambos de 1705. Buena parte de los conos basálticos del rift aparecen parcialmente cubiertos por una capa de pómez de proyección aérea, que podría corresponder a la descrita y datada por Edgar et al. (2002) en $270 \mathrm{ka}$.

Parece, pues, que la actividad eruptiva del Rift NE decreció paulatinamente a partir de la fase de máxima actividad del periodo $1.000-800 \mathrm{ka}$. Sin embargo, parece haberse producido una fuerte reactivación reciente en el extremo sur del rift, en las cercanías del borde de la Caldera de Las Cañadas, donde hay un grupo muy numeroso de centros eruptivos basálticos, que han dado edades de 31 a $37 \mathrm{ka}$ (Carracedo et al., 2007).

Descartadas las edades que se han descrito como inconsistentes, el resto de las publicadas son coherentes con el marco geológico general del Rift NE y la GPTS, por lo que se han utilizado en la reconstrucción de su historia volcánica y estructural.

\section{Estratigrafía magnética de la Pared de Güímar}

La afortunada circunstancia de haber encontrado en varios afloramientos, y con una entidad importante, tanto el evento M-B Precursor como el Jaramillo ha ayudado de forma crucial en la reconstrucción de la historia eruptiva y estructural del Rift NE de Tenerife. Sin embargo, esta circunstancia requiere un análisis más detallado.

El estudio paleomagnético y geocronológico de excursiones y periodos muy cortos de cambio de polaridad ha contribuido al progresivo refinamiento de la escala establecida de inversiones geomagnéticas (GPTS), importante, a su vez, como elemento 
de datación de formaciones volcánicas. La mayoría de estas excursiones y eventos de corta duración se han detectado en sedimentos, por su mayor continuidad, aunque es crucial detectarlos y confirmarlos, asimismo, en formaciones volcánicas. Sin embargo, las erupciones son sucesos discretos y el volcanismo raramente es lo suficientemente continuado como para registrar eventos cortos o hacerlo en una parte importante o su totalidad, para lo que se requiere que éste quede impreso en secuencias formadas por numerosas coladas, correspondientes a tasas de crecimiento muy elevadas.

Uno de estos eventos es el M-B Precursor, que se ha denominado así por anteceder en sólo unos pocos miles de años al límite Matuyama-Brunhes, con el que se había confundido anteriormente. En el estudio geológico de La Palma del programa MAGNA (Carracedo et al., 2001) se detectaron en numerosos perfiles en barrancos del escudo volcánico de Taburiente coladas con polaridad normal seguidas por algunas lavas de polaridad inversa, justo antes de alcanzar las lavas consistentemente normales correspondientes a la época Brunhes. Aunque en ese trabajo no se prestó atención a este hecho por su cercanía al límite Matuyama-Brunhes, sí se hizo más adelante un estudio detallado en el Barranco de Los Tilos, encontrándose lavas con magnetización transicional y edades de $822 \pm 8,7$ a 798,4 $\pm 6,2 \mathrm{ka}$ (Singer et al., 2002). Se interpretaron estas edades y su polaridad transicional como correspondientes a un evento precursor del cambio M-B, anterior a éste en varios miles de años.

Brown et al. (2004) encontraron lavas transicionales con edades de $801 \pm 12$ a $790 \pm 6 \mathrm{ka}$ en el complejo volcánico Tatara-San Pedro (Chile), que asignaron, asimismo, al evento M-B Precursor. Muestras de magnetización transicional obtenidas en una sección inversa-transicional-normal (R-T-N) del valle de Punaruu (Tahiti) dieron edades de $798,0 \pm 23,0,791,9 \pm 9,3$ y 798,0 $\pm 11,0$ ka (Singer et al., 2005). Petronille et al. (2005) encontraron evidencia del mismo evento en el complejo volcánico Ceboruco-San Pedro (Méjico), obteniendo una edad de $819 \pm 2 \mathrm{ka}$. Finalmente, Dreyfus et al. (2008) recalcularon el límite M-B, que dejaron establecido en $780 \pm 3$, edad muy parecida a la definida por Coe et al. (2004) en lavas de Maui que registran el cambio $\mathrm{M} / \mathrm{B}$, o a la edad astrocronológica de Shackleton et al. (1990). Dreyfus et al. (2008) delimitaron el evento M-B Precursor entre 798 y 788 ka a partir de intervalos de incremento de ${ }^{10} \mathrm{~B}$ en mues- tras de hielo del «EPICA Dome C ice core» (Raisbeck et al., 2006), que asociaron con periodos de baja intensidad del dipolo durante este evento.

Las coladas de la galería Los Dornajos presentan, asimismo, una serie inversa-normal-inversa (R-N-R) en que las lavas de polaridad normal forman una secuencia de 400-500 m intercalada entre dos secuencias de polaridad inversa datadas en $830 \pm 19 \mathrm{ka} \mathrm{y}$ $808 \pm 18 \mathrm{ka}$. La edad de las coladas de polaridad normal sería, por lo tanto, compatible con la del evento M-B Precursor.

El evento Jaramillo fue definido por Doell \& Dalrymple en 1966 en Valles Caldera, New Mexico (Estados Unidos), asignándole una edad de unos 0,9 Ma. Esta edad fue posteriormente refinada en numerosos trabajos. Shackleton et al. (1990) delimitaron la edad del evento Jaramillo por calibración astronómica. Posteriormente, Izett \& Obradovich (1994) dataron este evento entre 1,11 Ma y 0,97 Ma, mientras que Horng et al. (2002) definieron la base de este evento en $1.072 \pm 2 \mathrm{ka}$ y el techo en $988 \pm 3 \mathrm{ka}$.

El evento Jaramillo aparece muy bien registrado en la formación volcánica de la Pared de Güímar, que ofrece unas condiciones inmejorables para su estudio. Se trata de una secuencia de coladas basálticas de unos $500 \mathrm{~m}$ de potencia, de los que $400 \mathrm{~m}$ presentan polaridad normal, con diques de polaridad normal e inversa, pasando en la parte alta de la secuencia a lavas transicionales y finalmente de polaridad inversa (fig. 8).

Las únicas edades disponibles en esta secuencia antes de la realización de este trabajo eran insuficientes para determinar si las lavas de polaridad normal y transicional correspondían al evento Jaramillo. Abdel Monem et al. (1972) dataron las coladas de polaridad inversa del techo de la secuencia en $900 \pm 50 \mathrm{ka}$ (véase figs. 6 y 8). Ancochea et al. (1990) obtuvieron dos edades, $840 \pm 30 \mathrm{ka}$, a los $1.565 \mathrm{~m}$ y polaridad inversa (por encima de la secuencia correspondiente al evento Jaramillo), y $870 \pm 40 \mathrm{ka}$, a los $1.270 \mathrm{~m}$, de polaridad normal (en una colada de la secuencia del evento Jaramillo, con el que concuerda en polaridad pero no en la edad). En este trabajo se han obtenido varias edades en esta secuencia, dos de ellas, de $1.008 \pm 22$ (JCD$550)$, y $963 \pm 21$ (JCD-533) corresponden a la base y el techo de la sección. Es evidente que la primera de estas edades corresponde en efecto al evento Jaramillo, mientras que las de Ancochea et al. (1990) son claramente demasiado jóvenes, posiblemente a causa de pérdida de Ar. 

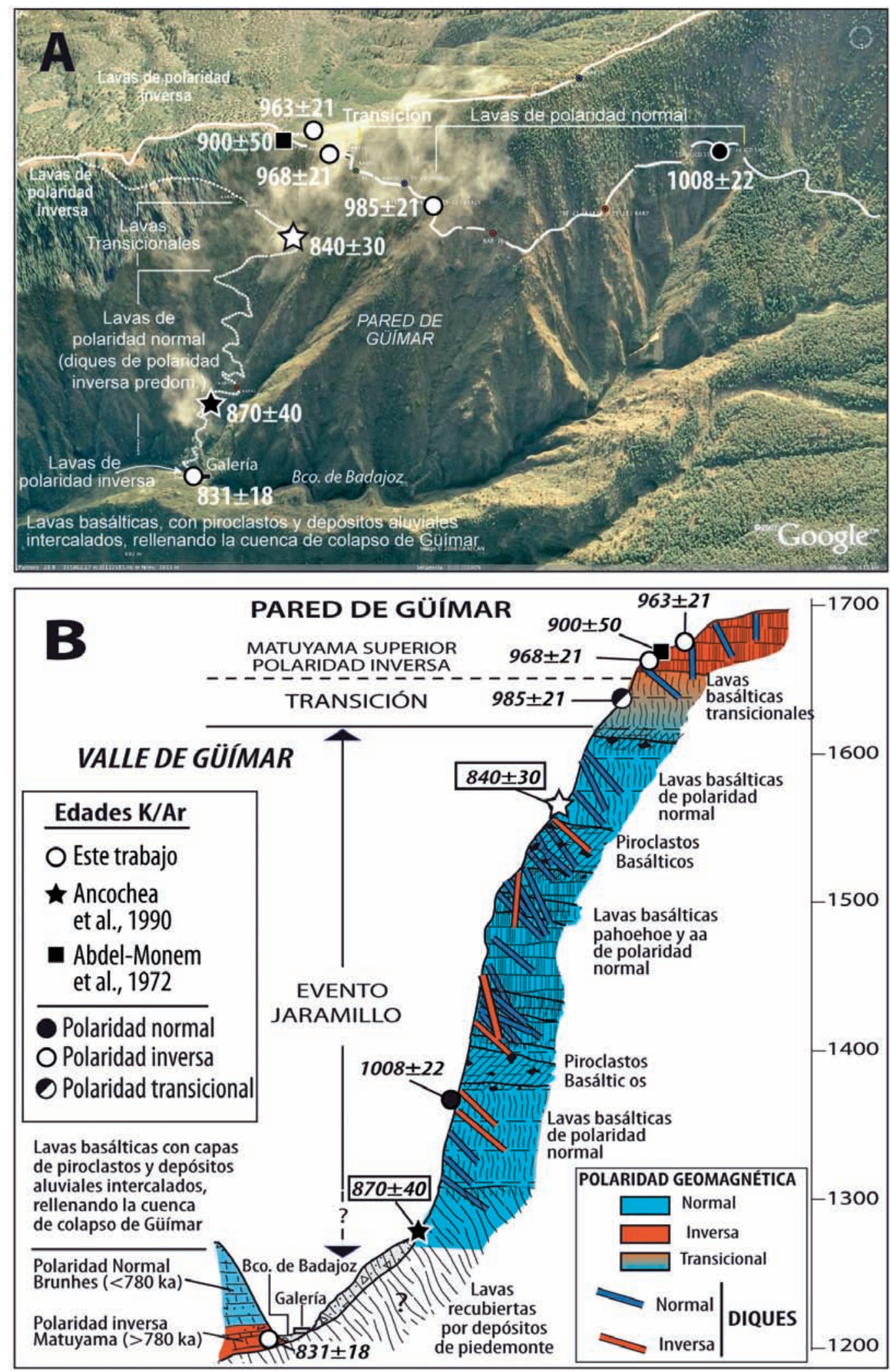

Fig. 8.-Secuencia de coladas con polaridad normal-transicional-inversa en el escarpe sur del valle de colapso lateral de Güímar (la Pared de Güímar). Las edades recuadradas son demasiado jóvenes, posiblemente por pérdida de Ar. Edades en ka. 
POLARIDAD NORMAL

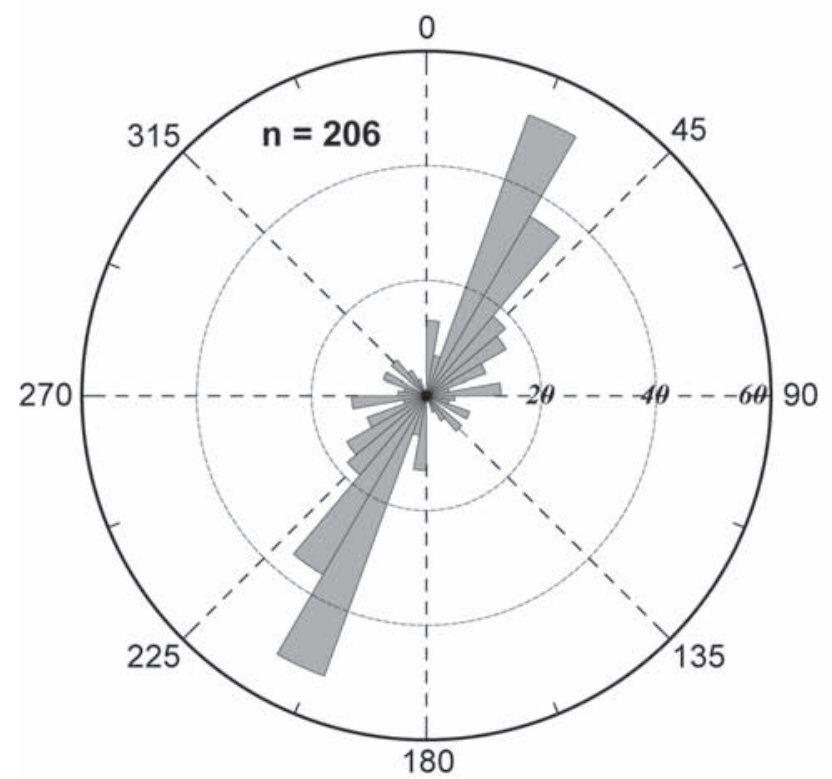

POLARIDAD INVERSA

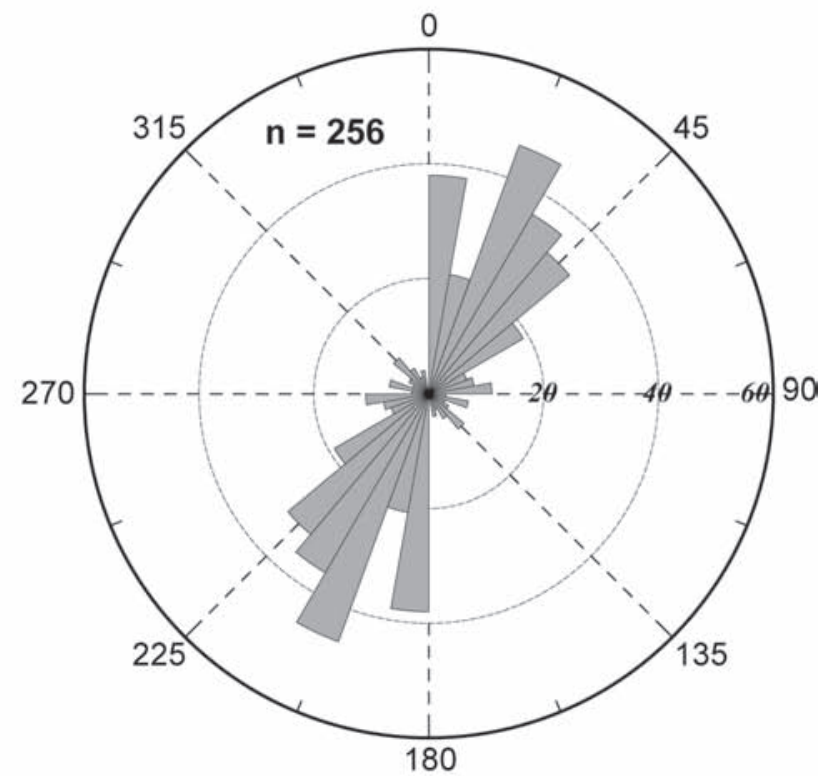

Fig. 9.-Distribución de las direcciones de los diques de polaridad normal e inversa del Rift NE de Tenerife (n representa el número de diques medidos de cada polaridad).

El estudio de esta secuencia para definir con precisión este evento, tanto sus características paleomagnéticas como su datación isotópica, se está abordando separadamente.

\section{Facies intrusiva del rift NE de Tenerife}

En este estudio se han tomado muestras y recopilado información de 462 diques del Rift NE, incluyendo sus parámetros estructurales — dirección, inclinación, potencia - y petrológicos, así como sus polaridades geomagnéticas. Como ya se ha indicado, la polaridad geomagnética de los diques ha sido crucial para la definición de unidades volcano-estratigráficas. Sin embargo, el estudio paleomagnético, estructural y petrológico detallado de la formación intrusiva de este rift está siendo abordado en otro trabajo (Delcamp et al., 2008).

Las direcciones de los diques analizados (fig. 9) muestran un claro agrupamiento en dos direcciones principales. Los de polaridad normal dominan claramente el sector de dirección N 20-30 E con un $25,2 \%$, seguido de N 30-40 E con un 17,5\%. En cuanto a los diques de polaridad inversa, el abanico de direcciones es más amplio. Aunque también domina la dirección N 20-30 E, con un 18\%, le sigue la N 0-10 E (casi N-S) con un 14,5\%. El arco
N 20-40 E representa el 32,1\%, mucho menos que en los de polaridad normal. Por el contrario, el arco de direcciones cercanas a N-S está muy bien representado, correspondiendo, fundamentalmente, estas direcciones a los diques que afloran en la Pared de Güímar. Estos diques cortan el Jaramillo y son anteriores a la época Brunhes. Indicarían un cambio en la dirección de los diques, pasando de NE-SO a N-S en el Matuyama superior.

\section{Etapas en la construcción del Rift NE}

La cartografía, datación y correlación de las secuencias volcánicas permiten intentar la reconstrucción de la historia eruptiva y estructural del rift, definiendo sus principales fases de actividad y delimitando los sucesivos colapsos laterales.

\section{El Rift NE durante el Mioceno y Plioceno}

La edad de 7,26 Ma obtenida en la pared sur del Valle de Tegueste confirma la existencia de una formación miocena en esa zona de Tenerife. Esta formación, constituida fundamentalmente por piroclastos basálticos densamente inyectados de diques y piroclastos y domos félsicos, difiere con- 


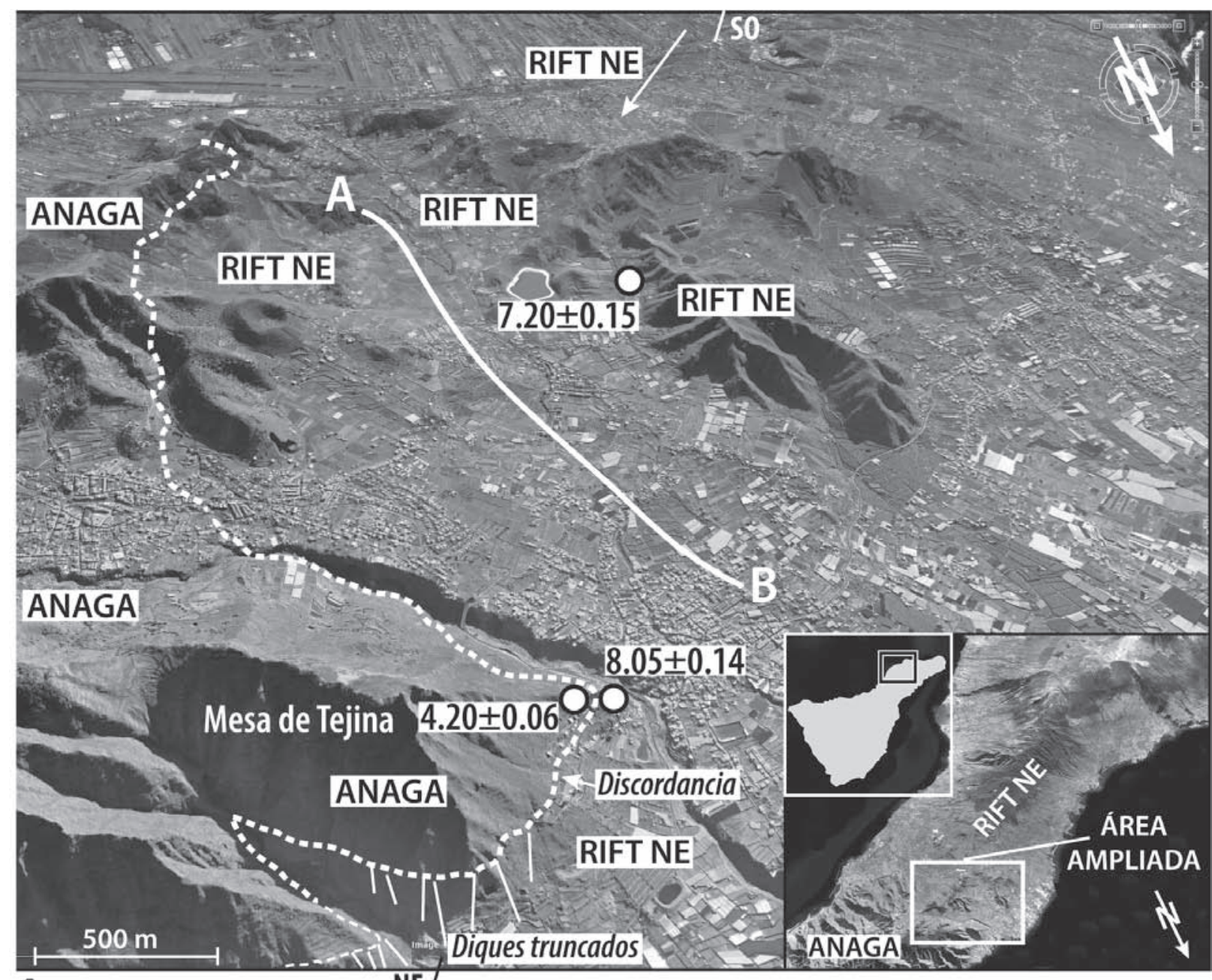

A

NE

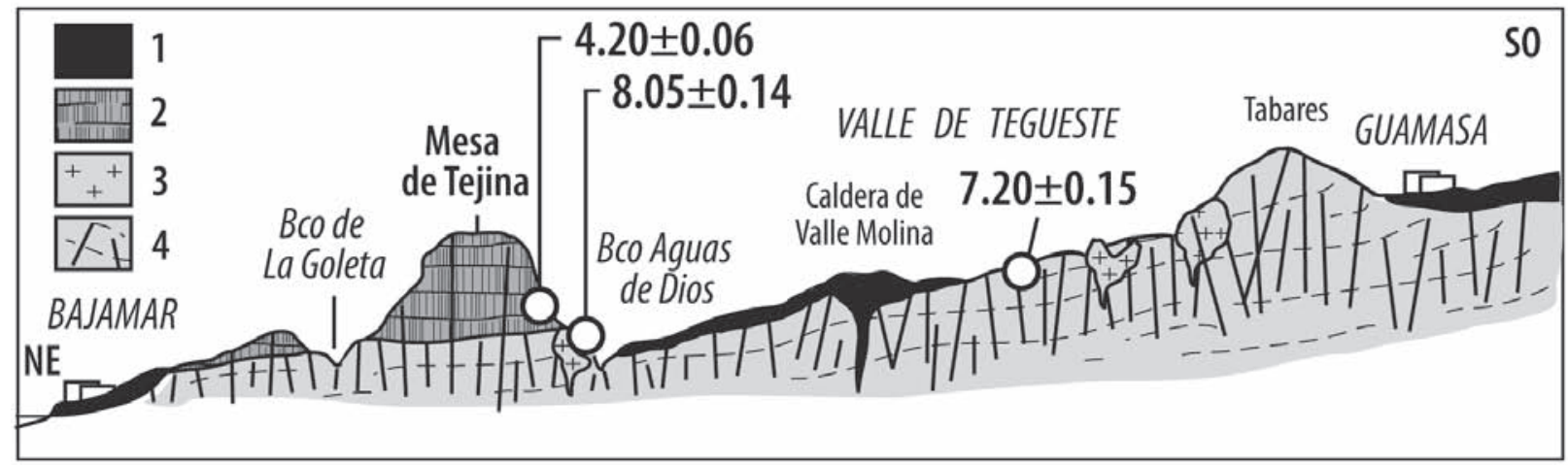

B

Fig.10.-A. Superposición del macizo plio-pleistoceno de Anaga sobre el extremo del Rift NE mioceno. En esta zona, el macizo de Anaga está predominantemente formado por coladas horizontales, disposición muy probablemente adquirida al acumularse en el contacto con el extremo del rift . El Valle de Tegueste ha podido formarse en el contacto entre ambos edificios volcánicos (Línea A-B en la figura). Obsérvese que el apoyo de Anaga sobre la formación subyacente es discordante, con diques truncados (Carracedo 1979). Esta discordancia parece evidenciarse, asimismo, por la gran diferencia de las edades radioisotópicas (en Ma) a ambos lados del contacto discordante. Sin embargo, la edad de la base de la formación Anaga ( $8.05 \mathrm{Ma})$ es muy similar a la del otro lado del valle (7.20 Ma), ambas del Mioceno y aparentemente correspondientes a la primera fase de actividad del Rift NE. B. Corte geológico SO-NE mostrando la disposición de las formaciones descritas. 1. Volcanismo de la fase dispersa del Rift NE (Pleistoceno). 2. Formación de lavas horizontales de Anaga (Plioceno). 3. Intrusiones sálicas en las formaciones miocenas del Rift NE. 4. Rift NE mioceno. 
siderablermente de las correspondientes al macizo de Anaga, que se caracterizan en esta zona por un predominio de coladas subhorizontales, lo que sugiere la acumulación contra una formación más antigua. Tanto las edades obtenidas como la polaridad geomagnética de las secuencias volcánicas que afloran en la parte inferior de la Mesa de Tejina, en el borde del macizo de Anaga, indican la existencia de dos unidades separadas en el tiempo (fig. 10). Estas formaciones volcánicas están, asimismo, limitadas por una fuerte discordancia erosiva con diques truncados, ya mencionada por Carracedo (1975, 1979). Ancochea et al. (1990) dataron un perfil en la Mesa de Tejina, obteniendo edades en las lavas basálticas horizontales de la parte media y alta de la secuencia de 3,59 y 3,28 $\mathrm{Ma}$, y de 6,12 y 6,5 Ma en la parte inferior, por debajo de la discordancia y en lavas de composición fonolítica. Posteriormente, Thirlwall et al. (2000) dataron con ${ }^{40} \mathrm{Ar} /{ }^{39} \mathrm{Ar}$ la parte inferior de esa misma secuencia, obteniendo una edad de $8,05 \pm 0,14$ Ma para una benmoreita, que estos autores correlacionan con las edades de 6,12 y 6,5 Ma de Ancochea et al. (1990). Finalmente, Guillou et al. (2004), realizaron un perfil en la misma secuencia, obteniendo edades de 4,20, 4,04 y 4,01 , pero sólo en las lavas por encima de la discordancia, considerando las inferiores muy alteradas y no aptas para su datación.

Parece, pues, evidente la existencia en esta secuencia de dos unidades, una inferior miocena y una superior pliocena, separadas por una clara discordancia erosiva de al menos $2 \mathrm{Ma}$ (posiblemente hasta $4 \mathrm{Ma}$ ). Estas características sugieren que la unidad inferior puede ser, en realidad, el extremo del Rift NE, sobre el que se apoyaría el macizo de Anaga (véase fig. 1). Esta prolongación miocena del rift correspondería a la fase 1 de su actividad (figs. 6, 7 y 10), en la que el escudo mioceno central de Tenerife se habría prolongado hacia el NE conformando el rift inicial (véase corte de la fig. 1), de actividad recurrente. En este contexto, se explicaría el amplio y profundo Valle de Tegueste, que se habría excavado en el contacto del rift con las lavas horizontales de Anaga (ver fig. 10).

El Rift NE parece haber tenido otra fase de actividad en el Plioceno, como indica la edad de 2,7 Ma obtenida en el frente de la galería Los Dornajos. Aunque no hay más edades que permitan reconstruir la historia volcánica del Rift NE en el Mioceno y Plioceno, su comportamiento en la última fase de actividad, en el Pleistoceno, parece sugerir que la actividad eruptiva se produjo en pulsos relativamente cortos (1,0-1,5 Ma) separados por periodos mucho más extensos de menor actividad e intensa erosión. En ese caso, las edades obtenidas corresponderían a distinas fases eruptivas, como se indica tentativamente en la figura 7 . El núcleo antiguo del rift (Mioceno-Plioceno) es el que se ha relacionado con la formación basáltica alterada y con una densa malla de diques que se corta en el fondo de las galerías en ambos flancos del rift (fig. 3), aunque en este trabajo sólo ha podido datarse el correspondiente al Plioceno (véase fig. 5).

\section{La última fase (pleistocena) del Rift NE}

En este último periodo de actividad eruptiva del Rift NE, que es el único que ha sido estudiado en detalle en este trabajo, la sucesión de episodios constructivos y colapsos laterales, que a su vez vuelven a rellenarse con un volcanismo anidado en las cuencas de deslizamiento, permite la separación de diferentes fases que, en conjunto, delimitan con gran precisión el desarrollo del rift en el último millón de años.

\section{Fase de desarrollo inicial}

En esta fase se levantó un edificio volcánico que pudo alcanzar $2.000 \mathrm{~m}$ de altitud - la altura actual de Izaña, coherente con la inclinación de las coladas - sobre un relieve anterior de una altura no inferior a 800-1.000 m. De este aparato volcánico, centrado en la zona entre los actuales Gaitero y Mña. de Joco, sólo aflora actualmente una parte del flanco NE, en forma de dos triángulos situados a ambos lados del Valle de Güímar (fig. 11). El resto del edificio ha sido desmantelado por sucesivos colapsos laterales o aparece recubierto por erupciones posteriores.

La polaridad de las lavas y diques de esta formación (Unidades $\mathrm{A}_{1}$ y $\mathrm{B}$ de la Pared de Güímar) y las edades descritas evidencian que este edificio volcánico se formó en el Matuyama superior, en el periodo que comprende la base del Jaramillo hasta unos $830 \mathrm{ka}$, época en que debió alcanzar una configuración inestable y colapsó. La fase crítica de construcción se desarrolló entre 1.100 ka y unos $900 \mathrm{ka}$, como puede apreciarse en la secuencia de la Pared de Güímar, en que la tasa de crecimiento pudo alcanzar hasta $10 \mathrm{~m} / \mathrm{ka}$, correlativa con una intensa fase de intrusión y la progresiva inestabili- 


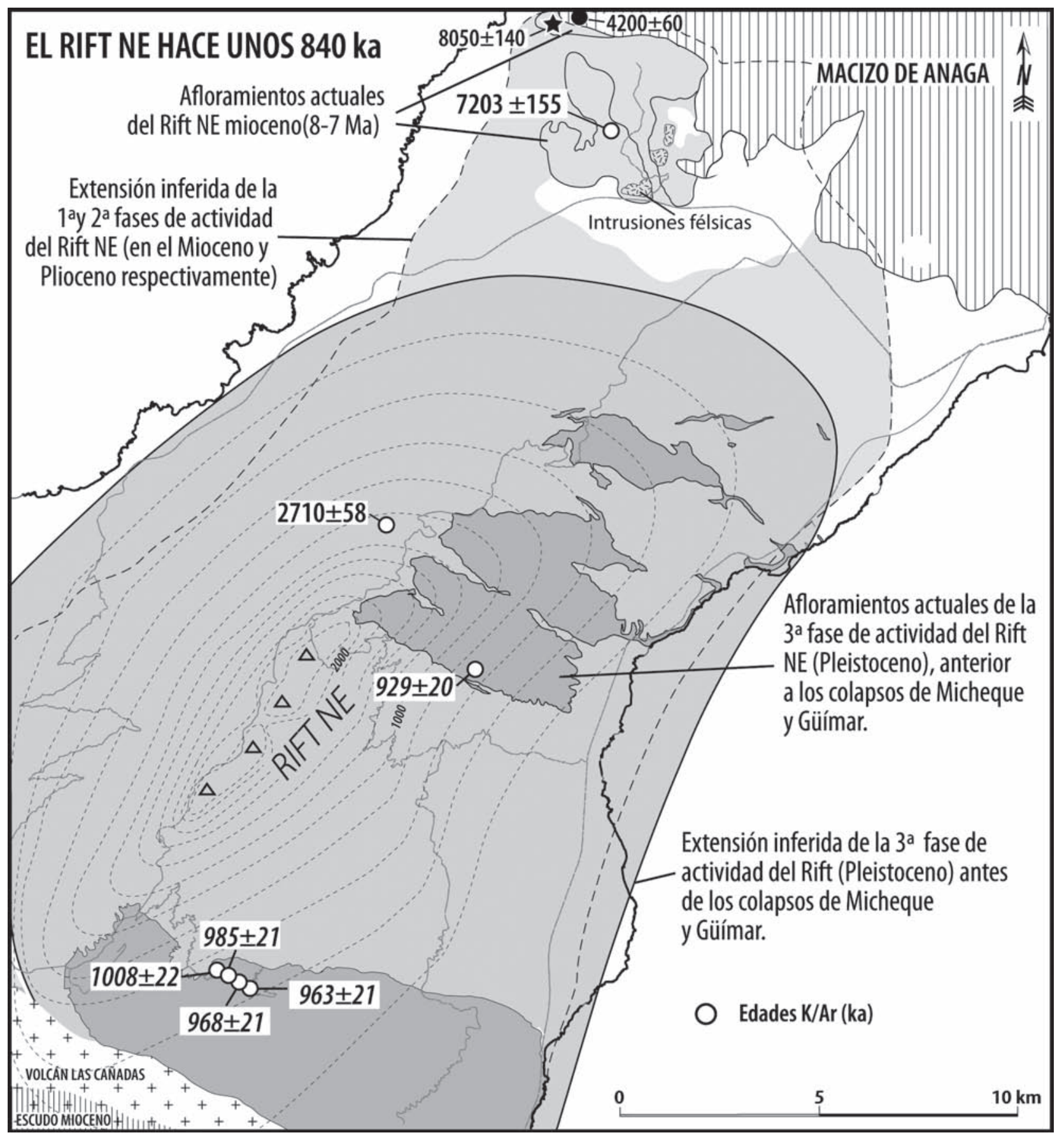

Fig. 11.-Actividad eruptiva del Rift NE desde el Mioceno hasta la época anterior a los primeros colapsos laterales (Micheque y Güímar). La edad de $2710 \pm 60$ ka corresponde a la muestra GLD-20, del frente de la galería Los Dornajos. Edades en miles de años.

dad del volcán. Un indicio de esta inestabilidad podría ser el cambio de dirección en los diques de polaridad inversa del Matuyama superior que pasa-

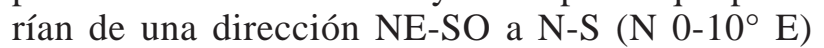
(véase fig. 9).

\section{El colapso lateral de Micheque}

El colapso lateral (Micheque) debió ocurrir hace unos $830 \mathrm{ka}$, la edad de las primeras lavas anidadas sobre la brecha de avalancha en el frente de la gale- 


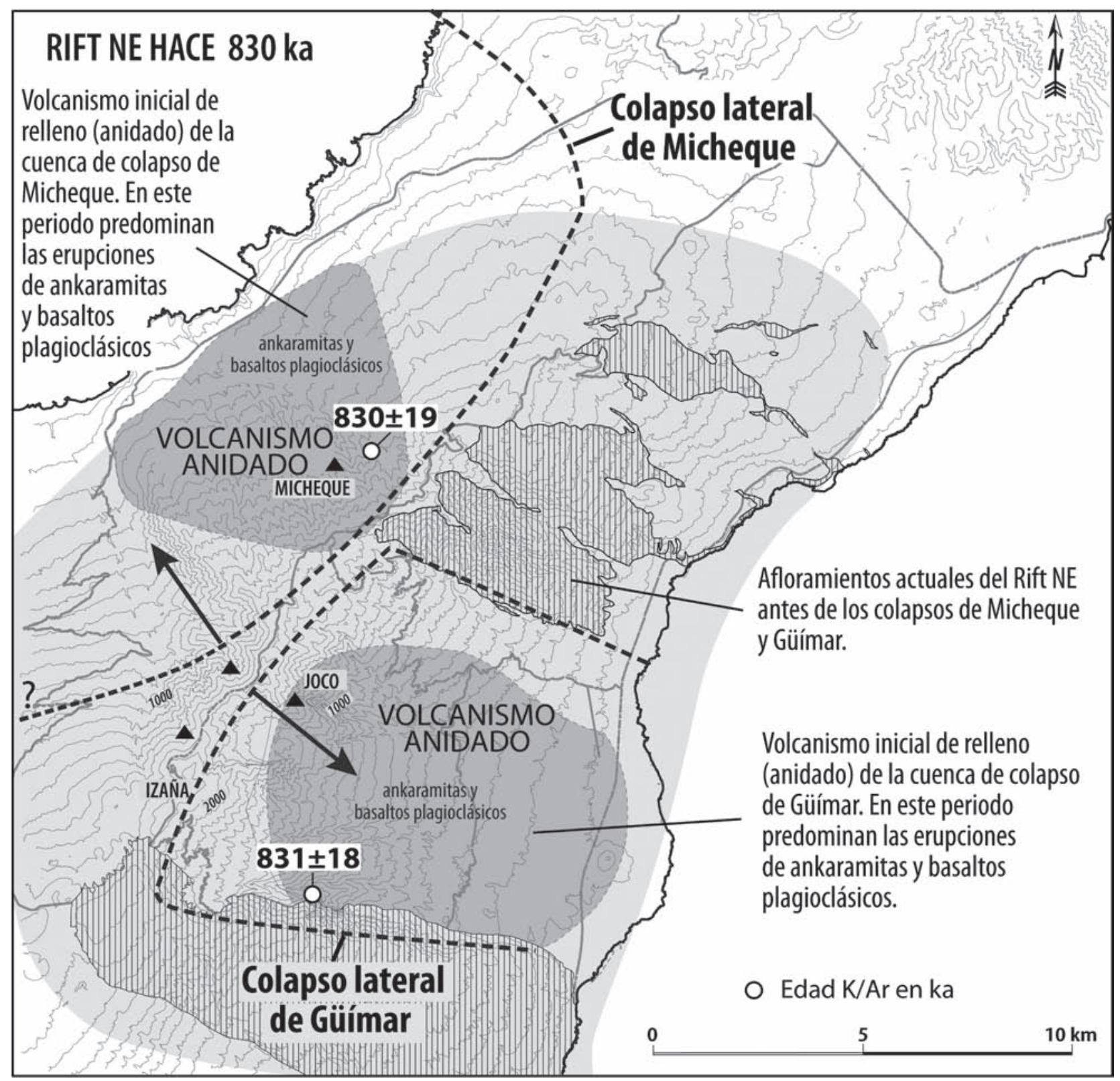

Fig. 12.- Hace unos 830 ka se produjeron los colapsos laterales simultáneos y opuestos de Micheque y Güímar. Es difícil establecer si fueron sincrónicos o hubo un cierto lapso de tiempo entre ellos, y cuál fue el primer colapso en producirse. Sin embargo, es evidente que la inestabilidad del resto del rift después del primer evento, ya crítica antes, debió incrementarse por efecto del colapso, dando lugar poco después al deslizamiento del flanco opuesto.

ría Los Dornajos y, por consiguiente, la edad mínima del colapso (véase fig. 5). La elevada tasa del volcanismo post-colapso sugiere que la actividad eruptiva no se interrumpió tras el deslizamiento, por lo que es plausible suponer que la edad de $830 \pm 19$ ka obtenida, estratigráficamente muy cercana a la brecha de colapso (véase fig. 5), sea prácticamente la del propio deslizamiento.
El colapso lateral generó una cuenca en el flanco norte del rift que abarcaría desde la zona de Tacoronte por el NE, hasta el interior del actual valle de La Orotava por el SO (fig. 12). El volcanismo posterior rellenó gran parte de esta cuenca y transgredió la línea de costa resultante del colapso, por lo que no son visibles ni la cicatriz ni la brecha de avalancha. Se ha datado en este trabajo la base del can- 
til costero formado en su integridad por la formación de relleno de esta cuenca de deslizamiento de Micheque, obteniéndose una edad de $694 \pm 15 \mathrm{ka}$ (véase figs. 6 y 14), claramente de una fase avanzada de la colmatación de la depresión.

No obstante, existe un pequeño afloramiento en el escarpe oriental del valle de La Orotava (en la zona de Pino Alto) de cantos angulosos y de composición variada, incluyendo rocas félsicas. Esta formación, emplazada en la base de la formación de relleno de la cuenca de Micheque, podría ser parte de la brecha de avalancha de este primer colapso lateral. El deslizamiento posterior que dio lugar al valle de La Orotava habría excavado más profundamente, exhumando esta parte de la cicatriz del colapso anterior de Micheque.

El relleno de la cuenca de deslizamiento de Micheque debió comenzar inmediatamente después del colapso, aumentando la tasa de crecimiento de la etapa inicial hasta alcanzar $15-25 \mathrm{~m} / \mathrm{ka}$. El volcanismo post-colapso (Unidad $\mathrm{A}_{2}$ ) se limitó fundamentalmente a erupciones anidadas en la cuenca de deslizamiento (fig. 13).

\section{El colapso lateral de Güímar}

El deslizamiento lateral de la parte meridional del flanco oriental del Rift NE formó una depresión de $10 \times 10 \mathrm{~km}$, en forma de artesa de escarpes rectos (fig. 13). La ocurrencia del colapso puede limitarse con bastante precisión por la existencia de coladas de polaridad inversa posteriores al evento Jaramillo en la parte alta del escarpe de la Pared de Güímar, datadas en $840 \pm 30 \mathrm{ka}$ (Abdel Monem et al., 1972), y la edad del primer volcanismo anidado, datado en $831 \pm 18 \mathrm{ka}$. Después del colapso se siguen produciendo erupciones en el borde sur de la depresión, por ejemplo, el volcán Anocheza (fig. 13), con algunas coladas vertiendo en cascada por el escarpe de la Pared de Güímar. Tanto estas coladas como las primeras de relleno, que afloran en el cauce del Bco. de Badajoz, son de polaridad inversa, correspondiendo, por consiguiente, al periodo Matuyama post-Jaramillo (798-988 ka).

Un hecho a destacar es la abundancia de basaltos ankaramíticos y plagioclásicos, generalmente con morfologías pahoehoe, en las fases iniciales del volcanismo anidado en estos colapsos, tanto en el de Micheque como en el de Güímar. Esta característica, descrita en otros deslizamientos, como el de Cumbre Nueva en La Palma y el Volcán Bejenado que se desarrolló anidado en su interior (Carracedo et al., 2001), o el de las Cañadas, con el volcán Teide (Carracedo et al., 2007), puede tener un importante significado, como se analiza más adelante. Hay que remarcar también que en esta época aún no se han llevado a cabo procesos de diferenciación en el Rift NE que hayan dado lugar a lavas félsicas, lo que ocurrirá en un proceso evolutivo posterior.

Por otra parte, es evidente que la tasa eruptiva y el volumen de la formación de relleno del colapso de Micheque es muy superior al del subsiguiente de Guiímar, lo que podría indicar que fuera éste el primer colapso en producirse, coincidiendo con una fase de gran actividad volcánica. Este hecho podría sugerir una notoria diferencia en los mecanismos que provocaron ambos deslizamientos, probablemente esfuerzos distensivos asociados a una fase de gran intensidad eruptiva e intrusiva en el primero, y por inestabilidad gravitatoria incrementada por el colapso anterior el segundo. Esto explicaría, asimismo, el hecho de que el grueso del volcanismo del rift continuara focalizado principalmente en el interior de la cuenca del primer colapso (Micheque), incluso después de producirse el deslizamiento de Guiímar y La Orotava, provocando el relleno total de esta depresión y la evolución de los magmas hacia términos diferenciados.

\section{El colapso lateral de La Orotava}

La facilidad en limitar con precisión la fecha de ocurrencia de los colapsos de Micheque y Güímar no ha sido equiparable en el tercer colapso, que ha formado el Valle de La Orotava. Lavas de polaridad normal (Unidad C) y edad de $690 \pm 10 \mathrm{ka}$ (Ibarrola et al., 1993) y $370 \pm 70$ y $270 \pm 70$ ka (Ancochea et al., 1990) coronan el escarpe oeste (Tigaiga) del valle de colapso, mientras que otras que caen en cascada por el escarpe este (ladera de Santa Úrsula) hacia el interior de la depresión han sido datadas en este trabajo en $566 \pm 13$ ka (fig. 14). Aunque Ibarrola et al. (1993) aceptan la posibilidad de que el colapso de La Orotava pueda ser posterior a esa edad de $270 \mathrm{ka}$, es evidente que la edad de la lava que cae en cascada por el escarpe oriental del valle indica una edad mínima para el deslizamiento de $566 \pm 13 \mathrm{ka}$. Las edades de $370 \pm 70$ y $270 \pm 70 \mathrm{ka}$ es muy posible que correspondan a erupciones posteriores al colapso, que tal vez vertieran coladas hacia el interior del valle (como se observa en la Pared de Güímar), y que han sido luego erosionadas por los numerosos desprendi- 


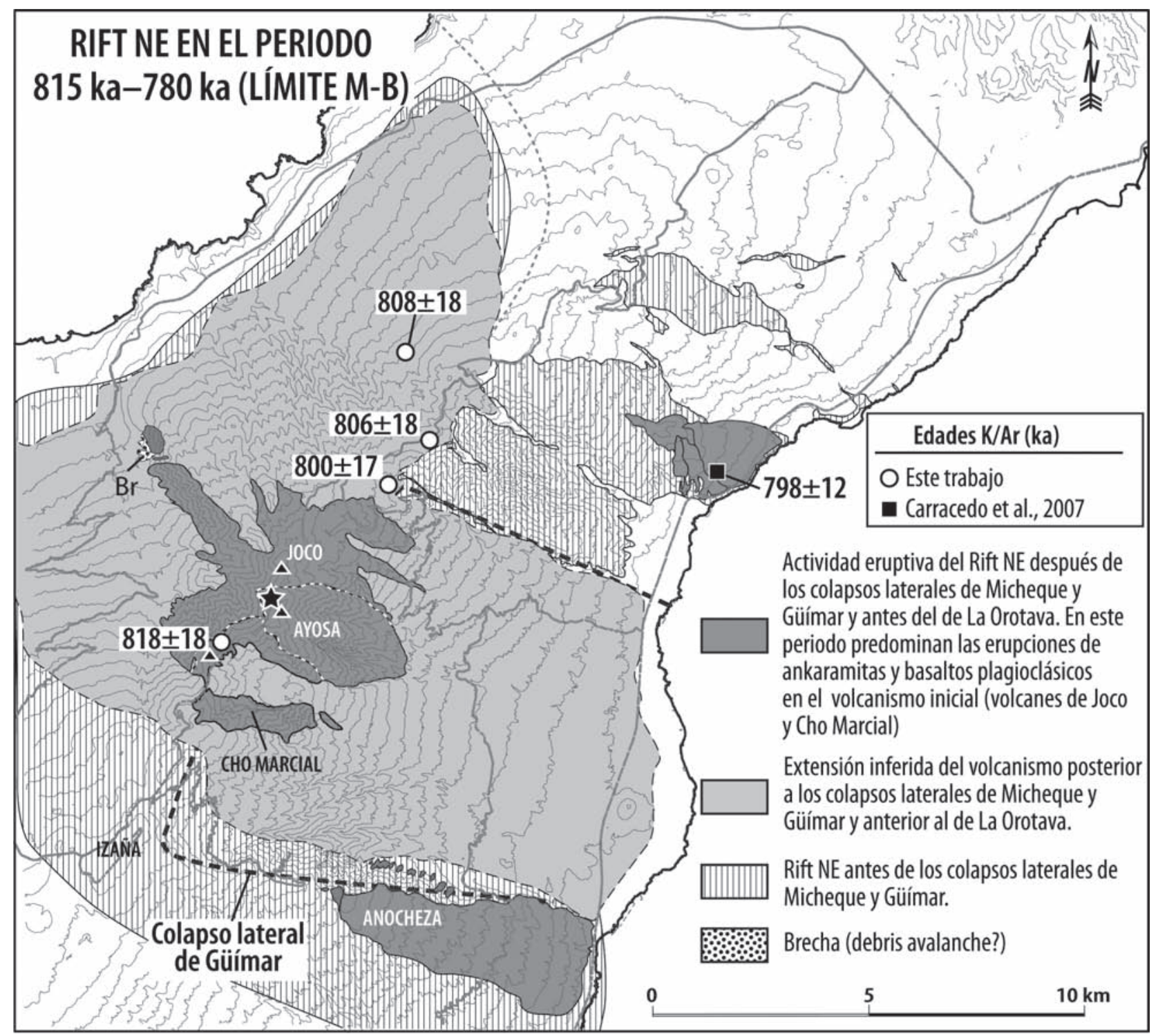

Fig. 13.-Actividad eruptiva del Rift NE después de los colapsos laterales de Micheque y Güímar, y, aparentemente, antes del de La Orotava. Mientras la cuenca de deslizamiento de Micheque continúa colmatándose con erupciones anidadas, se produce el relleno parcial de la depresión de Güímar con voluminosos aparatos volcánicos (Joco, Cho Marcial, Ayosa), predominantemente de basaltos ankaramíticos y plagioclásicos en las fases iniciales. La formación de polaridad normal de este periodo que aflora al N del Gaitero, en la galería Los Dornajos y, posiblemente, formando centros eruptivos basálticos en el flanco E, parece corresponder al evento M-B Precursor. Br indica un afloramiento de brechas que podrían pertenecer a las de avalancha del deslizamiento de Micheque, presentes en la base del relleno de la cuenca (véase fig. 5).

mientos en esa zona del escarpe. La única posibilidad de constreñir al máximo la edad real del colapso de La Orotava sería determinar la edad de las primeras lavas rellenando la cuenca, si éstas corresponden a erupciones ocurridas inmediatamente después del colapso, lo que en este caso no ha podido hacerse.

En los trabajos de cartografía geológica se observó un afloramiento de fonolita haüynica en la cabe- cera del valle de La Orotava (Ph en la fig. 14). El estado de erosión y alteración de esta formación fonolítica, con aspecto de domo, y su composición, completamente diferente de las lavas y diques del Rift NE, parecen indicar un resto erosivo del edificio Las Cañadas que ha permanecido sin recubrir. En tal caso formaría el escarpe del colapso de La Orotava que, en consecuencia, estaría situado a una cota más baja de lo anteriormente supuesto. 


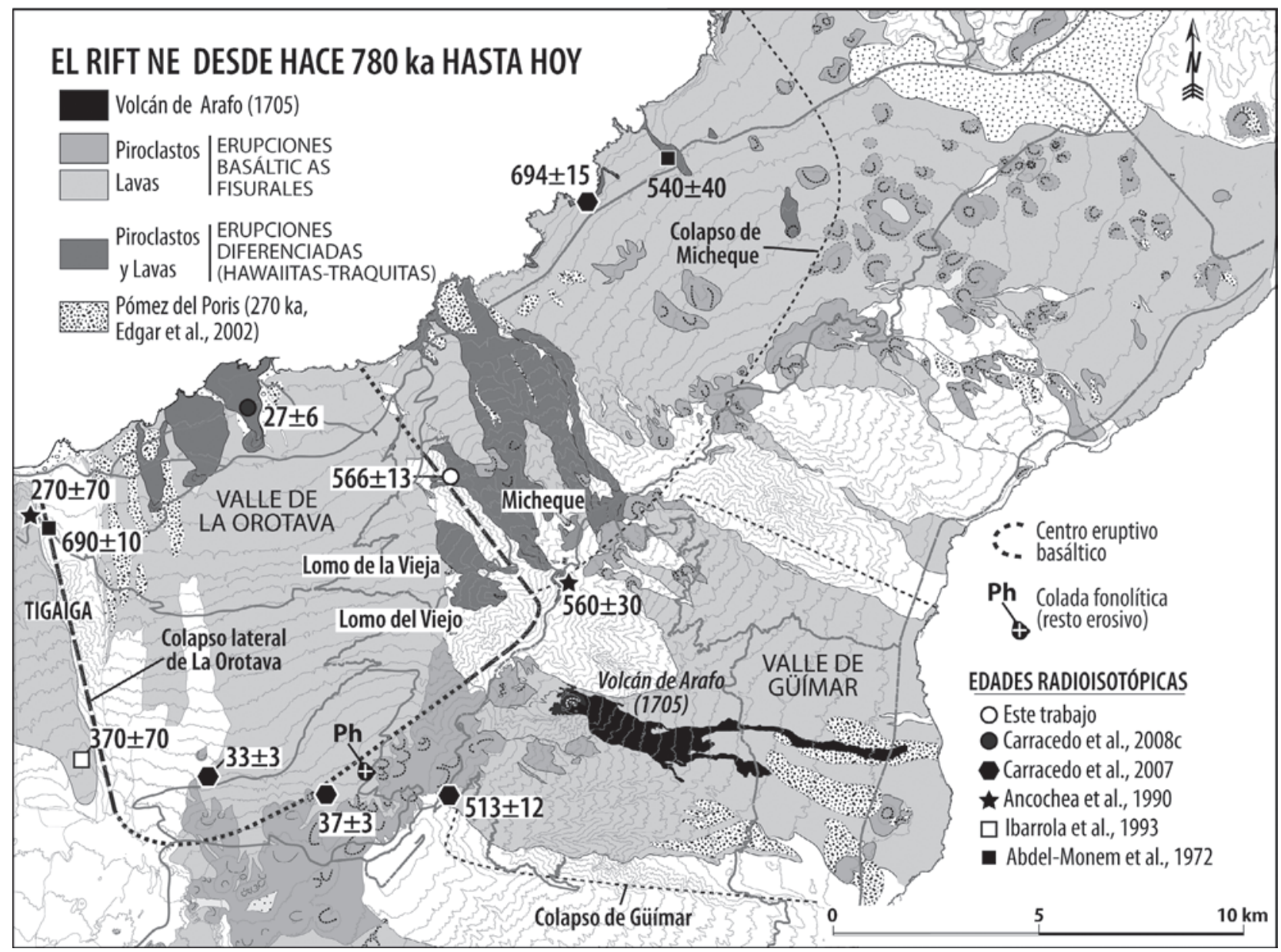

Fig. 14.-Actividad eruptiva del Rift NE después del colapso lateral de La Orotava. En esta fase las erupciones son consistentemente de polaridad normal, correspondiente al cron Brunhes, como confirman las edades K/Ar obtenidas. Las erupciones anidadas en la cuenca de deslizamiento de Micheque evolucionan hacia términos intermedios y traquíticos. No puede definirse con precisión la fecha del colapso de La Orotava, puede haber ocurrido ya en la época Brunhes ( $<780 \mathrm{ka})$. Las coladas fonolíticas que caen en cascada por el escarpe NE del Valle de La Orotava dan una edad mínima al colapso de $566 \pm 13 \mathrm{ka}$. Ph, afloramiento de fonolita haüynica. Edades en ka, excepto el Volcán de Arafo (1705 d.C.).

Un aspecto muy significativo es que en esta fase final de desarrollo del Rift NE, en que las lavas son todas de polaridad normal $\mathrm{y}$, por lo tanto, de edad $<780 \mathrm{ka}$, se han producido ya procesos de diferenciación magmática que dan lugar a erupciones de lavas de composición intermedia y traquítica (véase fig. 14), en proceso de datación. Sin embargo, esta evolución magmática parece completamente independiente del colapso de La Orotava, y seguir relacionada con focos magmáticos asociados al que posiblemente sea el primer colapso (Micheque). De hecho algunas erupciones diferenciadas, como los Lomos del Viejo y la Vieja (en la parte central de la fig. 14), se localizan en el mismo escarpe del Valle de La Orotava y parecen similares en edad y composición a las que vierten por el escarpe y han sido datadas en $566 \pm 13$ ka. Lavas de composición intermedia y félsicas (mugearitas, benmoreitas y traquitas) abundan en esta fase, aunque completamente restringidas a la cuenca de deslizamiento de Micheque. La importancia de esta limitación en la caracterización de los sucesivos colapsos del Rift NE, así como el significado y posible origen de esta variabilidad magmática, se analizan en detalle más adelante.

\section{La etapa de disminución y dispersión} de la actividad del Rift NE

Tras la ocurrencia de los tres colapsos descritos el rift parece entrar en una etapa de estabilización y disminución progresiva de la actividad eruptiva. Al mismo tiempo, las erupciones se producen preferen- 


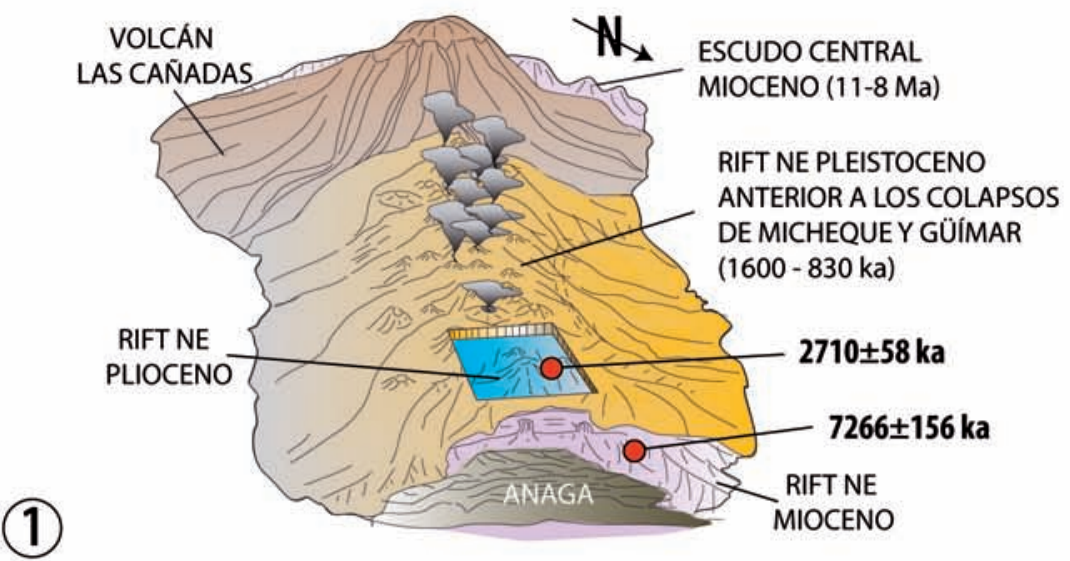

El Rift NE se inició como la prolongación desarrollada hace 8-7 Ma del Escudo Central Mioceno de Tenerife (11-8 Ma). Subyace el Escudo de Anaga (Plioceno). Esta etapa de construcción del Rift NE es coetánea con la del Edificio Las Cañadas.

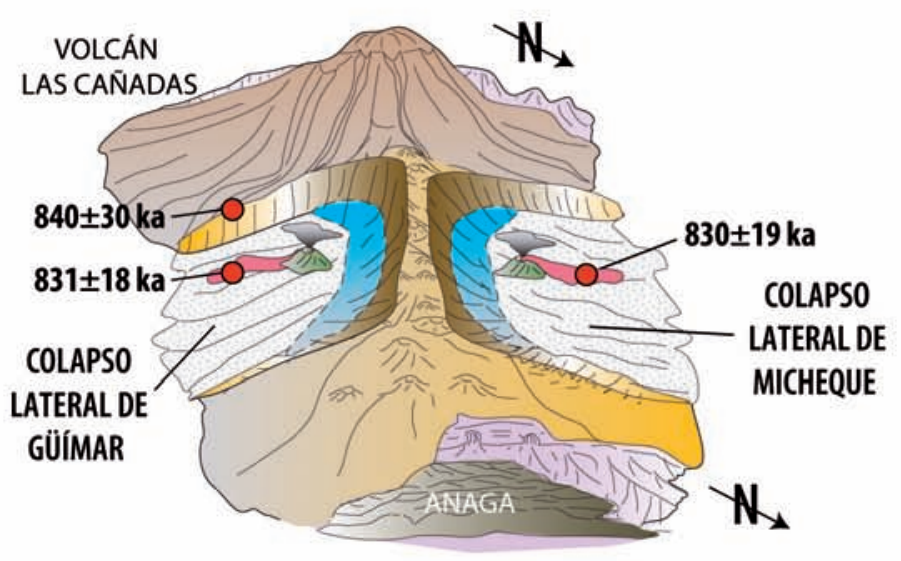

Actividad eruptiva intensa y concentrada en el periodo 1.1-0.83 Ma acabó desarrollando un rift de fuertes pendientes e inestable. Hace unos 830 ka se desplomaron los flancos NE y SO del rift, en dos deslizamientos simultáneos y opuestos, dando lugar a los valles de Micheque y Güímar, el primero totalmente recubierto por la actividad eruptiva posterior.

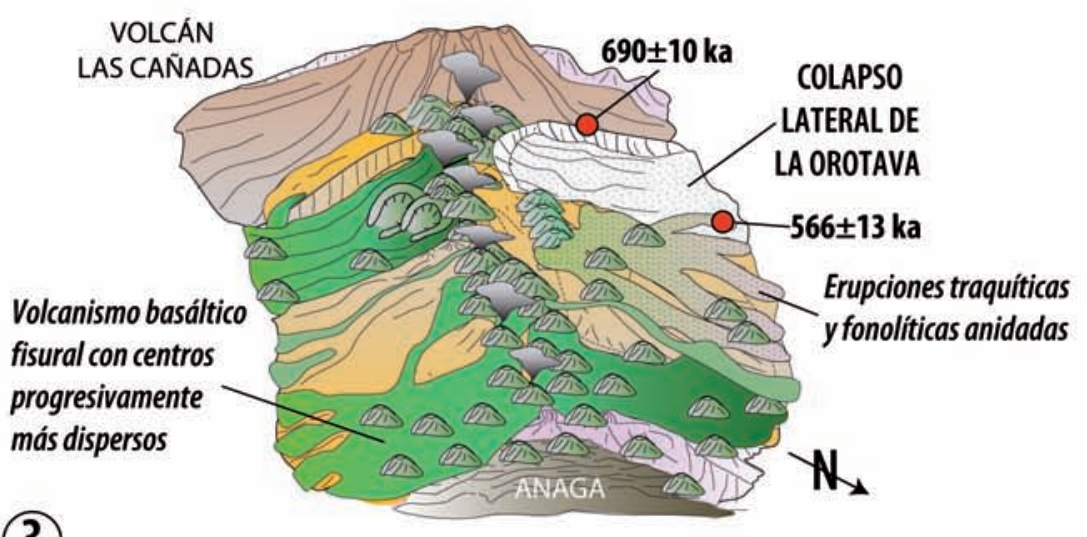

(3)

Un tercer colapso, que sólo ha podido fijarse entre unos 690 ka y 566 ka, formó el Valle de La Orotava. En este periodo el volcanismo en la cuenca de colapso de Micheque evolucionó hacia erupciones félsicas (traquitas, fonolitas). En cambio, en las de Güímar y la Orotava el volcanismo continuó siendo basáltico fisural, con centros eruptivos cada vez más dispersos.

Fig. 15.-Síntesis de la evolución volcánica y estructural del Rift NE de Tenerife. Todas las edades en ka. 


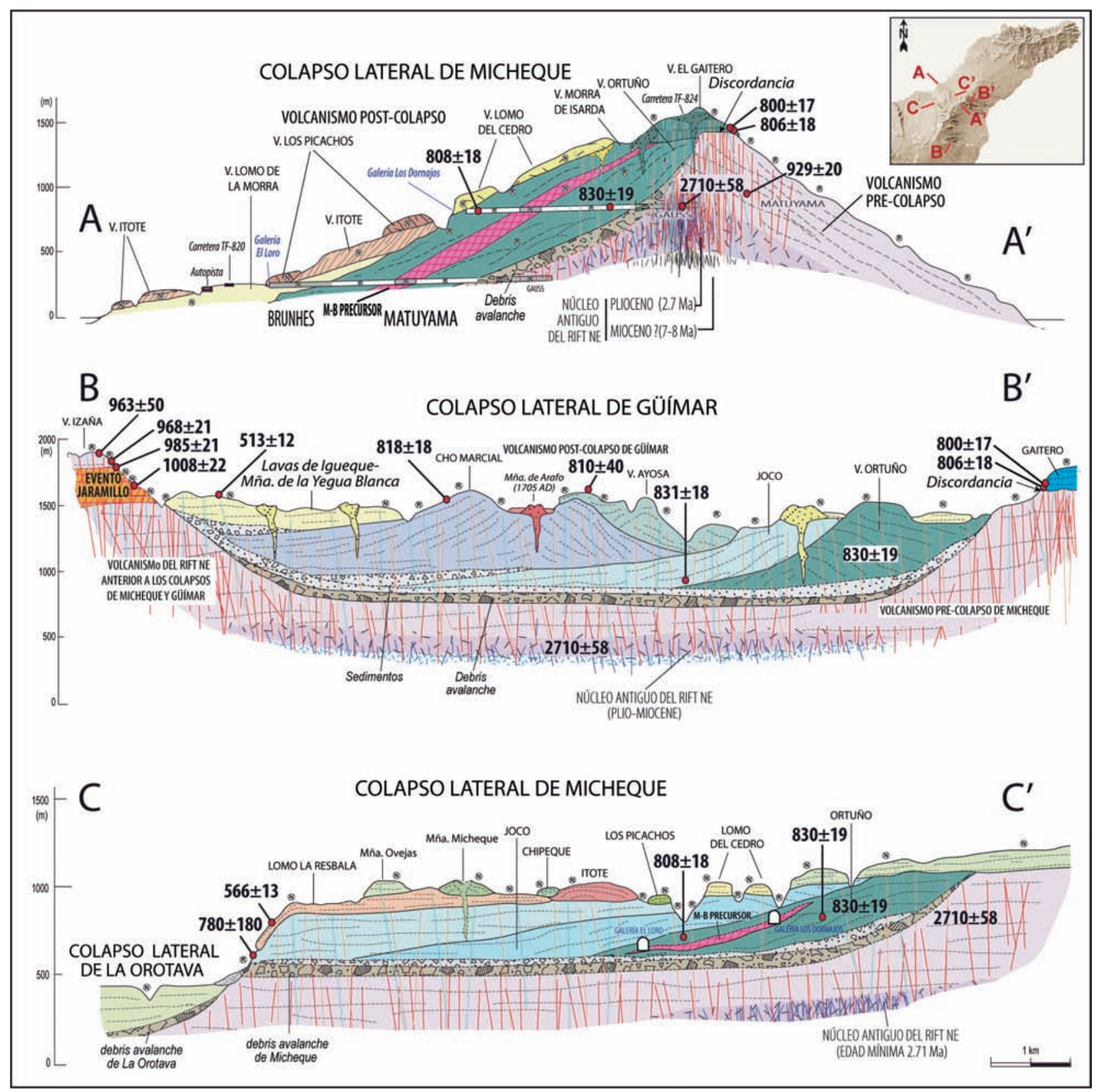

Fig. 16.-Cortes geológicos del Rift NE de Tenerife. Edades en ka. La polaridad de las unidades estratigráficas y edificios volcánicos se indica con $\mathrm{R}$, polaridad inversa, y N, polaridad normal.

temente en la cresta del rift, aumentando la dispersión de los centros eruptivos hacia su extremo distal al NE (véase fig. 14).

Estas erupciones, todas de polaridad normal, han dado edades de $513 \pm 12 \mathrm{ka}$ (Carracedo et al., 2007), $540 \pm 40$ ka (Abdel-Monem et al., 1972) y $560 \pm 30 \mathrm{ka}$ (Ancochea et al., 1990). Sin embargo, la actividad eruptiva, aunque atenuada, ha continuado hasta época más reciente, particularmente en la zona proximal (SO) del rift (edades de $37 \pm 3$, $33 \pm 3$ y $33 \pm 1$ ka en Carracedo et al., 2007), incluso hasta fecha histórica (erupciones de Fasnia y Arafo, en 1705). A esta etapa reciente pertenece la alineación eruptiva de Taoro, en el interior del Valle de La Orotava, que ha dado una edad de ${ }^{40} \mathrm{Ar} /{ }^{39} \mathrm{Ar}$ de 27,0 \pm 5,9 ka (Carracedo et al., 2008c,d).

$\mathrm{El}$ esquema de la figura 15 ilustra el comportamiento del Rift NE desde los inicios de su forma- 
ción hasta la actualidad. En la figura 16 se muestran diversos cortes geológicos del Rift NE que ilustran las relaciones estratigráficas de los diferentes colapsos laterales y los aparatos volcánicos afectados por ellos, o que han surgido anidados en las cuencas resultantes. En el corte A-A' se aprecia el edificio volcánico formado en el Pleistoceno sobre un núcleo antiguo (Mio-Plioceno), afectado en su flanco norte (izquierda del corte) por el colapso lateral de Micheque, posteriormente rellenado por completo por el volcanismo anidado posterior y la fase final de actividad del rift.

El corte B-B' muestra una sección transversal del valle de deslizamiento de Güímar y los volcanes anidados. Puede comprobarse cómo la formación correspondiente al evento M-B Precursor aparece en el corte A-A' formando parte del relleno del colapso de Micheque, $\mathrm{y}$, por lo tanto, posterior a ese deslizamiento, mientras que en el B-B' aparece el evento Jaramillo, más antiguo, que forma parte del edificio colapsado en el deslizamiento de Güímar, y que, por consiguiente, es anterior a este deslizamiento.

En el corte C-C' se observa cómo el colapso lateral de La Orotava corta la cuenca de relleno de Micheque con un ángulo más pronunciado, quedando colgada la formación de relleno de Micheque y aflorando la formación brechoide que pudiera indicar la base de ese deslizamiento.

\section{Significado de los sucesivos colapsos laterales y el volcanismo anidado posterior}

El Rift NE de Tenerife ha proporcionado por primera vez la historia completa de la evolución de un rift recurrente, con una información geológica mucho más precisa para la tercera y última fase (la única que se analiza), que ha experimentado tres colapsos laterales sucesivos (fig. 17). Esta circunstancia permite evaluar los cambios que se producen en el transcurso de los sucesivos colapsos y rellenos.

La datación de los sucesivos colapsos se ha realizado utilizando fundamentalmente la edad del volcanismo anidado más antiguo posible, en la asunción de que la actividad eruptiva no se interrumpe después de los colapsos, y por ello ese volcanismo inicial post-colapso da una edad mínima muy similar a la del propio deslizamiento. La edad máxima es más difícil de determinar. Generalmente se suele utilizar la edad más joven del escarpe de deslizamiento, pero puede darse el caso, como parece ocu- rrir en la Pared de Güímar y Tigaiga, que se localicen centros eruptivos muy posteriores al colapso y cerca de los escarpes. Estas erupciones suelen caer en cascada hacia el interior de la cuenca de colapso, pero desplomes secundarios y el retroceso erosivo pueden desmantelarlas parcialmente, por lo que pueden confundirse con las que forman el edificio pre-colapso y dar, por lo tanto, una edad máxima errónea.

Las edades obtenidas del volcanismo anidado más antiguo de Micheque $(830 \pm 19)$ y Güímar $(831 \pm 18)$ indican que ambos deslizamientos son esencialmente simultáneos, aunque pueda existir entre ellos años o centenares de años de diferencia. Las consideraciones ya expuestas parecen indicar que el colapso de Micheque fue el primero en tener lugar. Si tal es el caso, el primer deslizamiento dejaría el resto del rift en estado críticamente inestable, lo que explicaría la ocurrencia inmediatamente después del siguiente colapso. Parece plausible, a la vista de las tasas de crecimiento del rift antes de estos deslizamientos, que el primero se produjera coincidiendo con un máximo de la actividad eruptiva e intrusiva. El colapso subsiguiente, en cambio, pudo tener un origen predominantemente gravitatorio, incluso posiblemente con un deslizamiento relativamente lento (creeping).

La primera conclusión de estas observaciones es que la actividad eruptiva anidada en las cuencas de deslizamiento decrece en cada colapso. Mientras que la depresión del posible colapso inicial (Micheque) se rellena rápidamente y de forma total, en el segundo (Güímar) sólo se rellena parcialmente, y en el de La Orotava no parece haber existido volcanismo anidado significativo, estando esta cuenca recubierta fundamentalmente por lavas externas muy posteriores, procedentes del rift.

Este comportamiento parece sugerir un papel decreciente de los sistemas de esfuerzos tensionales originados por la acumulación de intrusiones en el eje del rift, en favor de esfuerzos gravitatorios posteriores al primer colapso.

El comportamiento del volcanismo anidado en las cuencas de deslizamiento aporta información interesante sobre cómo pudo ser la actividad eruptiva e intrusiva anterior al colapso. Si éste fue provocado por una fase de actividad eruptiva e intrusiva muy intensa, con un rápido proceso de spreading necesario para acomodar la acumulación de diques, parece plausible que la actividad continuara con características similares inmediatamente después del deslizamiento. Esto conllevaría un intenso vol- 

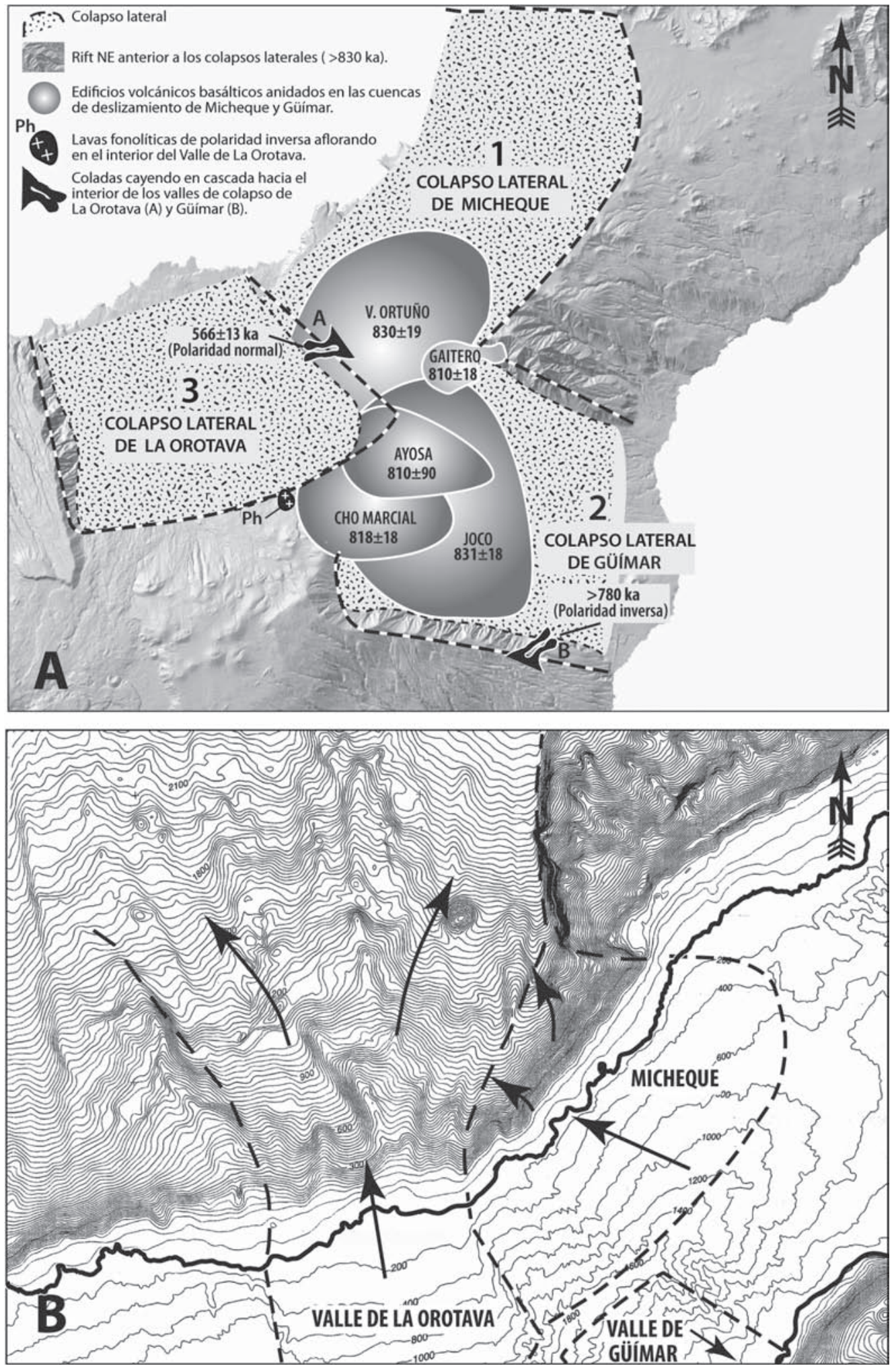

Fig. 17.-A. Esquema que sintetiza la sucesión de etapas de crecimiento y sucesivos colapsos en el Rift NE en función de la edad del volcanismo anidado en las diversas cuencas de deslizamiento. B. Batimetría de la zona (Palomo et al., 1998) mostrando las cicatrices de los sucesivos colapsos. Es evidente que el colapso de La Orotava se superpone sobre el de Micheque, afectando a la formación de relleno de este último, que se adentraba en lo que es hoy el Valle de La Orotava. 
canismo anidado en la cuenca de deslizamiento, que tendería a colmatarse (figs. 18A y B). Si, por el contrario, el proceso que provoca el colapso lateral es fundamentalmente la inestabilidad del edificio, alcanzada de forma gradual, el colapso se produce por inestabilidad gravitatoria y la actividad eruptiva anidada puede ser más limitada (C-E), e incluso casi inexistente $(\mathrm{F})$.

Por otra parte, si la actividad volcánica anidada es intensa y prolongada pueden producirse procesos de diferenciación magmática que den lugar a la evolución de las erupciones post-colapso, al principio típicamente de ankaramitas y basaltos plagioclásicos, hacia términos más diferenciados, que pueden llegar a fonolitas y traquitas. En el esquema de la figura 18 el colapso lateral de Güímar y, aún más, el de La Orotava, podrían deberse más a procesos de deslizamientos lentos (decenas o centenares de años en lugar de minutos, como en el sistema de fallas de Hilina en la isla de Hawaii) que a un volcanismo previo intenso acompañado de una importante acumulación de intrusiones. Esto explicaría, asimismo, la ausencia de erupciones félsicas anidadas en estas cuencas de deslizamiento.

\section{Tasas eruptivas y de crecimiento del Rift NE}

El Rift NE de Tenerife presenta en la actualidad un volumen de $615 \mathrm{~km}^{3}$ tomado desde la cota $0 \mathrm{~m} \mathrm{y}$ sin descontar la erosión (Carracedo et al., 2007), siendo, por lo tanto, el rift más voluminoso de las Islas Canarias, a pesar de que se trata de una estructura volcánica desarrollada en una isla en periodo de rejuvenecimiento posterosivo. No se han podido estimar los volúmenes y tasas eruptivas y de crecimiento de las fases de desarrollo del rift en el Mioceno y Plioceno por la limitación de afloramientos y datos. Sin embargo, la información aportada por las galerías y los afloramientos de la zona limítrofe con el macizo de Anaga sugieren que el volumen del rift podría alcanzar unos $200 \mathrm{~km}^{3}$ antes del comienzo de la última fase de crecimiento (Pleistoceno).

Ancochea et al. (1990) hicieron una primera evaluación de las tasas eruptivas de la Cordillera Dorsal (el Rift NE) para un edificio volcánico de 25 x 18 x $1,6 \mathrm{~km}$, del que asumen que 1/3-1/4 corresponde a la base antigua (Serie Basáltica Antigua, del Mioceno). Para un periodo de formación que limitan a $200 \mathrm{ka}$, estimaron una tasa eruptiva de 1,25-1,5 $\mathrm{km}^{3} / \mathrm{ka}$. De los datos obtenidos en este trabajo parece deducirse que para el último millón de años el volumen total emitido sería de más de $415 \mathrm{~km}^{3}$, lo que supone una tasa media de unos $0,41 \mathrm{~km}^{3} / \mathrm{ka}$. No obstante, dentro de este periodo final pueden distinguirse varias fases que concentran tasas muy superiores (fig. 19). Así, entre 1 Ma y 840 ka el crecimiento del rift es rápido y continuo $\left(2,5 \mathrm{~km}^{3} / \mathrm{ka}\right)$. Esta tasa eruptiva es más elevada que las estimadas para el estadio de desarrollo en escudo de las islas de El Hierro y La Palma $\left(<1,5 \mathrm{~km}^{3} / \mathrm{ka}\right)$, y en el rango de la inferida para la misma fase en escudo de la isla de Gran Canaria $\left(2 \mathrm{~km}^{3} / \mathrm{ka}\right)$.

En conjunto, los tres colapsos laterales (Micheque, Güímar y La Orotava) han supuesto la pérdidad de $\approx 170 \mathrm{~km}^{3}$, los cuales no se han recuperado en $\mathrm{su}$ totalidad en los rellenos posteriores, ya que, como se ha comentado (véase fig. 18), el relleno de los valles de Guiímar y La Orotava son parciales. La concentración de tres colapsos masivos en un corto intervalo (150-250 ka) parece requerir tasas de crecimiento del rift muy superiores a las típicas de las etapas de rejuvenecimiento en las Islas Canarias $\left(0,5-0,8 \mathrm{~km}^{3} / \mathrm{ka}\right)$. Después del colapso de La Orotava la tasa eruptiva ha declinado a $0,25 \mathrm{~km}^{3} / \mathrm{ka}$, lo que puede explicar la ausencia de más deslizamientos en el rift, que parece haber adquirido una configuración estable, al menos hasta que, eventualmente, se produzca una nueva fase de actividad eruptiva similar a las de las fases anteriores. En este último periodo de actividad eruptiva, dispersa y en declive, la erosión se ha circunscrito a la incisión de barrancos y retroceso de los cantiles interiores y costeros, lo que ha supuesto una pérdida de masa que puede estimarse en unos $5 \mathrm{~km}^{3}$.

Se pueden abordar estas estimaciones de una forma más precisa localmente si consideramos tasas de crecimiento en altura del rift, al menos en la fase de mayor actividad que antecede a los sucesivos colapsos laterales, lo que puede realizarse aprovechando las secuencias de coladas datadas, tanto en la Pared de Guiímar como en la galería Los Dornajos. En la Pared de Güímar, la sección, de unos 500 m de potencia, parece haberse formado en un lapso de tiempo que, como máximo, abarca desde la base del evento Jaramillo (1.072 ka), al límite MatuyamaBrunhes (780 ka), lo que daría una tasa de crecimiento del rift de $1,7 \mathrm{~m} / \mathrm{ka}$ como valor mínimo. Si tenemos en cuenta las edades de $1.008 \pm 20 \mathrm{ka}$ y $963 \pm 21$ de la base y el techo de la secuencia de la Pared de Güímar, la tasa de crecimiento en altura en este periodo supera $10 \mathrm{~m} / \mathrm{ka}$. Por otra parte, la secuencia del escarpe norte del Valle de Güímar incluye $500 \mathrm{~m}$ de coladas limitadas en la base por la edad de $929 \pm 20 \mathrm{ka}$, y en el techo por el relleno dis- 


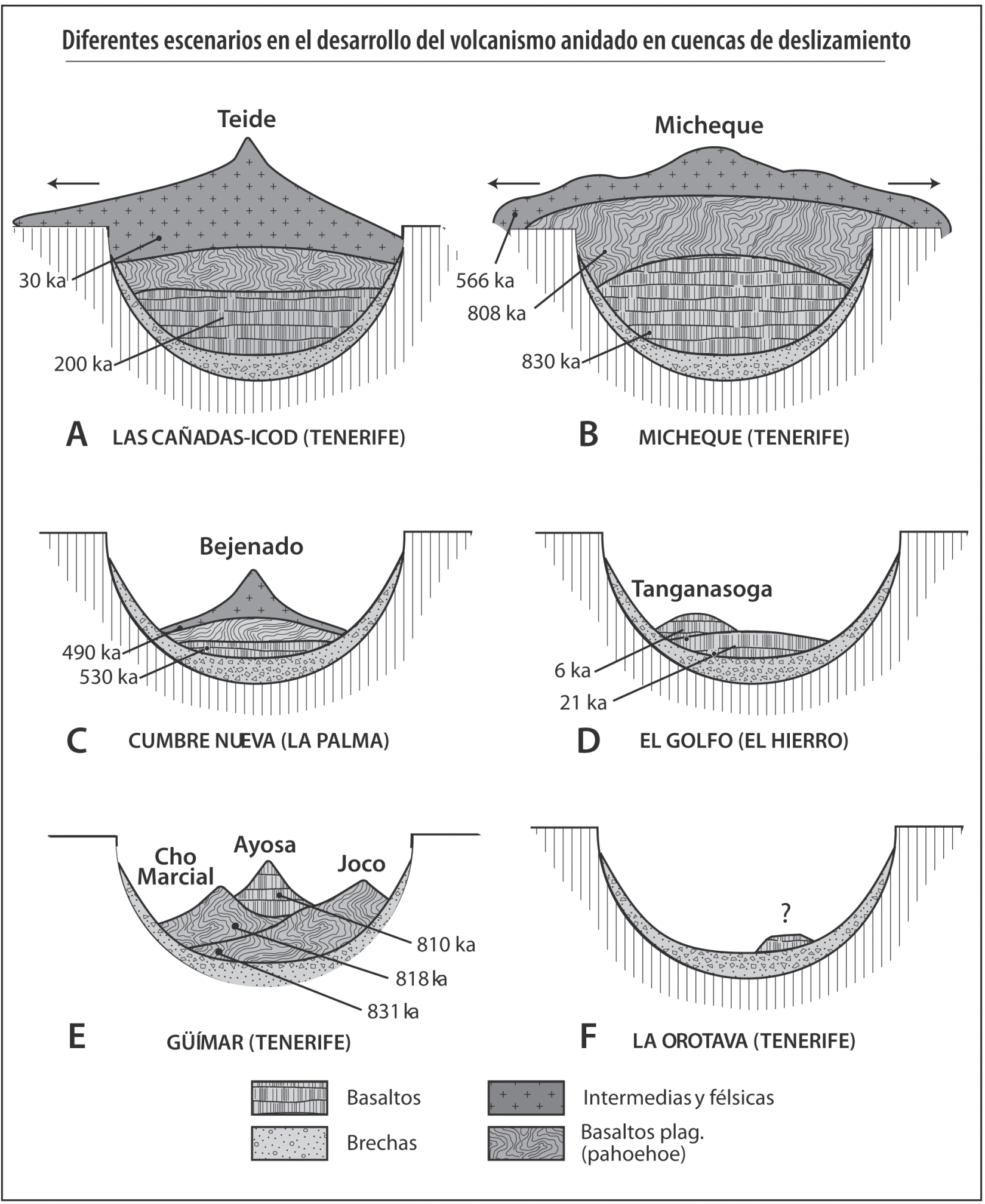

Fig. 18.-Diferentes comportamientos del volcanismo anidado en cuencas de colapso lateral en las Islas Canarias. 


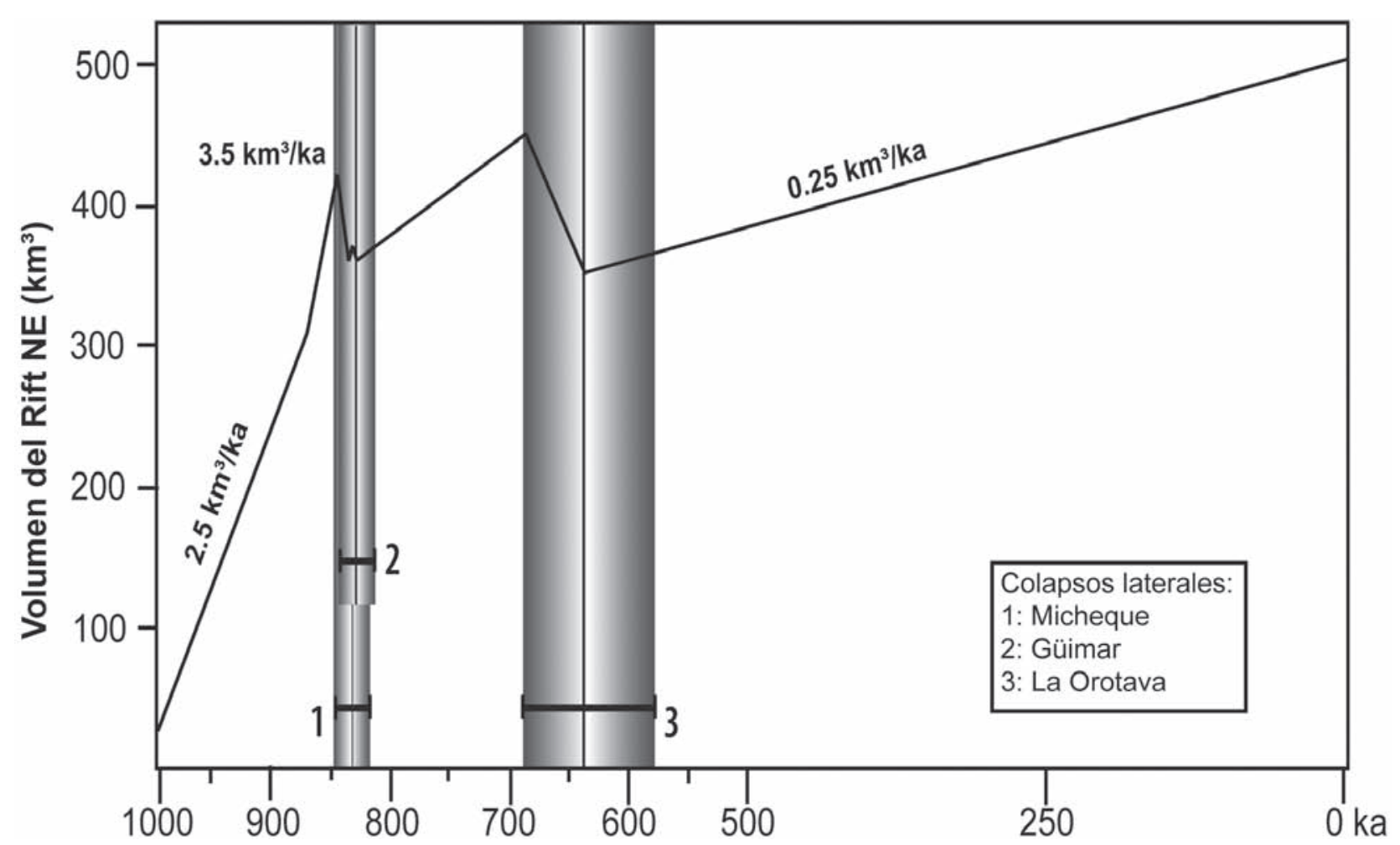

Fig. 19.-Evolución de las tasas eruptivas y volúmenes del Rift NE de Tenerife y su relación con los sucesivos colapsos laterales.

cordante del deslizamiento de Micheque, datado en esa zona en $806 \pm 18 \mathrm{ka}$, lo que da una tasa de crecimiento por encima de $4 \mathrm{~m} / \mathrm{ka}$.

En cualquier caso, las tasas eruptivas más elevadas se dan en el relleno inicial de la cuenca del primer colapso lateral (Micheque). La galería Los Dornajos recorre unos $2.800 \mathrm{~m}$ en la secuencia de relleno hasta alcanzar la brecha de avalancha. Suponiendo un buzamiento de las coladas de $5-10^{\circ}$, y una duración del relleno de unos 20 ka deducida de las edades obtenidas al principio y final de la secuencia de relleno inicial de la cuenca de deslizamiento (véase fig. 5), la tasa de crecimiento supera $12 \mathrm{~m} / \mathrm{ka}$, la más alta de todas las observadas, similar a las apuntadas para otros volcanes anidados, como el Bejenado en La Palma (Carracedo et al., 2001).

\section{Sobre el origen y desarrollo de los rifts}

Como se apuntó anteriormente, se han propuesto dos modelos de origen de los rifts. En uno de ellos estas estructuras se forman a partir de fracturas primordiales que atrapan diques, generando dorsales progresivamente más desarrolladas. En el segundo modelo los rifts se forman en un estadio avanzado de desarrollo de los edificios volcánicos, cuando éstos se vuelven inestables y se generan esfuerzos distensivos que atrapan los diques. Ambos modelos son convergentes en sus fases finales (estadio 3 en la fig. 19), pero totalmente diferentes en los procesos originarios y las fases iniciales.

El primer modelo (Carracedo, 1994) postula un empuje ascensional de la pluma (doming) que acaba fracturando la corteza oceánica (fracturing). El abombamiento emplazaría el magma por encima de la base de la litosfera, condición necesaria para un proceso autosostenido de fusión que proporcione los grandes volúmenes de magma requeridos para la formación de las Canarias (McKenzie \& Bickle, 1988; White \& McKenzie, 1989). En una corteza no fracturada y esencialmente isótropa el lento abombamiento ocasionado por la pluma ascendente del manto tiende a formar fracturas de mínimo esfuerzo, con geometría triple regular (Luongo et al., 1991; Carracedo, 1994). Estas fracturas primordiales controlarían desde el inicio la formación de los edificios insulares, atrapando los conductos de alimentación y concentrando los centros eruptivos. En este modelo el resultado es evidente: el desarro- 
llo de edificios de tendencia piramidal, con tres aristas de flancos inclinados y progresivamente inestables, correlativas a la zona de concentración del volcanismo en la vertical de las fracturas iniciales (A en la fig. 20). Una variante de este modelo supondría que la pluma no generaría las fracturas, sino que aprovecharía fracturas existentes en la corteza oceánica, lo que implicaría la existencia de islas sólo en las zonas de fractura. Sin embargo, parece suficientemente contrastada la idea de que el origen y localización del volcanismo que ha formado las Islas Canarias (y Madeira) son esencialmente independientes de la litosfera (Geldmacher et al., 2005; Hoernle \& Carracedo, 2009).

El segundo modelo prescinde de las etapas iniciales (B 1 y 2 en la fig. 20), pasando directamente al estadio en que el rift ya es inestable (B 3 en la fig. 20). En este modelo el rift es originado sólo por deformación inducida por gravedad, que proporciona el campo de esfuerzos adecuado para que los diques queden atrapados. Este proceso ocurre en el plano perpendicular al mínimo esfuerzo compresivo, que es perpendicular al rift, por lo que la alineación de diques resultante sigue la dirección del eje del rift (Dieterich, 1988). A este mismo resultado habían llegado Fiske \& Jackson (1972) utilizando modelos de gelatina, basando el proceso de captura de los diques en los esfuerzos y eventual deformación inducidos por la gravedad. Walter \& Troll (2003) alcanzan parecidas conclusiones con el uso de análogos de gelatina, concluyendo que la generación de los rifts está asociada a procesos superficiales (dentro de los propios edificios volcánicos inestables) inducidos por gravedad. Explican por este medio incluso la formación de rifts triples, como consecuencia de la curvatura del rift principal, que pasa de una estructura lineal a una doble, y la apertura de un tercer brazo en el extremo opuesto, donde se producirían esfuerzos distensivos.

Es evidente que los rifts son muy similares en ambos modelos en la etapa final de ambos (A3 y B3 en la fig. 20), cuando el edificio volcánico es ya empinado e inestable, pero el segundo modelo no explica cómo se adquiere esa configuración en ausencia de una estructura que concentre la actividad eruptiva. Sin esa estructura, el edificio tendería a extenderse, manteniendo una baja relación de aspecto, no alcanzando fácilmente configuraciones inestables que iniciaran el proceso de atrapamiento de los diques (B1 y 2 en la fig. 20). Un buen ejemplo es contrastar el comportamiento del Rift NE de Tenerife y el volcanismo post-erosivo de Lanzarote o Gran Canaria; la inexistencia de un sistema de rifts eficaces en la etapa reciente (post-Mioceno) del desarrollo de Lanzarote ha tenido como consecuencia que las erupciones fisurales se hayan distribuido de una manera dispersa, sin dar lugar a una dorsal definida (Carracedo et al., 2002); en ausencia de este sistema primigenio de concentración de centros eruptivos, inactivo desde hace millones de años y destruido por la erosión, y, en consecuencia, de una dorsal progresivamente más desarrollada e inestable, no se han generado los sistemas de esfuerzos que contribuirían el atrapamiento de diques y al reforzamiento del proceso.

Por el contrario, los rifts están ya bien configurados en las etapas iniciales en escudo, como es evidente en La Palma y El Hierro (Carracedo et al., 2001, 2002), posiblemente una geometría heredada de las etapas de construcción submarina. Al mismo tiempo, estos rifts continúan activos y con geometrías concordantes en etapas muy avanzadas del volcanismo post-erosivo, como es el caso de los rifts NO y NE de Tenerife (Carracedo et al., 2007 y este trabajo).

Otra observación que apoya el que estas estructuras trasciendan el ámbito de edificios volcánicos concretos para afectar al conjunto del edificio insular es la extensión en época reciente del rift NO de Tenerife, cuyas erupciones, aunque se concentran predominantemente en el flanco occidental del Volcán Las Cañadas, entre Pico Viejo y Santiago del Teide, continúan en una prolongación de centros eruptivos recientes que atraviesa todo el escudo mioceno de Teno hasta alcanzar el extremo NO de la isla, posiblemente continuando en su flanco submarino (véase figs. 3 y 6 en Carracedo et al., 2007). Igual ocurre en el Rift NE, en que los centros eruptivos cruzan el escudo mio-plioceno de Anaga, emplazándose algunos en el extremo de la isla, en la zona de Punta del Hidalgo. El caso más evidente es el de la isla de El Hierro, en que los tres brazos del rift triple atraviesan todo el edificio insular, continuando la concentración de centros eruptivos en los flancos submarinos de la isla (Carracedo et al., 2001; Gee et al., 2001; Mitchell et al., 2002).

Trabajos recientes han puesto de manifiesto la existencia de numerosos sistemas de rift restringidos a un sector concreto de las islas, incluso a un solo edificio volcánico. En este caso parece más plausible que sean los esfuerzos gravitatorios los que concentran la actividad eruptiva, generando rifts locales e incrementando su altura hasta sobrepasar los niveles de estabilidad y provocar desliza- 


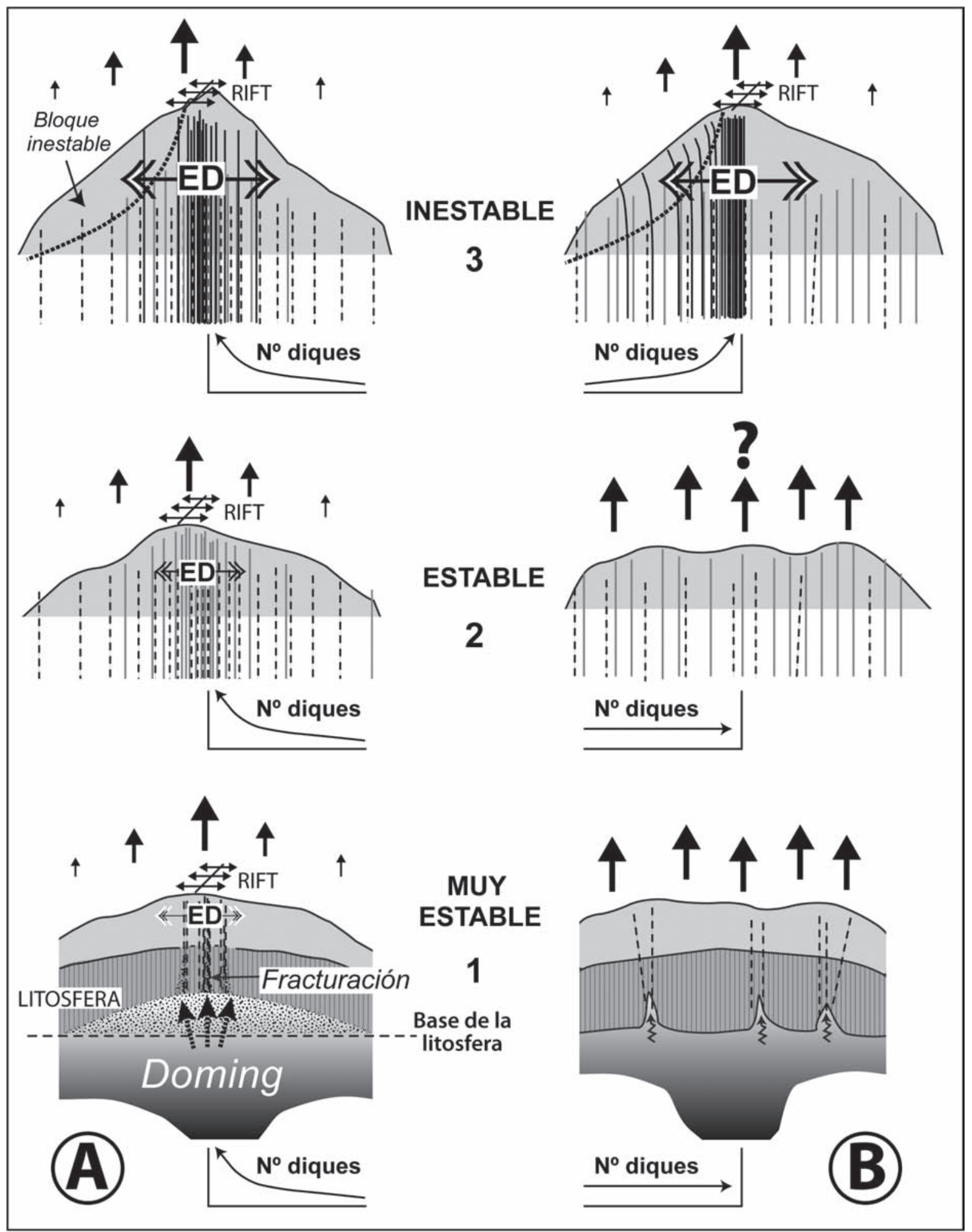

Fig. 20.-Dos modelos diferentes de origen de los rifts. A. Partiendo de fracturas generadas por empuje domático de la pluma del manto en su ascenso hacia zonas más superficiales. Estas fracturas primordiales controlarían la captura de los diques (conductos eruptivos) y el desarrollo de las islas desde sus inicios. B. Modelo que prescinde de fracturas iniciales, postulando el proceso de captura de diques por la generación de esfuerzos distensivos asociados a la inestabilidad de los edificios volcánicos. Este modelo no explica adecuadamente cómo se alcanzan esos niveles de inestabilidad (paso del estadio 2 al 3). ED, esfuerzos distensivos. 
mientos - por ejemplo los descritos en Teno (Walter \& Schmincke, 2002), y Anaga (Walter et al., 2005). Sin embargo, estos edificios volcánicos se asientan ya sobre una fractura previa (la fractura primordial), que favorecería inicialmente la captura de diques y la concentración de centros eruptivos necesarias para alcanzar el nivel de inestabilidad y la aparición de los esfuerzos gravitatorios que permiten continuar el proceso. En este sentido ambos mecanismos son coherentes (se refuerzan).

En consecuencia, se podrían definir dos tipos de rift:

1. Los rifts primarios, que se forman por fracturación de la corteza oceánica y dan lugar a estructuras de gran extensión y duración que controlan el desarrollo de las islas a lo largo de su historia geológica. Estos rifts primarios se habrían formado por la concentración de conductos eruptivos a favor de esas fracturas iniciales (Carracedo, 1994), y dan lugar a edificios volcánicos más inestables (dorsales).

2. Los rifts secundarios, más numerosos y de dimensiones más restringidas, están generalmente limitados a un edificio volcánico concreto. Estos rifts se formarían en estadios mas tardíos en volcanes ya inestables, por procesos superficiales (dentro de los propios edificios volcánicos) y por acción de la gravedad. El umbral de inestabilidad necesario para que actúe la gravedad sería proporcionado por la acumulación previa de erupciones a través de las fracturas primigenias.

\section{Factores externos desencadenantes de colapsos laterales masivos}

Los colapsos se producen por inestabilidad gravitacional del edificio volcánico. Los factores desencadenantes de los colapsos en islas oceánicas se agrupan en internos, asociados principalmente a la fuerza ascensional del magma (Siebert, 1984; Carracedo, 1994; Carracedo et al., 1998; McGuire, 1996; Elsworth \& Day, 1999), y externos, relacionados en última instancia con agentes climáticos (McMurtry et al., 2004; Quidelleur et al., 2008). Obviamente hay una amplia casuística y se puede dar una combinación de factores desencadenantes. Teniendo en cuenta esto, sin embargo, se empiezan a tener datos que permiten trazar los rasgos generales de los grandes colapsos y modelar, aunque por ahora de forma bastante especulativa, el papel que desempeñan en la evolución de las islas oceánicas.
En este contexto, uno de los debates más interesantes se centra en la ubicación temporal de los colapsos en relación con los periodos glaciales durante el cuaternario. El principal reto es la datación de los colapsos. La edad de un colapso no se puede obtener de forma directa y hay que recurrir a su acotación a través de las edades de los sedimentos o formaciones volcánicas que se hallen lo más cerca posible en el tiempo, tanto con anterioridad como con posterioridad al evento. Aquí juega un papel crítico el error del método analítico. Un colapso es un evento que puede generarse por el despegue continuado durante varios años de grandes masas de depósitos volcánicos hasta que se llega a un punto crítico en el que normalmente en pocas horas se produce el desenlace. Sin embargo, los errores con los que se trabaja, en el mejor de los casos, son de unos pocos miles de años.

En el caso del Rift NE de Tenerife se han detectado tres colapsos gigantes: Micheque, Güímar y La Orotava. La información geocronológica previamente expuesta permite ubicar el colapso de Micheque muy próximo, aunque anterior, a los $830 \pm 19 \mathrm{ka}$. El colapso de Güímar se habría producido posiblemente con posterioridad al anterior, pero tan próximo en el tiempo que podría considerarse simultáneo al anterior. El colapso de La Orotava es muy posterior, pero malogradamente la ventana de edades no se ha podido restringir tanto y por ahora sólo se puede ubicar en un rango que está entre $566 \pm 13$ y $690 \pm 10$ ka.

Las variaciones de $\delta^{18} \mathrm{O}$ en sedimentos marinos bentónicos se considera un buen indicador de los cambios de nivel del mar generados por los ciclos glaciales-interglaciales durante el Cuaternario (Lisiecki \& Raymo, 2005). La relación $\delta^{18} \mathrm{O}$ varía inversamente al nivel del mar relativo, por lo que este parámetro se suele representar en los gráficos en forma decreciente, indicando los valores bajos condiciones climáticas cálidas (casquetes polares reducidos) y los altos las situaciones de máximos glaciales (Lambeck et al., 2002).

Cuando se sitúan los colapsos estudiados sobre la variación temporal del nivel del mar, indicada por las variaciones de $\delta^{18} \mathrm{O}$ (fig. 21), se observa que la ventana de tiempo acotada para el colapso de Micheque se sitúa en un máximo interglacial. En esta ubicación temporal, el colapso de Micheque se habría generado tras un brusco cambio climático hacia condiciones más cálidas y húmedas que provocaron a escala global la fusión de los casquetes polares y el ascenso rápido del nivel del mar. Respecto al colapso de Güímar, la substracción del 


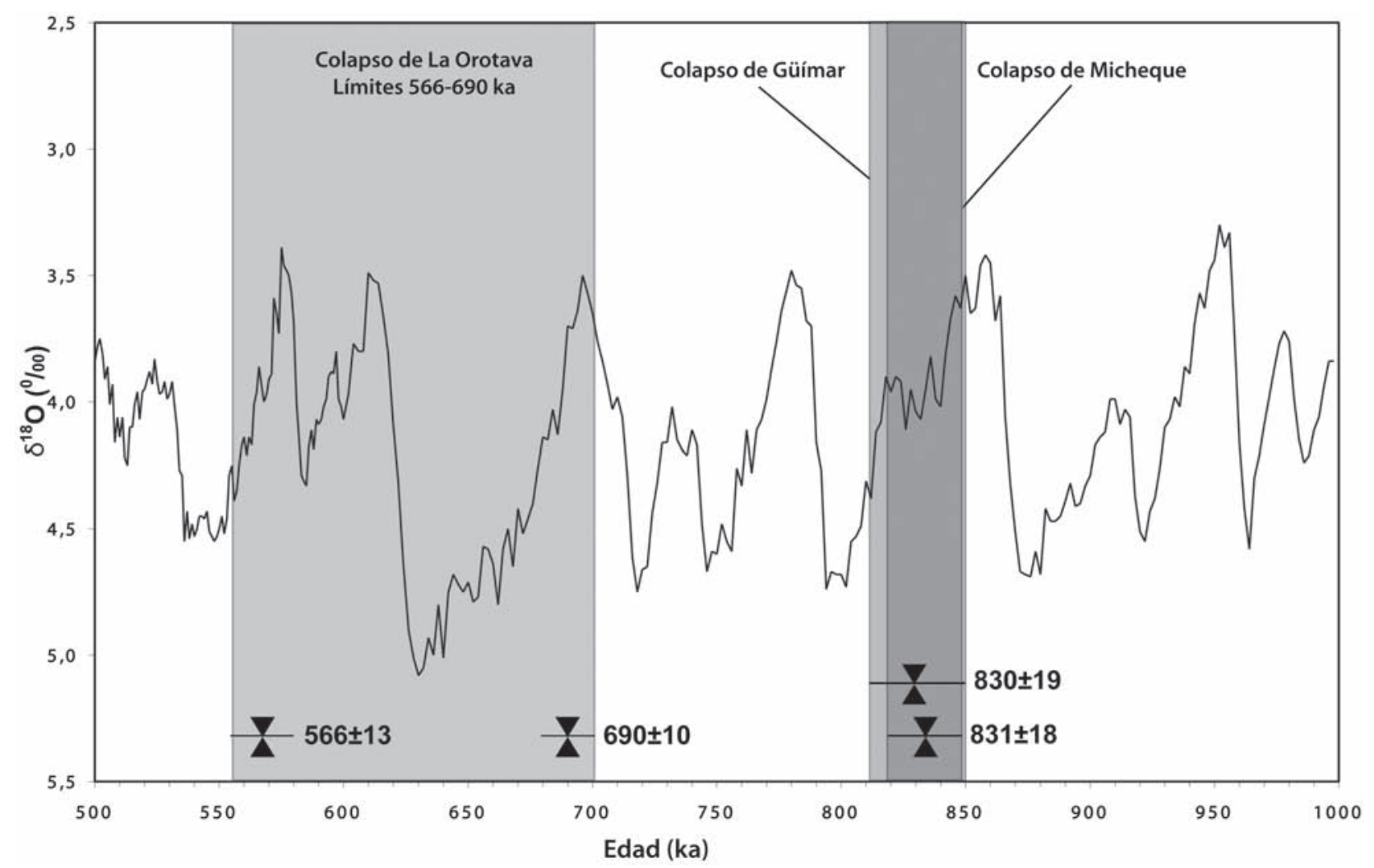

Fig. 21.- Situación de los colapsos estudiados sobre la variación temporal $\delta^{18} \mathrm{O}$, indicador de los cambios de nivel del mar generados por los ciclos glaciales-interglaciales durante el Cuaternario (Lisiecki and Raymo, 2005). Las edades radiosotópicas más significativas para acotar temporalmente los colapsos son mostradas con su rango de incertidumbre analítica $(2 \sigma)$.

error analítico de $18 \mathrm{ka}$ a la edad de 831 ka sitúa el umbral mínimo de la ventana temporal de generación del evento en $813 \mathrm{ka}$. Esta edad se aproxima al mínimo glacial del estadio isotópico marino 20. El umbral superior viene dado por el colapso de Micheque, ya que éste, como se ha discutido, parece anterior al de Güímar. En consecuencia, ambos colapsos se produjeron entre los mínimos glaciales de los estadios isotópicos marinos 20 y 22. Abstrayéndonos de los errores analíticos, la edad del colapso de Güimar se puede restringir al lapso 815830 ka. Esta edad situaría el colapso en un máximo secundario de un intervalo interglacial.

Finalmente, la ventana temporal del colapso de La Orotava (566 $\pm 13-690 \pm 10 \mathrm{ka}$ ) abarca un importante mínimo glacial (estadio isotópico 16) y tres máximos interglaciales. A la espera de futuros datos que permitan reducir este rango temporal, de forma tentativa este colapso se ha situado a $600 \mathrm{ka}$ (fig. 21). Uno de los criterios utilizados es que la lava datada en $566 \pm 13$ cae en cascada por el escarpe NE hacia el interior del Valle de La Orotava. La lava fosiliza un escarpe con bajo índice de erosión, lo que indicaría que se depositó no demasiado después del colapso. El otro criterio sería, en sentido interpretativo contrario al de Micheque, que el colapso debió producirse en un intervalo interglacial, preferentemente después de un brusco ascenso del nivel de mar.

Estas observaciones en el Rift NE, junto con otras en Tenerife (colapso del Valle de Icod a $161 \pm 13$-Gillot et al., 2001) y en otras Islas Canarias (La Palma, El Hierro-Carracedo et al., 1999b; Guillou et al., 2001), así como en otras islas oceánicas alrededor del mundo (Tahiti, Hawaii, Martinica, Guadalupe-McMurtry et al., 2004; Quidelleur et al., 2008) parecen tener en común que la interrupción de la estabilidad de grandes edificios volcánicos se produce en periodos interglaciales con elevados niveles del mar, preferentemente poco después de bruscas deglaciones. La disponibilidad de elevadas cantidades de agua en medios geológicos ya de por sí con elevada inestabilidad aceleraría e incrementaría el despegue de grandes masas de depósitos volcánicos. 
Además de los efectos externos sobre el relieve por la pérdida de masa en la isla, el gran volumen de las masas desplazadas podría tener consecuencias sobre el propio sistema magmático. En este sentido, se han apuntado incluso efectos a elevada profundidad como el incremento de la tasa de fusión parcial (por ej., Waianae, Oahu Island, Hawaii; Presley et al., 1997). Esto en Canarias es inverosímil por el gran espesor de la corteza oceánica. En cambio, sí son de esperar cambios más superficiales sobre el sistema de alimentación magmático e incluso sobre la composición de los magmas, como se discute en este trabajo.

\section{El volcanismo félsico como marcador de colapsos gravitatorios masivos en islas oceánicas}

Un aspecto relevante de la evolución del Rift NE es el de los cambios experimentados en la composición de las erupciones, que pasan de un predominio inicial absoluto de las lavas basálticas y basaníticas, a los términos finales félsicos, como traquitas y fonolitas.

Si observamos los esquemas que indican la evolución del Rift NE (figs. 11-15) vemos que sólo existen erupciones traquíticas en el interior de la cuenca de colapso de Micheque. El relleno de esta cuenca se realiza inicialmente con ankaramitas y basaltos plagioclásicos, generalmente en forma de coladas pahoehoe. Estos basaltos se cortan en el fondo de los barrancos más profundos del flanco norte y en las galerías (véase fig. 5). Más tarde, la composición cambia a basaltos olivínico-piroxénicos, que van alternando con rocas de composición intermedia (hawaiitas, mugearitas) y, finalmente, benmoreitas y traquitas.

Un aspecto a destacar es que esta secuencia petrológica sólo se da completa en la cuenca del primer colapso y no en las subsiguientes; en la cuenca de colapso de Güímar el volcanismo anidado se inicia con basaltos plagioclásicos, predominantes en los volcanes Joco y Cho Marcial, y basaltos olivínico-piroxénicos, predominantes en el volcán Ayosa y en todo el volcanismo posterior del rift. Las erupciones de composición intermedia y félsica comienzan a producirse en la cuenca de Micheque en la época Brunhes (todas tienen polaridad consistentemente normal, son posteriores al evento M-B Precursor y al Matuyama posterior). Se extienden por toda la depresión de colapso, aunque en la parte más septentrional de la cuenca están casi completamente recubiertas por volcanismo reciente del rift, aflorando en los cantiles costeros, mientras que las que podrían existir en la parte meridional de esa formación de relleno fueron eliminadas por el colapso de La Orotava.

La asociación del volcanismo diferenciado con el primer colapso se pone de manifiesto en el hecho de que algunas erupciones traquíticas, como las del Lomo de la Vieja y el Lomo del Viejo se emplacen directamente en el escarpe de colapso de La Orotava y no en su interior, indicando que este último colapso no afecta al sistema de alimentación de estos magmas (véase fig. 14).

La secuencia petrológica observada en el Rift NE de Tenerife coincide con la descrita en el volcán Bejenado (La Palma), anidado en la cuenca de colapso de Cumbre Nueva, que en tan sólo 10-20 ka evolucionó de basaltos plagioclásicos a traquitas (Carracedo et $a l .$, 2001). Esta secuencia se ha observado en condiciones excepcionales en las formaciones que rellenan el deslizamiento lateral que dio lugar a la depresión de la Caldera de las Cañadas-Valle de Icod-La Guancha y que acabaron levantando un estratovolcán doble (Teide y Pico Viejo). Este complejo volcánico, en el que la secuencia de relleno de la cuenca de deslizamiento pudo, asimismo, observarse en su integridad a través de galerías, se formó por acumulación de erupciones que evolucionaron de basaltos plagioclásicos, con morfologías pahoehoe, a basaltos olivínico-piroxénicos, lavas de composición intermedia y finalmente fonolitas (Carracedo et al., 2006, 2007).

Tendencias similares de evolución del volcanismo anidado hacia términos félsicos (fonolitas, traquitas) se han observado en El Hierro, en el edificio volcánico de El Golfo, anidado en la cuenca de colapso de Tiñor y posteriormente colapsado (Carracedo et al., 2001) y en La Gomera, en el complejo volcánico de Vallehermoso (Ancochea et al., 2003; Paris et al., 2005). No se da esta variabilidad petrológica en otros rifts muy desarrollados y activos, pero que no han tenido colapsos, como el de Cumbre Vieja (La Palma), o el rift triple actual de El Hierro. Podría, pues, especularse con la posibilidad de que sean precisamente los colapsos masivos los que fuercen en ocasiones las condiciones que favorecen cambios importantes en la composición de los magmas, aportando variabilidad geoquímica a estos volcanes oceánicos. A favor de esta hipótesis estaría la correlación existente entre procesos de deslizamiento gravitatorios masivos y los complejos volcánicos félsicos más importantes de 


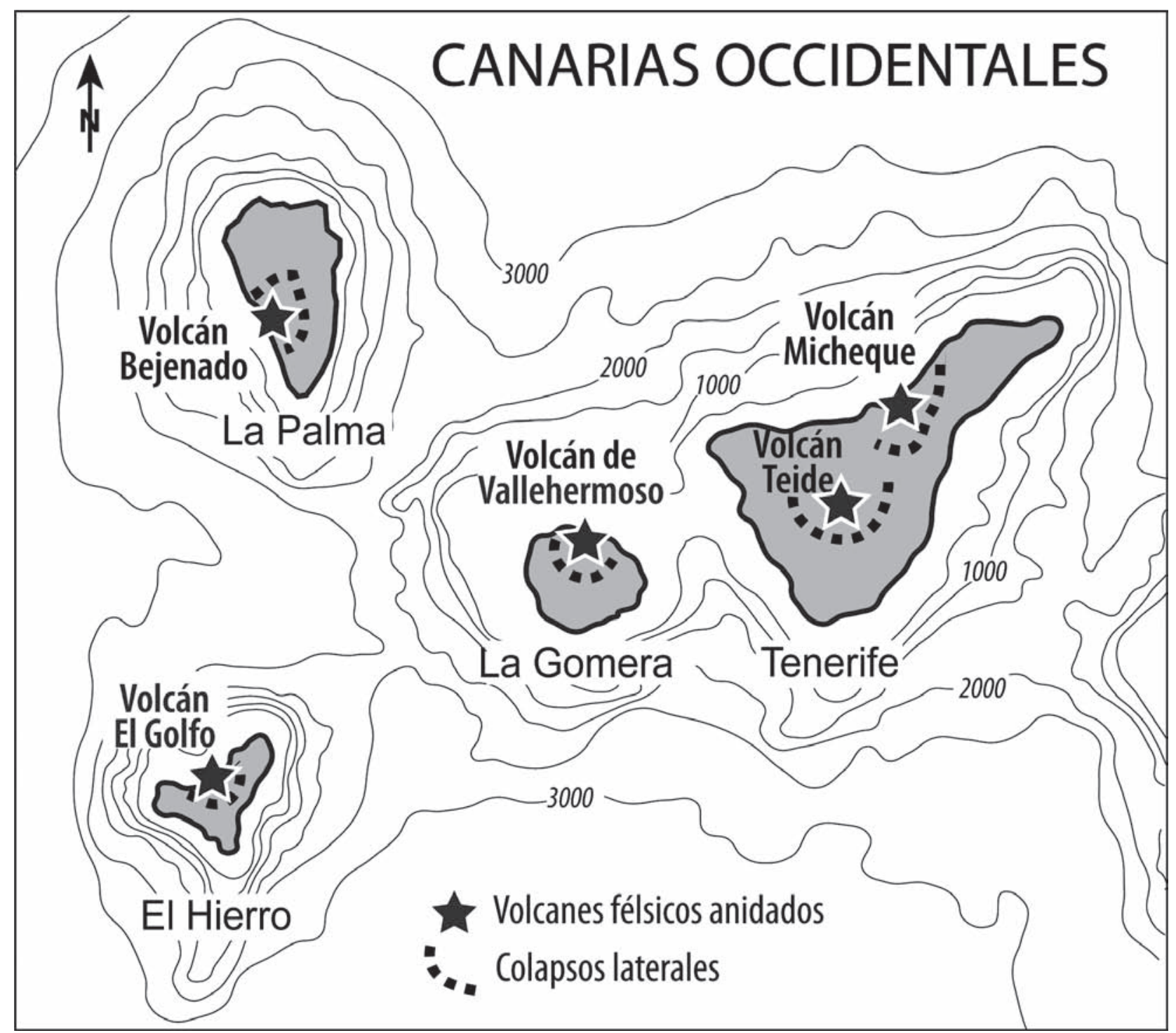

Fig. 22.-Correlación entre procesos de deslizamiento gravitatorios masivos y los complejos volcánicos félsicos más importantes de Tenerife y las Canarias occidentales.

Tenerife y las Canarias occidentales, que aparecen consistentemente anidados en ellos (fig. 22).

La posible influencia de los procesos constructivos y destructivos de muchos volcanes oceánicos en la regulación de sus regímenes geoquímicos ha sido analizada con anterioridad. Presley et al. (1997) estudiaron las diferencias petrológicas entre las formaciones volcánicas anteriores y posteriores al deslizamiento de Waianae (Oahu, Islas Hawaii), encontrando que a partir del colapso los magmas se tornaron menos diferenciados, lo que explican por un pequeño incremento del grado de fusión del manto. Los cálculos establecidos por Mckenzie \& Bickle
(1988) indican que la cantidad de magma generado por fusión inducida por descompresión adiabática del magma ascendente es del orden de 1-2\% por kbar, valores coherentes con los cambios petrológicos observados. Un proceso similar ha sido observado por Hildenbrand et al. (2004) en Tahiti-Nui (Polinesia Francesa), con un súbito cambio hacia magmas más subsaturados (basanitas) inmediatamente después del colapso del flanco norte de la isla, lo que explican, asimismo, por un incremento del grado de fusión parcial del manto por descompresión adiabática inducida por el colapso. Más recientemente Longpré et al. (2008) aplican este 
mismo modelo como explicación de los cambios observados en el escudo de Teno (Tenerife).

Sin embargo, en todos estos casos el resultado es el opuesto al descrito para los deslizamientos laterales en las Canarias, en que las variaciones tienden hacia magmas progresivamente más saturados, pasando de basaltos-basanitas a fonolitas-traquitas. Por otra parte, es relativamente fácil aceptar que la descarga producida por la liberación súbita de unos $6.100 \mathrm{~km}^{3}$ en Waianae, uno de los mayores colapsos gravitatorios que se conocen (Moore et al., 1989), pueda afectar en profundidad al edificio insular. Sin embargo, los colapsos que estamos analizando en las Canarias son de mucho menor volumen, de uno a unos pocos cientos de $\mathrm{km}^{3}$ (Urgelés et al., 1999; Masson et al., 2002), lo que unido al mayor espesor de la litosfera bajo Canarias, parece insuficiente para producir cambios significativos en el régimen de fusión parcial en el sistema magmático por simple liberación de peso, teniendo en cuenta las proporciones de masa de estos colapsos en relación con el conjunto de la isla (del orden de $25.000 \mathrm{~km}^{3}$ ).

En el modelo que apuntamos no es la súbita descarga de peso sino la destrucción del sistema de alimentación del rift el que induciría los cambios. El sistema establecido en los rifts no colapsados consiste en la emisión de magmas generalmente profundos y primarios, que se intruyen en un sistema fisural bien configurado dando lugar a erupciones fisurales de composición monótona (consistentemente basáltica-basanítica). Sin una modificación drástica, este sistema tiende a continuar hasta alcanzar una altura que dificulte la alimentación y bloquee el ulterior desarrollo del rift, o bien provoque inestabilidad y un colapso gravitatorio. En este último escenario además de la súbita descompresión se produciría una intensa fracturación, lo que favorecería la generación de cámaras magmáticas relativamente superficiales en las que el magma podría residir y diferenciarse. Los magmas van a encontrar una mayor facilidad para liberarse a través de la zona fracturada, lo que dará lógicamente lugar a la concentración de erupciones anidadas en el interior de la cuenca de colapso.

Una revisión de los restantes aparatos volcánicos félsicos existentes en las Canarias nos puede llevar a la propuesta tentativa de que puedan estar, asimismo, relacionados con colapsos gravitatorios. El edificio central Las Cañadas, que se levantó en el centro de Tenerife en los últimos $3 \mathrm{Ma}$, se desarrolló en tres fases separadas por colapsos laterales, representados por las correspondientes formaciones de ava- lancha (Ancochea et al., 1999; Huertas et al., 2002). La última de estas fases culmina con la formación de la depresión de la Caldera de Las Cañadas-Valle de Icod-La Guancha y su posterior relleno con la secuencia de basaltos-traquibasaltos-fonolitas y la construcción del complejo volcánico central TeidePico Viejo. Estas fases parecen haberse formado en todos los casos con volcanismo basáltico evolucionando a términos félsicos, aunque con mecanismos eruptivos mucho más explosivos en los primeros ciclos. Excluyendo este carácter altamente explosivo, que no se da en el complejo volcánico del Teide, las primeras fases del Edificio Las Cañadas son similares a esta última, y se puede especular con que el volcanismo félsico se haya generado, asimismo, inducido por sucesivos colapsos. Esta hipótesis apoyaría el que los distintos estadios de este edificio central hayan sido consecuencia de sucesivos colapsos laterales.

Finalmente, se puede especular, a sensu contrario, que la presencia de volcanismo félsico importante es un marcador de la existencia de colapsos laterales previos. En el caso de formaciones muy antiguas la formación de relleno podría haber desaparecido desmantelada por la erosión, permaneciendo únicamente restos erosivos de los aparatos félsicos desmantelados. El caso de Taganana ilustra esta suposición, ya que las formaciones de relleno de la cuenca de colapso han sido casi totalmente desmanteladas por la erosión, pero permanecen intrusiones (diques y domos) fonolíticos en el interior de la cuenca de colapso de Taganana, además de coladas de la misma naturaleza en inversión de relieve en los flancos del escudo de Anaga (Fúster et al., 1968; Carracedo, 1975). En este caso serían estos restos félsicos, que con toda probabilidad corresponden a un volcanismo diferenciado extenso, el marcador del colapso lateral de Taganana (Walter et al., 2005).

Este modelo podría aplicarse a escenarios aún más antiguos y en estadios de desmantelamiento erosivo más avanzados.

\section{Conclusiones}

El Rift NE de Tenerife parece haberse formado como una prolongación del escudo volcánico que formaba en el Mioceno el centro de la isla. Esta prolongación continúa hasta el macizo de Anaga, que lo recubre.

El Rift NE parece haber tenido tres fases de actividad volcánica, en el Mioceno, hacia 8-7 Ma; en el 
Plioceno, alrededor de los 2,7 Ma (de estas dos primeras fases apenas hay datos), y la tercera y última en el Pleistoceno, entre 1,1 Ma y la actualidad.

En la última fase de desarrollo del Rift NE hubo una fase de actividad eruptiva e intrusiva muy intensa entre 1,1 Ma y 0,83 Ma, época en la que la estructura volcánica podría haber alcanzado una configuración muy inestable después de un periodo con tasas de crecimiento en altura del edificio volcánico de al menos $1,7 \mathrm{~m} / \mathrm{ka}$ (con periodos como el comprendido entre $1.008 \mathrm{ka}$ y $963 \mathrm{ka}$ en el que se pudo superar $10 \mathrm{~m} / \mathrm{ka}$ ). En esta fase parece que la orientación de los diques que afloran en la Pared de Güímar cambió de NE-SO a N-S.

El límite de estabilidad del rift quedó rebasado hace unos $830 \mathrm{ka}$, momento en que se produjeron dos deslizamientos simultáneos y opuestos de los flancos del rift, un primer colapso lateral del flanco norte, generándose la cuenca de deslizamiento de Micheque, y otro del flanco sur, generando la de Güímar. En algunas galerías (Los Dornajos, El Loro) se ha reconocido una brecha de deslizamiento que se apoya sobre una formación mucho más antigua (Plioceno) y que forma, a su vez, el sustrato de una secuencia de relleno que abarca desde $830 \mathrm{ka}$ hasta unos $530 \mathrm{ka}$. Las tasas de crecimiento en altura en las fases iniciales del relleno superaron 12 $\mathrm{m} / \mathrm{ka}$, pudiendo alcanzar $24 \mathrm{~m} / \mathrm{ka}$. Este primer colapso lateral fue inmediatamente seguido por el de Güímar, hacia el este, y más tarde por el de La Orotava, hacia el norte, entre 690 y 566 ka.

El relleno de la cuenca del primer deslizamiento (Micheque) registra un cambio en la composición del volcanismo, que evoluciona de basaltos a lavas de composición intermedia $y$, finalmente, félsicas (traquitas, fonolitas). Esta variación no se produce en las cuencas de los colapsos laterales de Güímar y La Orotava.

Tanto en el relleno de la cuenca de Micheque como en el escarpe del colapso de Güímar se han detectado sendos eventos de polaridad normal dentro de la época de polaridad inversa Matuyama. Las datación por K/Ar ha permitido identificar el primero como el subcron M-B Precursor (819-788 ka) y el segundo como el Jaramillo (1.072-988 ka).

El estudio del Rift NE refuerza la idea de que estas estructuras pueden ser de larga duración y de actividad recurrente, controlando posiblemente desde las etapas iniciales la formación de las islas oceánicas.

Las variaciones en la composición de los magmas parecen producirse como respuesta a los colapsos laterales, tanto en el Rift NE de Tenerife, como en otros deslizamientos masivos en Tenerife y otras islas del Archipiélago. El colapso implica la ruptura del sistema de alimentación en el rift establecido, consistente en el aporte de magmas básicos a través de erupciones basálticas fisurales. Como respuesta se produce la concentración de erupciones focalizadas en el interior de la cuenca de deslizamiento y el emplazamiento del magma a niveles someros, cambios que inducen procesos de cristalización fraccionada que dan lugar a erupciones progresivamente más diferenciadas, alcanzando frecuentemente términos félsicos (traquitas, fonolitas). Estos procesos son favorecidos, asimismo, por el progresivo aumento en altura de los edificios volcánicos anidados en las cuencas de deslizamiento.

Buena parte del volcanismo diferenciado de volumen importante parece estar asociado en Canarias a deslizamientos masivos, que son seguidos por erupciones que a veces evolucionan de términos básicos iniciales a félsicos terminales. Podría, en consecuencia, considerarse a los colapsos laterales como inductores de variabilidad petrológica. Por otra parte, la existencia de volcanismo félsico de importancia podría considerarse como un marcador de anteriores procesos de colapso lateral.

\section{AGRADECIMIENTOS}

Este trabajo ha sido financiado por los Proyectos del Plan Nacional de I+D+I CGL2005-00239/BTE y CGL200802842/BTE. Agradecemos al Departamento de Medio Ambiente del Cabildo Insular de Tenerife las facilidades prestadas para la obtención de muestras orientadas y al Consejo Insular de Aguas de Tenerife (particularmente a Ricardo Balcells) su ayuda en el estudio de las galerías.

\section{Referencias}

Abdel-Monem, A.; Watkins, N.D. \& Gast, P. (1972). Potassium-argon ages, volcanic stratigraphy and geomagnetic polarity history of the Canary Islands: Tenerife, La Palma and Hierro. American Journal of Science, 272: 805-825.

Ablay, G.J. \& Marti, J. (2000). Stratigraphy, structure, and volcanic evolution of the Pico Teide-Pico Viejo formation, Tenerife, Canary Islands. Journal of Volcanology and Geothermal Research, 103: 175-208. doi:10.1016/S0377-0273(00)00224-9

Ancochea, E.; Fúster, J.M.; Ibarrola, E.; Cendrero, A.; Hernán, F.; Cantagrel, J.M. \& Jamond, C. (1990). Volcanic evolution of the Island of Tenerife (Canary Islands) in the light of new K-Ar data. Journal of Volcanology and Geothermal Research, 44: 231-249. doi:10.1016/0377-0273(90)90019-C 
Ancochea, E.; Huertas, M.J.; Cantagrel, J.M.; Coello, J.; Fúster, J.M.; Arnaud, N. \& Ibarrola, E. (1999). Evolution of the Cañadas Edifice and its implications for the origin of the Cañadas Caldera (Tenerife, Canary Islands). Journal of Volcanology and Geothermal Research, 88: 177-199. doi:10.1016/S0377-0273(98)00106-1

Ancochea, E.; Brändle, J.L.; Huertas, M.J.; Cubas, C.R. \& Hernán, F. (2003). The felsic dikes of La Gomera (Canary Islands): Identification of cone sheet and radial dike swarms. Journal of Volcanology and Geothermal Research, 120: 197-206. doi:10.1016/S0377-0273(02)00384-0

Brown, L.L.; Singer, B.S.; Pickens, J.C. \& Jicha, B.R. (2004). Paleomagnetic directions and 40Ar/39Ar ages from the Tatara-San Pedro volcanic complex, Chilean Andes: Lava record of a Matuyama-Brunhes precursor? Journal of Geophysical Research, 109: B12101. doi:10.1029/2004JB003007

Carracedo, J.C. (1975). Estudio paleomagnético de la isla de Tenerife. PhD thesis, Univ. Complutense de Madrid, 265 pp.

Carracedo, J.C. (1979). Paleomagnetismo e historia volcánica de Tenerife. Aula Cultura Cabildo de Tenerife, Tenerife, $81 \mathrm{pp}$.

Carracedo, J.C. (1994). The Canary Islands: an example of structural control on the growth of large oceanic island volcanoes. Journal of Volcanology and Geothermal Research, 60: 225-242. doi:10.1016/0377-0273(94)90053-1

Carracedo, J.C. (1996). Morphological and structural evolution of the western Canary Islands: Hotspot induced three armed rifts or regional tectonic trends? Journal of Volcanology and Geothermal Research, 72: 151-162. doi:10.1016/0377-0273(95)00080-1

Carracedo, J.C. (1999). Growth, structure, instability and collapse of Canarian volcanoes and comparisons with Hawaiian volcanoes. Journal of Volcanology and Geothermal Research, 94: 1-19. doi:10.1016/S0377-0273(99)00095-5

Carracedo, J.C.; Rodríguez Badiola, E. \& Soler, V. (1992). The 17301736 eruption of Lanzarote: an unusually long, high magnitude fissural basaltic eruption in the recent volcanism of the Canary Islands. Journal of Volcanology and Geothermal Research, 53: 239-250. doi:10.1016/0377-0273(92)90084-Q

Carracedo, J.C.; Day, S.; Guillou, H.; Rodríguez Badiola, E.; Canas, J.A. \& Pérez-Torrado, F.J. (1998). Hotspot volcanism close to a passive continental margin: the Canary Islands. Geological Magazine, 135: 591-604. doi:10.1017/S0016756898001447

Carracedo, J.C.; Day, S.; Guillou, H. \& Gravestock, P. (1999a). Later stages of the volcanic and structural evolution of La Palma, Canary Islands: The Cumbre Nueva giant collapse and the Cumbre Vieja volcano. Geological Society of America Bulletin, 111: 755-768. doi:10.1130/0016-7606(1999)111<0755:LSO$\mathrm{VEO}>2.3 . \mathrm{CO} ; 2$

Carracedo, J.C.; Day, S.; Guillou, H. \& Pérez-Torrado, F.J. (1999b). Giant Quaternary landslides in the evolution of La Palma and El Hierro, Canary Islands. Journal of Volcanology and Geothermal Research, 94: 169-190. doi:10.1016/S0377-0273(99)00102-X

Carracedo, J.C.; Rodríguez Badiola, E.; Guillou, H.; De la Nuez, J. \& Pérez-Torrado, F.J. (2001). Geology and volcanology of La Palma and El Hierro, Western Canaries. Estudios Geológicos, 57: 1-124. doi:10.3989/egeol.01575-6

Carracedo, J.C.; Pérez-Torrado, F.J.; Ancochea, E.; Meco, J.; Hernán, F.; Cubas, C.R.; Casillas, R.; Rodríguez Badiola, E. \& Ahijado, A. (2002). Cenozoic Volcanism II: The Canary Islands. En: The Geology of Spain (Gibbons, W. \& Moreno, T., eds.). Geological Society of London, London, 439-472.

Carracedo, J.C.; Guillou, H.; Paterne, M.; Scaillet, S.; Rodríguez Badiola, E.; Pérez-Torrado, F.J.; Hansen, A. \& Paris, R. (2004). Nested central volcanism related to rift development and giant landsliding in oceanic islands. IA VCEI General Assembly presentation, Pucón, Chile.

Carracedo, J.C.; Rodríguez Badiola, E.; Guillou, H.; Paterne, M.; Scaillet, S.; Pérez-Torrado, F.J.; Paris, R.; Criado, C.; Hansen, A.; Arnay, M.; González Reimers, E.; Fra-Paleo, U. \& González Pérez, R. (2006). Los volcanes del Parque Nacional del Teide: El Teide, Pico Viejo y las dorsales activas de Tenerife. Serie Técnica, Organización de Parques Nacionales, Ministerio de Medio Ambiente, Madrid, 388 pp.

Carracedo, J.C.; Rodríguez Badiola, E.; Guillou, H.; Paterne, M.; Scaillet, S.; Pérez-Torrado, F.J.; Paris, R.; Fra-Paleo, U. \& Hansen, A. (2007). Eruptive and structural history of Teide Volcano and Rift Zones of Tenerife, Canary Islands. Geological Society of America Bulletin, 119: 1027-1051. doi:10.1130/B26087.1

Carracedo, J.C.; Guillou, H.; Rodríguez Badiola, E.; Pérez-Torrado, F.J.; Troll, V.; Delcamp, A.; Paris, R. \& Rodríguez González, A. (2008a). Volcanic and Structural History of the NE Rift Zone of Tenerife, Canary Islands, Spain. AGU 2008 Fall Meeting.

Carracedo, J.C.; Pérez-Torrado, F.J.; Rodríguez Badiola, E.; Balcells, R.; Guillou, H.; Scaillet, S.; Troll, V.; Paris, R.; Martín Escorza, C.; Hansen, A. \& Rodríguez González, A. (2008b). Nota preliminar sobre las características estructurales del Rift NE de Tenerife (Preliminary results about structural features of the NE rift of Tenerife). Geo-Temas, 10: 1265-1268.

Uri: $10261 / 5960$

Carracedo, J.C.; Rodríguez Badiola, E.; Guillou, H.; Paterne, M.; Scaillet, S.; Pérez-Torrado, F.J.; Paris, R.; Rodríguez González, A. \& Socorro, S. (2008c). El Volcán Teide, Volcanología, interpretación de paisajes e itinerarios comentados. Ed. Saquiro, Santa Cruz de Tenerife, $600 \mathrm{pp}$.

Carracedo, J.C.; Pérez-Torrado, F.J.; Rodríguez Badiola, E.; Paris, R. \& Singer, B.S. (2008d). Fiabilidad de la interpretación de las referencias de erupciones subhistóricas de Tenerife: la erupción pre-holocena de Mña. Taoro (Reliability of interpretation of references in eyewitness accounts to subhistorical eruptions in Tenerife: the pre-Holocene Mña. Taoro eruption). Geo-Temas, 10: 1261-1264. Uri: 10261/5961 
Coe, R.S.; Singer, B.S.; Pringle, M.S. \& Zhao, X. (2004). Matuyama Brunhes reversal and Kamikatsura event on Maui: Paleomagnetic directions, 40Ar/39Ar ages and implications. Earth and Planetary Science Letters, 222: 667-684. doi:10.1016/j.epsl.2004.03.003

Coello, J. (1973). Las series volcánicas en subsuelos de Tenerife. Estudios Geológicos, 29: 491-512.

Delcamp, A.; Petronis, M.S.; Troll, V.R.; Carracedo, J.C.; Wyk de Vries, B. van \& Wiesmaier, S. (2008). New paleomagnetic constraints on the evolution of the NE rift zone and associated landslide, Tenerife, Spain. AGU 2008 Fall Meeting.

Dieterich, J.H. (1988). Growth and persistence of Hawaiian volcanic rift zones. Journal of Geophysical Research, 93: 4258-4270. doi:10.1029/JB093iB05p04258

Doell, R.R. \& Dalrymple, G.B. (1966). Geomagnetic polarity epochs: a new polarity event and the age of the Brunhes Matuyama boundary. Science, 152: 10601061. doi:10.1126/science.152.3725.1060

Dreyfus, G.B.; Raisbeckc, G.M.; Parrenind, F.; Jouzela, J.; Guyodoa, Y.; Nomadea, S. \& Mazaud, A. (2008). An ice core perspective on the age of the Matuyama-Brunhes boundary. Earth and Planetary Science Letters, 274: 151.156.

Edgar, C.J.; Wolff, J.A.; Nichols, H.J.; Cas, R.A.F. \& Martí, J. (2002). A complex Quaternary ignimbrite-forming phonolitic eruption: the Poris member of the Diego Hernández Formation (Tenerife, Canary Islands). Journal of Volcanology and Geothermal Research, 118: 99-130. doi:10.1016/S0377-0273(02)00252-4

Elsworth, D. \& Day, S.J. (1999). Flank collapse triggered by intrusion: The Canarian and Cape Verde Archipelagoes. Journal of Volcanology and Geothermal Research, 94: 323-340. doi:10.1016/S0377-0273(99)00110-9

Fiske, R.S. \& Jackson, E.D. (1972). Orientation and growth of Hawaiian volcanic rifts: the effect of regional structure and gravitational stresses. Proceedings of the Royal Society of London, 329: 299-326.

Fúster, J.M.; Araña, V.; Brandle, J.L.; Navarro, M.; Alonso, U. \& Aparicio, A. (1968). Geología y volcanología de las Islas Canarias: Tenerife. Instituto «Lucas Mallada», CSIC, Madrid, 218 pp.

Gee, M.J.R.; Masson, D.G.; Watts, A.B. \& Mitchell, N.C. (2001). Offshore continuation of volcanic rift zones, El Hierro, Canary Islands. Journal of Volcanology and Geothermal Research, 105: 109-119. doi:10.1016/S0377-0273(00)00241-9

Geldmacher, J.; Hoernle, K.; Bogaard, P.V.D.; Duggen, S. \& Werner, R. (2005). New 40Ar/39Ar age and geochemical data from seamounts in the Canary and Madeira Volcanic Provinces: A contribution to the «Great Plume Debate». Earth and Planetary Science Letters, 237: 85-101. doi:10.1016/j.epsl.2005.04.037

Gillot, P.Y.; Soler, V. \& Quidelleur, X. (2001). Piling rate and magmatic evolution through time of the Teide volcano (Tenerife, Canary islands). XI Meeting of the European Union of Geosciences, Strasbourg, VPP3: 802.

Guillou, H.; Carracedo, J.C.; Pérez-Torrado, F. \& Rodríguez Badiola, E. (1996). K-Ar ages and magnetic stratigraphy of a hotspot-induced, fast grown oceanic island: El Hierro, Canary Islands. Journal of Volcanology and Geothermal Research, 73: 141-155.

doi:10.1016/0377-0273(96)00021-2

Guillou, H.; Carracedo, J.C. \& Day, S.J. (1998). Dating of the upper Pleistocene-Holocene volcanic activity of La Palma using the unspiked K-Ar technique. Journal of Volcanology and Geothermal Research, 86: 137-149. doi:10.1016/S0377-0273(98)00074-2

Guillou, H.; Carracedo, J.C. \& Duncan, R.A. (2001). $\mathrm{K}-\mathrm{Ar}$, 40Ar/39Ar ages and magnetostratigraphy of Brunhes and Matuyama lava sequences from La Palma Island. Journal of Volcanology and Geothermal Research, 106: 175-194.

doi:10.1016/S0377-0273(00)00294-8

Guillou, H.; Carracedo, J.C.; Paris, R. \& Pérez-Torrado, F.J. (2004). Implications for the early shield-stage evolution of Tenerife from K/Ar ages and magnetic stratigraphy. Earth and Planetary Science Letters, 222: 599-614. doi:10.1016/j.epsl.2004.03.012

Hildenbrand, A.; Gillot, P.Y. \& Le Roy, I. (2004). Volcano-tectonic and geochemical evolution of an oceanic intra-plate volcano: Tahiti-Nui (French Polynesia). Earth and Planetary Science Letters, 217: 349-365. doi:10.1016/S0012-821X(03)00599-5

Hoernle, K. \& Carracedo J.C. (2009). The Canary Islands. En: Encylopedia of Islands (Gillespie, R. \& Clague, D., eds). University of California Press, $1.008 \mathrm{pp}$.

Horng, C.S.; Lee, M.Y.; Pälike, H.; Wei, K.Y.; Liang, W.T.; Iizuka, Y. \& Torii, M. (2002). Stronomically calibrated ages for geomagnetic reversals within the Matuyama chron. Earth, Planets and Space, 54: 679-690.

Huertas, M.J.; Arnaud, N.O.; Ancochea, E.; Cantagrel, J.M. \& Fúster, J.M. (2002). 40Ar/39Ar stratigraphy of main pyroclastic units from the Cañadas Volcanic Edifice (Tenerife, Canary Islands) and their bearing on structural evolution. Journal of Volcanology and Geothermal Research, 115: 351-365.

doi:10.1016/S0377-0273(01)00331-6

Ibarrola, E.; Ancochea, E.; Fúster, J.M.; Cantagrel, J.M.; Coello, J.; Snelling, N.J. \& Huertas, M.J. (1993). Cronoestratigrafía del Macizo de Tigaiga: evolución de un sector del Edificio Cañadas (Tenerife, Islas Canarias). Boletín de la Real Sociedad Española de Historia Natural (Sección Geología), 88: 57-72.

IGME (1978). Mapa Geológico de España. Hoja La Orotava (1104-3).

Izett, G.A. \& Obradovich, J.D. (1994). 40Ar/39Ar age constraints for the Jaramillo Normal Subchron and the Matuyama-Brunhes geomagnetic boundary. Journal of Geophysical Research, 99: 2925-2934.

doi:10.1029/93JB03085

Lambeck, K.; Esat, T.M. \& Potter, E.K. (2002). Links between climate and sea levels for the past three million years. Nature, 419: 199-206. doi:10.1038/nature01089

Lisiecki, L.E. \& Raymo, M.E. (2005). A Pliocene-Pleistocene stack of 57 globally distributed benthic $\delta^{18} \mathrm{O}$ records. Paleoceanography, 20: PA1003. doi:10.1029/2004PA001071 
Longpré, M.A.; Troll, V.R. \& Hansteen, T.H. (2008). Upper mantle magma storage and transport under a Canarian shield-volcano, Teno, Tenerife (Spain). Journal of Geophysical Research, 113: B08203. doi:10.1029/2007JB005422

Luongo, G.; Cubellis, E.; Obrizzo, F. \& Petrazzuoli, S.M. (1991). A physical model for the origin of volcanism of the Tyrrhenian margin: the case of the Neapolitan area. Journal of Volcanology and Geothermal Research, 48: 173-185. doi:10.1016/0377-0273(91)90041-W

Masson, D.G.; Watts, A.B.; Gee, M.J.R. Urgeles, R.; Mitchell, N.C.; Le Bas, T.P. \& Canals, M. (2002). Slope failures on the flanks of the western Canary Islands. Earth Science Reviews, 57: 1-35. doi:10.1016/S0012-8252(01)00069-1

McGuire, W.J. (1996). Volcano instability: A review of contemporary themes. Geological Society, London, Special Publication, 110: 1-23.

McKenzie, D. \& Bickle, M.J. (1988). The volume and composition of melt generated extension of the lithosphere. Journal of Petrology, 29: 625-679.

McMurtry, G.M.; Watts, P.; Fryer, G.J.; Smith, J.R. \& Imamura, F. (2004). Giant landslides, mega-tsunamis, and paleo-sea level in the Hawaiian Islands. Marine Geology, 203: 219-233. doi:10.1016/S0025-3227(03)00306-2

Mitchell, N.C.; Masson, D.G.; Watts, A.B.; Gee, M.J.R. \& Urgeles, R. (2002). The morphology of the submarine flanks of volcanic ocean islands: A comparative study of the Canary and Hawaiian hotspot islands. Journal of Volcanology and Geothermal Research, 115: 83-107. doi:10.1016/S0377-0273(01)00310-9

Moore, J.G.; Clague, D.A.; Holcomb, R.T.; Lipman, P.W.; Normark, W.R. \& Torresan, M.E. (1989). Prodigious submarine landslides on the Hawaiian ridge. Journal of Geophysical Research, 94: 17465-17484. doi:10.1029/JB094iB12p17465

Navarro, J.M. \& Coello, J. (1989). Depressions originated by landslide processes in Tenerife. ESF Meeting on Canarian Volcanism, Lanzarote, 150-152.

Palomo, C.; Acosta, J.; Muñoz, A.; Herranz, P.; Sanz, J.L.; Molinero, J.; Bécares, M.A. \& Gómez, R. (1998). Mapa batimorfológico del área norte de la isla de Tenerife. Instituto Español de Oceanografía. Madrid.

Paris, R.; Guillou, H.; Carracedo, J.C. \& Pérez-Torrado, F.J. (2005). Volcanic and morphological evolution of La Gomera (Canary Islands), based on new K-Ar ages and magnetic stratigraphy: implications for oceanic island evolution. Journal of the Geological Society of London, 162: 501-512. doi:10.1144/0016-764904-055

Petronille, M.; Goguitchaichvili, A.; Henry, B.; Alva-Valdivia, L.M.; Rosas-Elguera, J.; Urrutia-Fucugauchi, J.; Rodríguez Ceja, M. \& Calvo-Rathert, M. (2005). Paleomagnetism of Ar-Ar dated lava flows from the Ceboruco-San Pedro volcanic field (western Mexico): Evidence for the Matuyama-Brunhes transition precursor and a fully reversed geomagnetic event in the Brunhes chron. Journal of Geophysical Research, 110: B08101. doi:10.1029/2004JB003321

Presley, T.K.; Sinton, J.M. \& Pringle, M. (1997). Postshield volcanism and catastrophic mass wasting of the
Waianae Volcano, Oahu, Hawaii. Bulletin of Volcanology, 58: 597-616. doi:10.1007/s004450050165

Quidelleur, X.; Hildenbrand, A. \& Samper, A. (2008). Causal link between Quaternary paleoclimatic changes and volcanic islands evolution. Geophysical Research Letters, 35: L02303. doi:10.1029/2007GL031849

Raisbeck, G.M.; Yiou, F.; Cattani, O. \& Jouzel, J. (2006). ${ }^{10} \mathrm{Be}$ evidence for the Matuyama-Brunhes geomagnetic reversal in the EPICA Dome $\mathrm{C}$ ice core. Nature, 444: 82-84. doi:10.1038/nature05266

Shackleton, N.J.; Berger, A. \& Peltier, W.R. (1990). An alternative astronomical calibration of the lower Pleistocene timescale based on OPD site 677, Transactions of the Royal Society of Edinburgh, Earth Sciences, 81: 251-261.

Siebert, L. (1984). Large volcanic debris avalanches: Characteristics of source areas, deposits, and associated eruptions. Journal of Volcanology and Geothermal Research, 22: 163-197. doi:10.1016/0377-0273(84)90002-7

Singer, B.S.; Relle, M.K.; Hoffman, K.A.; Battle, A.; Laj, C.; Guillou, H. \& Carracedo, J.C. (2002). Ar/Ar ages from transitionally magnetized lavas on La Palma, Canary Islands, and the geomagnetic instability timescale. Journal of Geophysical Research, 107: 2307. doi:10.1029/2001JB001613

Singer, B.S.; Relle, M.K.; Hoffman, K.A.; Coe, R.S.; Brown, L.L.; Jicha, B.R.; Mal Pringle, M.S. \& Chauvin, A. (2005). Structural and temporal requirements for geomagnetic field reversal deduced from lava flows. Nature, 434: 633-636. doi:10.1038/nature03431

Steiger, R.H. \& Jäger, E. (1977). Subcommission on geochronology: convention on the use of decay constants in geo- and cosmochronology. Earth and Planetary Science Letters, 36: 359-362. doi:10.1016/0012-821X(77)90060-7

Swanson, D.A.; Duffield, W.A. \& Fiske, R.S. (1976). Displacement of the south flank of the Kilauea volcano: The result of forceful intrusion of magma into the rift zones. U.S. Geological Survey, Professional Paper, 963, 93 pp.

Thirlwall, M.F.; Singer, B.S. \& Marriner, G.F. (2000). $39 \mathrm{Ar}-40 \mathrm{Ar}$ ages and geochemistry of the basaltic shield stage of Tenerife, Canary Islands, Spain. Journal of Volcanology and Geothermal Research, 103: 247-297. doi:10.1016/S0377-0273(00)00227-4

Urgelés, R.; Masson, D.G, Canals, M.; Watts, A.B. \& Le Bas, T. (1999). Recurrent large scale landsliding on the west flank of La Palma, Canary Islands. Journal of Geophysical Research, 104: 25331-25348. doi:10.1029/1999JB900243

Walker, G.P.L. (1986). Koolau dike complex, Oahu: Intensity and origin of a sheeted-dike complex high in a Hawaiian volcanic edifice. Geology, 14: 310-313. doi:10.1130/0091-7613(1986)14<310:KDCOIA>2.0.CO;2 Walker, G.P.L. (1987). The dike complex of Koolau Volcano, Oahu: internal structure of a Hawaiian rift zone. US Geological Survey Professional Paper, 1350: 961-993.

Walker, G.P.L. (1992). «Coherent intrusion complexes» in large basaltic volcanoes -a new structural model. Journal of Volcanology and Geothermal Research, 50: 41-54. doi:10.1016/0377-0273(92)90036-D 
Walter, T.R. \& Schmincke, H-U. (2002). Rifting, recurrent landsliding and Miocene structural reorganization on NW-Tenerife (Canary Islands). International Journal of Earth Sciences, 91: 615-628. doi:10.1007/s00531-001-0245-8

Walter, T.R. \& Troll, V.R. (2003). Experiments on rift zone formation in unstable volcanic edifices. Journal of Volcanology and Geothermal Research, 127: 107-120. doi:10.1016/S0377-0273(03)00181-1

Walter, T.R.; Troll, V.R.; Cailleau, B.; Belousov, A.; Schmincke, H.-U.; Amelung, F. \& Van Den Bogaard, P. (2005). Rift zone reorganization through flank instability in ocean island volcanoes: an example from Tenerife, Canary Islands. Bulletin of Volcanology, 67: 281-291. doi:10.1007/s00445-004-0352-z

Walter, T.R.; Klügel, A. \& Münn, S. (2006). Gravitational spreading and formation of new rift zones on over- lapping volcanoes. Terra Nova, 18: 26-33. doi:10.1111/j.1365-3121.2005.00656.x

Watts, A.B. \& Masson, D.G. (1995). A giant landslide on the north flank of Tenerife, Canary Islands. Journal of Geophysical Research, 100: 24487-24498. doi:10.1029/95JB02630

White, R. \& McKenzie, D. (1989). Magmatism at rift zones- The generation of volcanic continental margins and flood basalts. Journal of Geophysical Research, 94: 7685-7729. doi:10.1029/JB094iB06p07685

Wyss, M. (1980). Hawaiian rifts and recent Icelandic volcanism: expressions of plume generated radial stress fields. Journal of Geophysics, 47: 19-22.

Recibido el 3 de noviembre de 2008 Aceptado el 8 de enero de 2009 Publicado online el 16 de abril de 2009 